Defense Threat Reduction Agency

8725 John J. Kingman Road, MS-6201

Fort Belvoir, VA 22060-6201

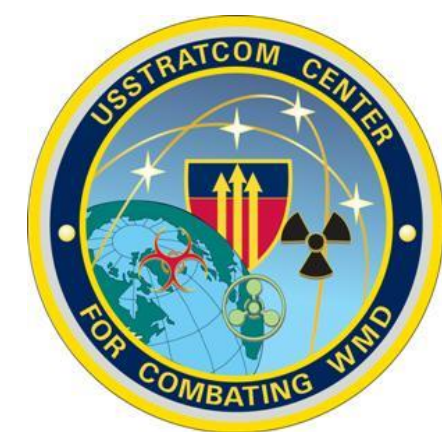

DTRA-TR-15-3

\title{
Plutonium 238/239 Decorporation Model
}

Distribution Statement A. Approved for public release; distribution is unlimited.

October 2014

HDTRA1-10-C-0025

Daniela Stricklin et al.

Prepared by:

Applied Research Associates, Inc.

801 N. Quincy Street

Suite 700

Arlington, VA 22203 


\section{DESTRUCTION NOTICE:}

Destroy this report when it is no longer needed.

Do not return to sender.

PLEASE NOTIFY THE DEFENSE THREAT REDUCTION

AGENCY, ATTN: DTRIAC/ J9STT, 8725 JOHN J. KINGMAN ROAD, MS-6201, FT BELVOIR, VA 22060-6201, IF YOUR ADDRESS

IS INCORRECT, IF YOU WISH THAT IT BE DELETED FROM THE

DISTRIBUTION LIST, OR IF THE ADDRESSEE IS NO

LONGER EMPLOYED BY YOUR ORGANIZATION. 


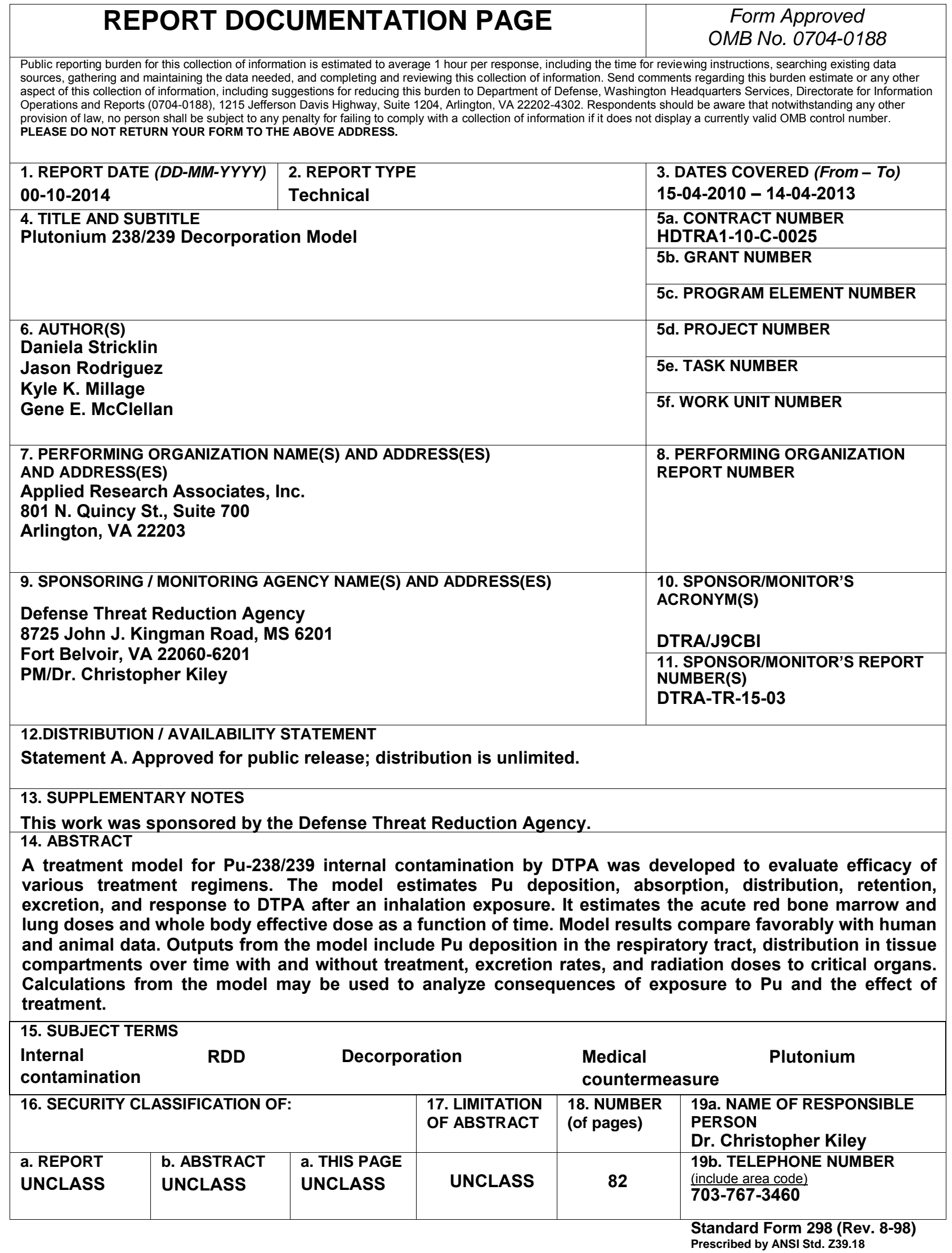

Prescribed by ANSI Std. Z39.18 


\section{CONVERSION TABLE}

\section{Conversion factors for U.S. customary to metric (SI units of measurement)}

\begin{tabular}{|c|c|c|}
\hline $\begin{array}{l}\text { MULTIPLY } \\
\text { TO GET }\end{array}$ & $\begin{array}{l}\text { BY } \\
\text { BY }\end{array}$ & $\begin{array}{l}\text { TO GET } \\
\text { DIVIDE } \\
\end{array}$ \\
\hline angstrom & $1.000000 \times E-10$ & meters $(\mathrm{m})$ \\
\hline atmosphere & $1.01225 \times E+2$ & kilo pascal $(\mathrm{kPa})$ \\
\hline bar & $1.000000 \times E+2$ & kilo pascal $(\mathrm{kPa})$ \\
\hline barn & $1.000 \times E-28$ & meter $^{2}\left(\mathrm{~m}^{2}\right)$ \\
\hline British thermal unit (thermochemical) & $1.054350 \times E+3$ & joule $(\mathrm{J})$ \\
\hline calorie (thermochemical) & 4.184000 & joule $(\mathrm{J})$ \\
\hline cal (thermochemical)/cm² & $4.184000 \times \mathrm{E}-2$ & mega joule $/ \mathrm{m}^{2}\left(\mathrm{MJ} / \mathrm{m}^{2}\right)$ \\
\hline curie & $3.7000000 \times E+1$ & giga becquerel $(\mathrm{GBq})^{*}$ \\
\hline degree (angle) & $1.745329 \times E-2$ & radian (rad) \\
\hline degree (Fahrenheit) & $\mathrm{Tk}=(\mathrm{t}+459.69) / 1.8$ & degree kelvin $(\mathrm{K})$ \\
\hline electron volt & $1.60219 \times E-19$ & joule $(\mathrm{J})$ \\
\hline erg & $1.000000 \times E-7$ & joule $(\mathrm{J})$ \\
\hline $\mathrm{erg} / \mathrm{sec}$ & $1.000000 \times E-7$ & watt $(\mathrm{W})$ \\
\hline foot & $3.048000 \times X-1$ & meter $(\mathrm{m})$ \\
\hline foot-pound-force & 1.355818 & joule $(\mathrm{J})$ \\
\hline gallon (U.S. liquid) & $3.785412 \times E-3$ & meter $^{3}\left(\mathrm{~m}^{3}\right)$ \\
\hline inch & $2.540000 \times E-2$ & meter $(\mathrm{m})$ \\
\hline jerk & $1.000000 \times E+9$ & joule $(\mathrm{J})$ \\
\hline joule/kilogram (J/kg) (absorbed dose) & 1.000000 & Gray $(\mathrm{Gy})^{\star *}$ \\
\hline kilotons & 4.183 & terajoules \\
\hline kip (1000 lbf) & $4.448222 \times E+3$ & newton $(\mathrm{N})$ \\
\hline kip/inch ${ }^{2}(\mathrm{ksi})$ & $6.894757 \times \mathrm{E}+3$ & kilo pascal $(\mathrm{kPa})$ \\
\hline ktap & $1.000000 \times E+2$ & newton-second $/ \mathrm{m}^{2}\left(\mathrm{~N}-\mathrm{s} / \mathrm{m}^{2}\right)$ \\
\hline micron & $1.000000 \times E-6$ & meter $(\mathrm{m})$ \\
\hline mil & $2.540000 \times E-5$ & meter $(\mathrm{m})$ \\
\hline mile (international) & $1.609344 \times E+3$ & meter $(\mathrm{m})$ \\
\hline ounce & $2.834952 \times E-2$ & kilogram (kg) \\
\hline pound-force (Ibf avoirdupois) & 4.448222 & newton $(\mathrm{N})$ \\
\hline pound-force inch & $1.129848 \times E-1$ & newton-meter $\left(\mathrm{N}^{*} \mathrm{~m}\right)$ \\
\hline pound-force/inch & $1.751268 \times E+2$ & newton-meter $(\mathrm{N} / \mathrm{m})$ \\
\hline pound-force/foot ${ }^{2}$ & $4.788026 \times E-2$ & kilo pascal (kPa) \\
\hline pound-force/inch ${ }^{2}$ (psi) & 6.894757 & kilo pascal $(\mathrm{kPa})$ \\
\hline pound-mass-foot ${ }^{2}$ (moment of inertia) & $4.214011 \times E-2$ & kilogram-meter ${ }^{2}\left(\mathrm{~kg}^{*} \mathrm{~m}^{2}\right)$ \\
\hline pound-mass/foot ${ }^{3}$ & $1.601846 \times E+1$ & kilogram $/ \mathrm{m}^{3}\left(\mathrm{~kg} / \mathrm{m}^{3}\right)$ \\
\hline rad (radiation absorbed dose) & $1.000000 \times E-2$ & Gray (Gy) ** \\
\hline rem (roentgen equivalent man) & & Sievert (Sv) ${ }^{* * *}$ \\
\hline roentgen & $2.579760 \times E-4$ & coulomb/kilogram $(\mathrm{C} / \mathrm{kg})$ \\
\hline shake & $1.000000 \times E-8$ & second $(\mathrm{s})$ \\
\hline Slug & $1.459390 \times E+1$ & kilogram (kg) \\
\hline Torr $(\mathrm{mm} \mathrm{Hg}, 0$ degrees $\mathrm{C})$ & $133322 \times E-1$ & kilo pascal (kPa) \\
\hline
\end{tabular}

* The Becquerel $(\mathrm{Bq})$ is the SI unit of radioactivity: $1 \mathrm{~Bq}=1$ event/s.

** The Gray $(G y)$ is the SI unit of absorbed radiation.

*** The Sievert $(S V)$ is the SI unit of dose equivalent. 


\section{Table of Contents}

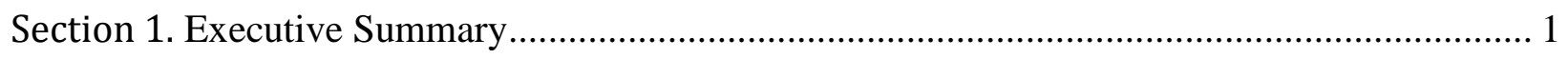

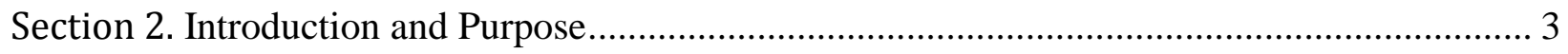

$2.1 \quad$ Summary of Deliverables....................................................................... 4

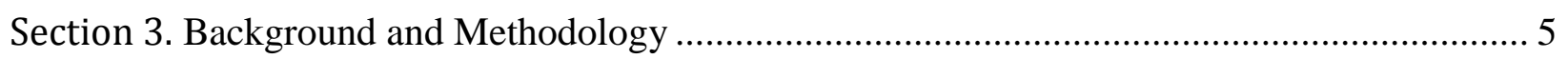

3.1 Importance of Plutonium-238 and -239 ................................................... 5

3.2 Plutonium-238/239 Decorporation ............................................................ 6

3.3 Composite Model Approach ......................................................................... 7

Section 4. Plutonium-238/239 Decorporation Model …………………………......................... 9

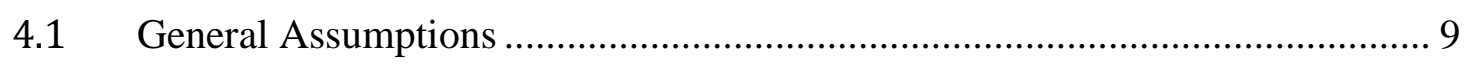

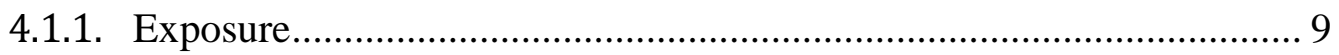

4.1.2. Physical and Chemical Form ……..................................................... 9

4.1.3. Inhalation Exposure …………………………….......................... 10

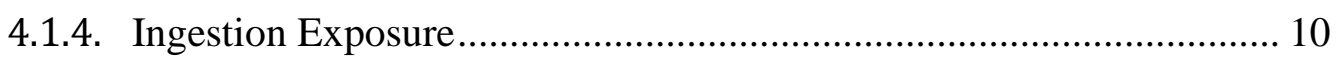

4.2 Inhalation Exposure Model: Calculation of Plutonium Body Burden .............. 11

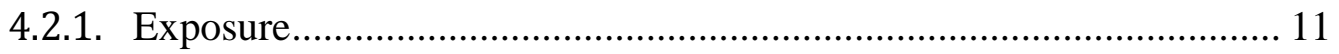

4.2.2. Inhaled Fraction ......................................................................... 11

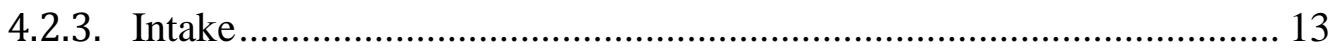

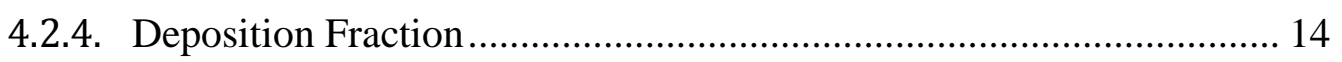

4.2.5. Respiratory Clearance and Systemic Uptake ……................................ 16

4.2.6. Uptake from the GI Tract ................................................................. 21

4.3 Plutonium Biokinetic Model .................................................................... 21

4.3.1. Transfer Coefficients for Plutonium ………………………………... 22

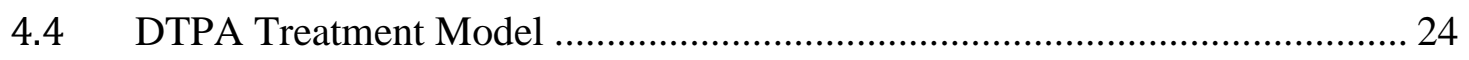

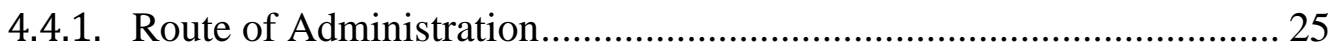

4.4.2. Formulation, Dose, and Time Course ……………………………..... 25

4.4.3. Time from Exposure to Treatment ...................................................... 26

4.4.4. Plutonium Decorporation ............................................................... 26

4.4.5. Optimizing DTPA Effective Residence Time....................................... 26

4.4.6. Toxicity/Side Effects.......................................................................... 29 


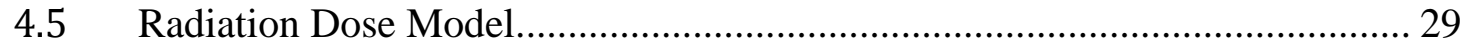

4.5.1. Organ Specific Acute Doses .......................................................... 30

4.5.2. Effective Whole Body Equivalent ................................................... 32

4.5.3. Calculation of Acute Health Effects Severity .................................. 34

4.5.4. Calculation of Long-Term Carcinogenic Risk................................. 35

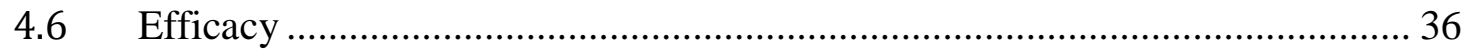

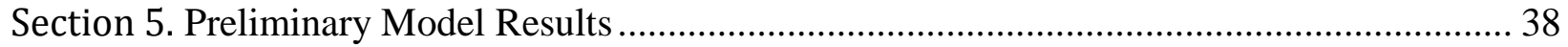

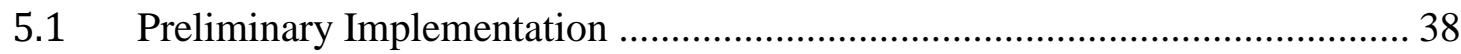

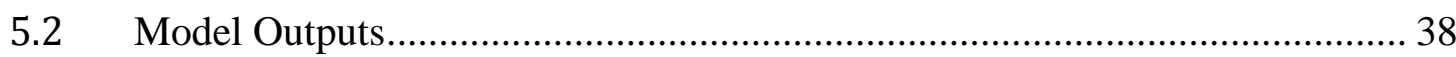

5.2.1. Impact of Particle Size on Plutonium Biokinetics and Dose Estimates 39

5.2.2. Plutonium Tissue Distribution ...................................................... 41

5.2.3. Comparison of Predicted Plutonium Retention to Experimental and Human Data ................................................................................ 42

5.2.4. DTPA Decorporation of Plutonium ............................................. 43

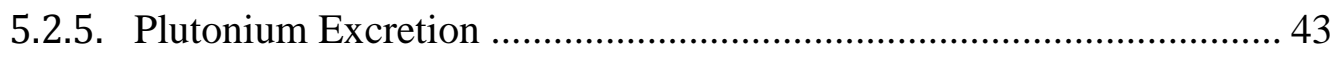

5.2.6. Plutonium Acute and Whole Body Effective Doses .......................... 45

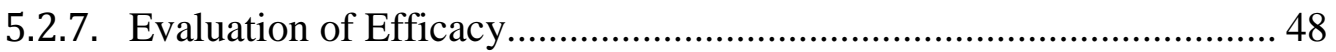

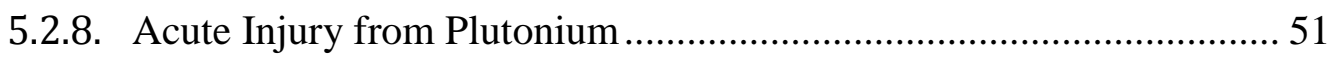

5.2.9. Long-term Health Effects......................................................... 51

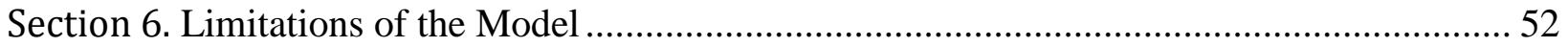

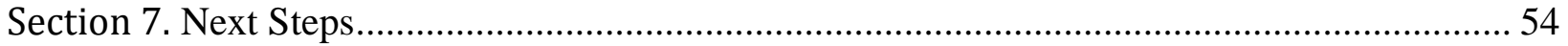

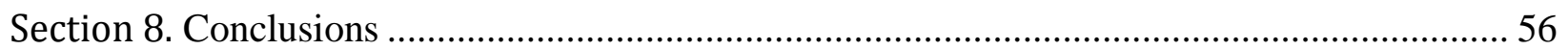

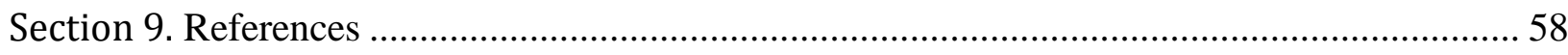

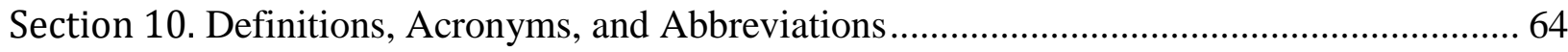

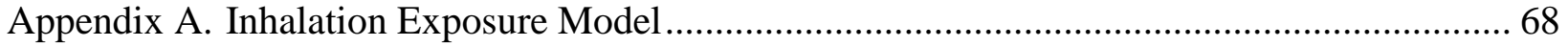

Appendix B. Respiratory Clearance and Uptake Model ..................................................... 70

Appendix C. Plutonium Biokinetic Model............................................................................... 72 


\section{List of Figures}

Figure 1. Diethylene Triamine Pentaacetic Acid, DTPA ...................................................... 7

Figure 2. Composite Pu-238/239 Decorporation Model Components ..................................... 8

Figure 3. Inhalation Exposure Model Overview............................................................. 11

Figure 4. Nasal Fraction as a Function of Breathing Rate ................................................. 13

Figure 5. TheTthree Functional Regions of the Respiratory Tract (Asgharian 2006a) .............. 15

Figure 6. ICRP Respiratory Tract Model: Mechanical Clearance (Bailey 2007)...................... 17

Figure 7. Pulmonary Retention of $\mathrm{PuO}_{2}$ as Predicted by Different Absorption Parameters ........ 20

Figure 9. DTPA Biokinetic Model (Breustedt 2010)............................................................. 24

Figure 10. Effect of Different Effective Residence Times of DTPA in the Blood.................... 28

Figure 11. Pu Burden in the Lung as a Function of Particle Size and Breathing Rate ............... 39

Figure 12. Pu Retention as Function of Particle Size and Breathing Rate ................................ 40

Figure 13. Radiation Dose to the Lung from Different Particle Sizes.................................... 40

Figure 14. Plutonium Retention in Selected Tissues Over 30 Days ....................................... 41

Figure 15. Pu Distribution for Selected Tissues Over 180 Days ............................................ 42

Figure 16. Model Predictions of Pu Retention (Leggett 2005) ............................................. 42

Figure 17. Plutonium Retention With and Without Treatment............................................... 43

Figure 18. Plutonium Excretion With and Without Treatment............................................. 44

Figure 19. Urinary Excretion of Plutonium With and Without Treatment............................... 44

Figure 20. Plutonium Total and Fecal Excretion Over 60 Days ........................................... 45

Figure 21. Acute Doses to Critical Organs from $\mathrm{Pu}-238$ and $\mathrm{Pu}-239$ Over 90 Days .................. 46

Figure 22. Doses from Pu-238 and Pu-239 Over 90 Days in Treated and Untreated Cases ........ 48 


\section{List of Tables}

Table 1. Respiratory Compartments for Clearance Calculations........................................... 18

Table 2. Respiratory Tract Absorption Values for Generic Insoluble Materials and $\mathrm{PuO}_{2} \ldots \ldots \ldots . . .19$

Table 3. Transfer Coefficients (Leggett 2005) ..................................................................... 22

Table 4. Transfer Coefficients for the DTPA Biokinetic Model (Breustedt 2009) .................... 25

Table 5. Decay Properties of Pu-238 and Pu-239 (NCRP 2008b)........................................... 30

Table 6. Photon SAF Values for Pu-238/239 for Red Bone Marrow (RBM) and Lungs............ 32

Table 7. The 50-Year Committed Effective Whole Body Radiation Doses from Pu-238 and Pu239 in Untreated and Treated Cases

Table 8. Comparison of Doses at 365 Days (Gy/Bq of Pu-238 or Pu-239 Intake) by Different

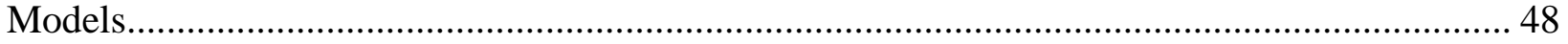

Table 9. Doses After 90 Days from $1 \mu \mathrm{Ci} \mathrm{Pu}-238$ Exposure in Untreated and 30-Day DTPA Treated Subjects with Different Treatment Initiation Times ................................................ 49

Table 10. 50-Year Committed Whole Body Effective Doses (Sv) ......................................... 50

Table 11. Dose Reduction Factors for Different Treatment Regimens .................................... 50

Table 12. Efficacy of Different Treatment Regimens ..................................................... 51

Table 13. Fraction of Exposure Deposited in the Three Primary Respiratory Regions .............. 68

Table 14. Fraction of Intake Deposited in the Three Primary Respiratory Regions.................... 68

Table 15. Fraction of the Tracheobronchial Deposition in the Bronchi and Bronchioles ............ 69 


\section{Preface}

The research and development work, described in this report, was conducted under subcontract for Gryphon Scientific, LLC (Gryphon) for the Joint Science and Technology Office (JSTO) of the Department of Defense (DoD) Chemical and Biological Defense (CBD) Program. JSTO is also the Chemical/Biological Technologies (CB) Directorate in the Research and Development (RD) Enterprise of the Defense Threat Reduction Agency (DTRA). Contract HDTRA1-10-C-0025 is titled Medical Countermeasures for CBR Agents.

This project was initiated by Ms. Nancy Nurthen, of the Information Systems Capability Development Division (J9-CB) and continued by Dr. Christopher Kiley. It was funded under DTRA Contract Number HDTRA1-10-C-0025 to Gryphon Scientific, LLC, with subcontractor Applied Research Associates, Inc. (ARA). The target application for the product of this contract is under the auspices of the Joint Project Manager for Information Systems (JPM IS) of the Joint Program Executive Office for Chemical and Biological Defense (JPEO-CBD). 


\section{Section 1.}

\section{Executive Summary}

A model for the treatment of plutonium-238/239 (Pu-238/239) internal contamination by trisodium calcium and trisodium zinc diethylenetriamine pentaacetate (DTPA) was developed to evaluate the efficacy of various treatment regimens. The baseline uptake and decorporation model was developed by adapting existing models for inhalation exposure, uptake/respiratory clearance, and physiologically-based biokinetic distribution for plutonium. A treatment model was developed for DTPA decorporation of plutonium that simulates the chelation of DTPA in the body and its enhanced excretion. A radiation dosimetry model for calculating doses was also developed and integrated with the biokinetic model and treatment model. Collectively, the models simulate the in vivo distribution and excretion of Pu over time and the impact of DTPA treatment (via chelation of $\mathrm{Pu}$ and enhanced excretion). The composite $\mathrm{Pu}-238 / 239$ decorporation model, presented in this work, estimates plutonium deposition, absorption, distribution, retention, excretion, and response to DTPA treatment in adult healthy males after an inhalation exposure. The model further estimates the acute red bone marrow and lung doses, as well as the whole body effective dose as a function of time. The long term carcinogenic risk from a given exposure and treatment regime can be estimated. The results of the model compare favorably with human and animal data and provide estimates within the uncertainty limits of alternative models developed by the International Commission on Radiological Protection (ICRP) and the National Council on Radiation Protection and Measurements (NCRP). Outputs from the model include the distribution of plutonium deposited in the respiratory tract, the amount of $\mathrm{Pu}$ in different tissue compartments over time with and without treatment, $\mathrm{Pu}-238 / 239$ excretion rates, and radiation doses to critical organs. Calculations from the model may be used to analyze consequences of exposure to $\mathrm{Pu}-238 / 239$, in particular the resulting absorbed radiation dose from the exposure, severity of pneumonitis, and risk of long-term health effects. These data can be compared to model output simulating the effect of treatment based on different initiation and duration times. Comparison of radiation dose reduction from different treatment regimens can be used to analyze the efficacy of different treatment approaches. The model may facilitate interpretation of $\mathrm{Pu}-238 / 239$ bioassay data and aid in treatment planning. The $\mathrm{Pu}-238 / 239$ decorporation model is a valuable and versatile tool for assessing the effect of exposure to $\mathrm{Pu}$ 238/239 and subsequent DTPA treatment. 
This page is intentionally left blank. 


\section{Section 2.}

\section{Introduction and Purpose}

Accurate modeling of medical countermeasure efficacy against chemical, biological, and radiological agents (CBR agents) is essential to understanding the vulnerability of our war fighters on the modern battlefield. In helping to calculate the benefit of countermeasures, modeling can inform data-driven purchasing decisions and logistical tradeoffs. In this study, Gryphon Scientific and Applied Research Associates, Inc. (ARA) have developed models to predict the efficacy of medical countermeasures in preventing casualties and reducing the severity and duration of illness caused by a variety of CB agents and in terms of radiation dose reduction and reduced long-term health effects risk for $\mathrm{R}$ agents.

This volume (prepared by ARA) is one of ten, describing the medical countermeasure models constructed for this project. This volume focuses exclusively on the modeling approach, parameters, and calculations used for the medical countermeasure model (MCM) for plutonium238/239 (Pu-238/239) internalized contamination. The composite model includes the appropriate parameters necessary for calculating the impact of trisodium calcium $(\mathrm{Ca})$ and trisodium zinc ( $\mathrm{Zn}$ ) diethylenetriaminepentaacetate (Ca-DTPA and Zn-DTPA, respectively) countermeasure treatment of $\mathrm{Pu}-238 / 239$ internalized contamination. The report describes how the calculations are made and provides examples of model outputs and comparisons to data and other model outputs when possible. Other volumes describe models for B. anthracis (volume 1), organophosphates (volume 2), cesium-137 (volume 3), F. tularensis (volume 4), sulfur mustard (volume 5), americium-241 (volume 6), Y. pestis (volume 7), botulinum toxin (volume 8), plutonium-238/239 (volume 9) and vesicants (volume 10, an expansion on volume 5).

This paper presents an inhalation exposure model for calculating the deposition fraction of $\mathrm{Pu}-238 / 239$ in different regions of the respiratory tract from a given air concentration. The paper also presents an uptake/clearance model for $\mathrm{Pu}-238 / 239$, which describes the rate of transfer of Plutonium $(\mathrm{Pu})$ from the respiratory tract to the systemic circulation or the gastrointestinal (GI) tract. Subsequently, a biokinetic model that describes the systemic distribution of $\mathrm{Pu}-238 / 239$ within the body, a decorporation model for DTPA binding and removal of Pu-238/239 in the systemic circulation, and a radiation dose model for calculating the absorbed radiation dose in the whole body and to two critical organs, the red bone marrow (RBM) and the lungs, is presented. Each model approach is described and justified along with the assumptions and key parameters that are implemented in each model. The composite model connects each set of calculations and is collectively used to calculate the acute and committed radiation doses, which can be related to potential adverse health effects. The radiation dose, with and without DTPA treatment, can be calculated and compared to determine efficacy of treatment. Different treatment initiation times and treatment duration times can be evaluated to determine the impact of different treatment scenarios on radiation dose. A model for estimating the long term carcinogenic risk from a given intake and treatment regime is included. 


\section{$2.1 \quad$ Summary of Deliverables}

Below is a description of the four deliverables assigned for each agent of interest, and a description of what is included in each deliverable. The third numbered item (the "MCM Model" deliverable) is the deliverable presented in this interim report.

1. Modeling Approach

The modeling approach deliverable describes each of the parameters that we anticipate including in our MCM model. For each parameter, a description of the approach for developing and justifying the parameter is presented. The approach is based on prior knowledge of the agent and on the general types of data available for each agent, but specific citations are not included, as it is a preliminary document.

2. Modeling Parameters

The modeling parameters deliverable defines the value or function for each parameter used to develop the MCM model. Each parameter is supported with a description of the rationale for choosing the parameter, including any scientific evidence used in parameter development or assumptions that were made.

3. MCM Model

In addition to the information already developed in the "Modeling Parameters" deliverable, the "MCM Model" includes a description of the model, user inputs, the model calculations, and the model outputs. For the biological agents, the report is an accompaniment to a preliminary implementation of the MCM model built in Microsoft Excel.

4. MCM Model in a Graphical User Interface (GUI)

The MCM models will be implemented in their final version in a graphical user interface. This implementation of the model will include feedback and adjustments made after review of the previous deliverables. 


\section{Section 3.}

\section{Background and Methodology}

\subsection{Importance of Plutonium-238 and -239}

Plutonium $(\mathrm{Pu})$ is primarily a man-made actinide element (although trace amounts of primordial $\mathrm{Pu}$ do exist) and has no stable isotopes. Pu-239 is a fissile material that is used to create chain reactions for use in nuclear weapons and nuclear reactors. Release of Pu-239 into the environment has occurred from nuclear weapons tests and accidents. High specific activity $\mathrm{Pu}-238$ can generate significant amounts of heat and therefore has industrial use in radioisotope thermoelectric generators (RTGs).

Between the two most commonly used $\mathrm{Pu}$ isotopes, $\mathrm{Pu}-238$ poses the greater threat for use in a radiological dispersal device (RDD) because it has been used in industry for purposes other than nuclear weapons and reactors and is therefore more readily accessible. According to the National Nuclear Security Administration (NNSA), the NNSA Offsite Source Recovery Project had recovered over 2000 abandoned or unwanted Pu-238 sources worldwide, totaling over 10,000 Curies (Ci), as of 2007 (NRC 2008). NNSA efforts indicate that a significant number of previous industrial sources exist; many of which have been abandoned or are no longer wanted nationally, and more importantly, internationally. NNSA has this ongoing activity to limit such sources existing in non-secure environments, where they could potentially be obtained and collected for malicious purposes. Nevertheless, abandoned and unwanted sources not yet collected by NNSA remain potential RDD threats.

$\mathrm{Pu}-239$ is an impractical target for an RDD in part due to stringent security of nuclear weapons and fissile material. The Pu-239 associated with nuclear reactors is in a matrix with other extremely radioactive material such that it renders the material extremely hazardous and not a practical source for use in an RDD that could be encountered "in the field". However, Pu239 could be an inhalation hazard in the event of an improvised nuclear device that does not detonate properly but results in the spread of radioactive material, similar to the weapon accident that occurred in Palomares, Spain in 1966 (Maydew 1997).

The primary form of plutonium used in industrial applications is in the oxide form, plutonium dioxide $\left(\mathrm{PuO}_{2}\right)$, which is considered insoluble. The metal oxide is used in RTGs (NRC 2008), and DOE indicates that "Plutonium dioxide $\left(\mathrm{PuO}_{2}\right)$ may now be the most important and most thoroughly studied of all plutonium compounds. Due to its chemical stability and relative inertness, it is the preferred form for shipping and storing plutonium at the present time" (DOE 2006). Since plutonium readily oxidizes in air (DOE 2006) and in an RDD, an explosion would likely be used to disperse a plutonium monolith (further facilitating oxidation); any form of plutonium used would likely oxidize into $\mathrm{PuO}_{2}$. Pu-238 decays by alpha emission accompanied by a low-energy photon to uranium-234 with a half-life of 87.7 years. Pu-239 decays by alpha emission followed by a low-energy photon to uranium- 235 with a half-life of over 24,110 years. 


\subsection{Plutonium-238/239 Decorporation}

The pharmaceutical countermeasures, calcium and zinc diethylenetriaminepentaacetate (Caand Zn-DTPA), are the only Food and Drug Administration (FDA)-approved decorporation agents for Pu and the actinides americium (Am) and curium (Cm) (FDA 2009). Therefore, DTPA (for actinides) and Prussian Blue (for Cs-137) are currently part of the Strategic National Stockpile (SNS) for which significant stores of the agents are able to be quickly distributed if a significant radiological release were to occur (FDA 2009, FDA 2011, REMM 2012).

It is worthwhile to note that the US Department of Health and Human Services Radiation Emergency Medical Management website for "Managing Internal Contamination" lists the following alternative treatment options: "DFOA [desferrioxamine], EDTA [ethylenediamine tetraacetic acid], and DTPA [diethylenetriaminepentaacetate]+DFOA" (REMM 2011). However, the authors explicitly state that these options are not FDA approved. Their source reference (NCRP Report 161, NCRP 2008a), used extensively in the development of the approach presented in this work, indicates that DTPA is the preferred treatment for actinides, such as plutonium and americium. The main body of that guidance only provides details on the use of DTPA in the treatment of internalized actinides. However, ethylenediamine tetraacetic acid (EDTA) was used early on in the treatment of internalized plutonium, but was determined to be significantly inferior to DTPA (Norwood 1960). Desferrioxamine (DFOA) was investigated in animal models for improved plutonium chelation with limited success (Volf 1986, 1993). However, DFOA has been discussed as an alternative treatment option in the event of a massive demand for actinide chelation, corresponding to depletion of DTPA supplies. Such an emergency "off-label" use of DFOA arises from the fact that it is used clinically for chelation therapy in the event of iron poison (Chang 2011). The potential exists for its "off-label" use in the event of an emergency. However, very limited data is available for the chelating agents EDTA and DFOA.

The structure of the composite model presented in this report will allow for implementation of other decorporation models, as additional data becomes available for new decorporation agents. This utility will allow for the comparison of different decorporation agents. Because the composite model uses a series of sub-models and is built on biokinetic data, it provides the flexibility to more easily adjust or integrate additional parameters applicable for novel decorporation agents. As an example, there is an effort to improve current chelation methods through formulation of an orally administered form of DTPA (Phan 2006a) and development of novel chelating agents is ongoing (Cassatt 2008). As data becomes available, orally administered DTPA kinetics can easily be integrated by adding parameters for absorption of DTPA into the circulation where it can chelate Pu. Likewise, as data becomes available on novel decorporation agents, terms may be added to the Pu biokinetic model to reflect removal from relevant compartments. The biokinetic model foundation provides a useful platform for additional development. The other components of the model, such as the inhalation, uptake, and dosimetry models, also remain valid and provide the main structure for additional Pu decorporation models.

DTPA, shown in its acid form, in Figure 1, is a chelating agent with amino- and carboxylic acid groups that can coordinate and bind actinides with relatively high affinity and enable enhanced renal excretion of these radionuclides. DTPA can be administered by intravenous drip or direct injection into a vein as the $\mathrm{Ca}$ or $\mathrm{Zn}$ salt in a 5 milliliter $(\mathrm{mL})$ hyperosmolar solution. The optimal dosing regimen for an adult is 1 gram (g) of Ca-DTPA on the initial day of treatment, followed by $1 \mathrm{~g}$ Zn-DTPA per day for subsequent treatments, until the radionuclide 
burden is adequately reduced (FDA 2004). For pregnant or lactating women, treatment should begin and continue only with Zn-DTPA (NCRP 2008a).<smiles>O=C(O)CN(CCN(CC(=O)O)CC(=O)O)CC(=O)O</smiles>

Figure 1. Diethylene Triamine Pentaacetic Acid, DTPA

Human and animal data indicate that DTPA effectively increases the rate of elimination of plutonium, which then in turn reduces the radiation dose absorbed by the body. While DTPA reduces the absorbed radiation dose, it does not treat the effects of radiation dose, such as hematopoietic cell damage and loss. The benefit of DTPA treatment depends on the total Pu238/239 absorbed into the body and the time to DTPA administration. The actinide elements can be incorporated into bone and result in long term retention of the nuclides. Early administration of DTPA can minimize the radionuclide deposition in the bone and afford greater reduction of radiation dose and improved countermeasure efficacy.

\subsection{Composite Model Approach}

This paper presents a composite model for determining the efficacy of DTPA treatment of internal contamination of $\mathrm{Pu}-238$ and $\mathrm{Pu}-239$. Descriptions of the parameters used in each of the sub-model components are provided. The sub-model components include:

- An inhalation exposure model for calculating the fractions of plutonium deposited in the three primary regions of the respiratory tract from a given air exposure concentration. This model provides the initial body burden after the exposure.

- A radionuclide-specific uptake model for absorption of plutonium from the respiratory tract to the circulatory system and the GI tract.

- A radionuclide-specific biokinetic model for calculating the distribution of plutonium within the body.

- A radiation dosimetry model for calculating the absorbed radiation dose to the critical target organs for $\mathrm{Pu}-238$ and $\mathrm{Pu}-239$. This model is used for estimating acute effects and the projected whole body dose over 50 years for long-term effects.

- Dose bands assigning projected severity levels in lung doses for the pulmonary effects of a given exposure.

- A decorporation model of DTPA for binding and removal of plutonium in the systemic circulation.

- A long-term carcinogenic risk model for projecting cancer risk from a given intake of $\mathrm{Pu}-238$ or $\mathrm{Pu}-239$, with or without treatment. 
Each modeling approach is discussed and justified along with the key parameters for each model set. Collectively, these models can be used to calculate the acute radiation dose to critical target organs for determining acute effects, as well as the long-term committed radiation dose and associated carcinogenic risk. The difference in the radiation dose resulting from different DTPA treatment regimens, including varying the start time and the duration of administration, can be calculated and compared. The composite modeling approach is outlined in Figure 2. The parameters necessary for calculating the effect of DTPA countermeasure treatment of internalized $\mathrm{Pu}$ are further outlined for each model component in the next section.

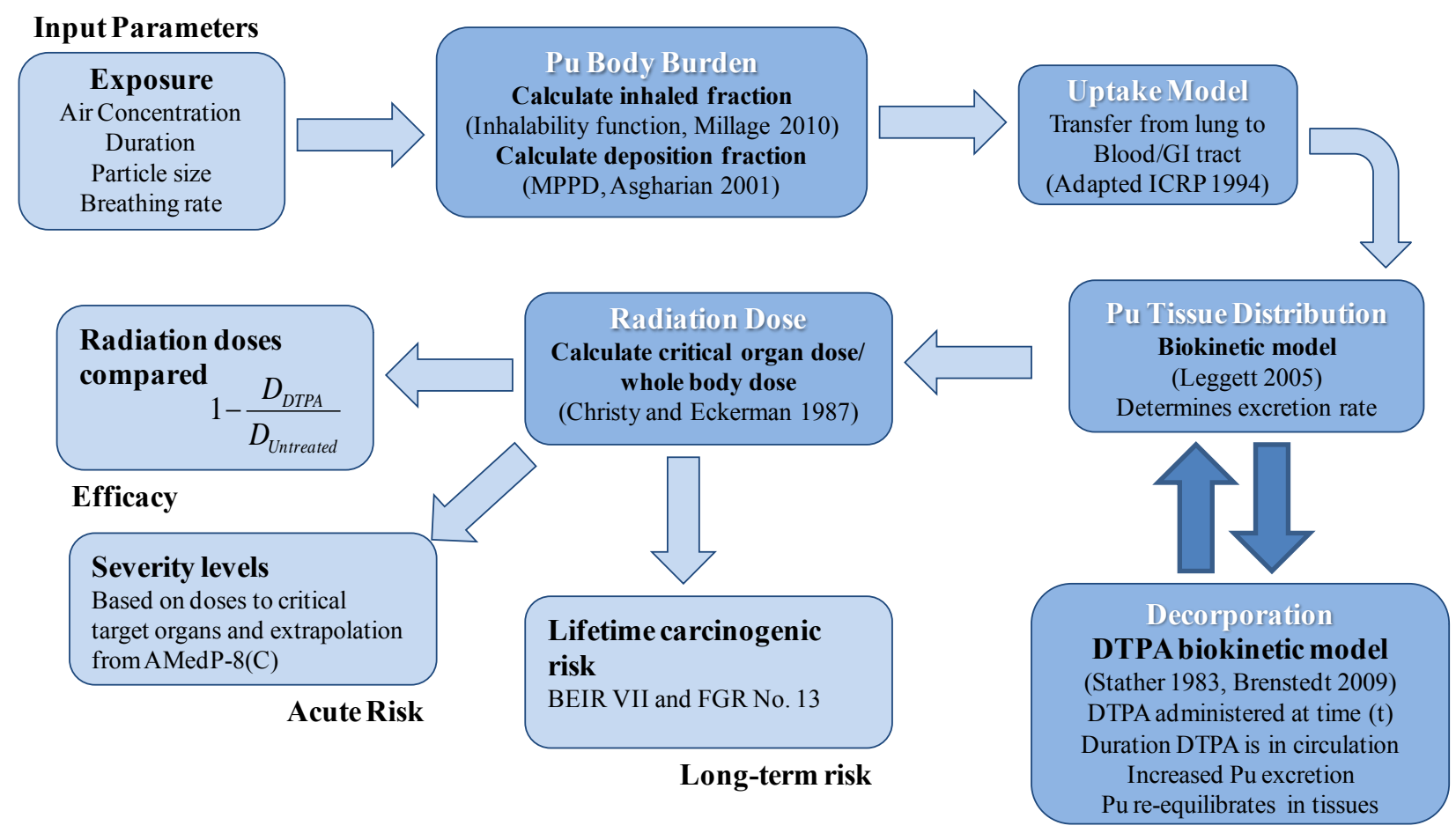

Figure 2. Composite Pu-238/239 Decorporation Model Components 


\section{Section 4.}

\section{Plutonium-238/239 Decorporation Model}

\subsection{General Assumptions}

\subsubsection{Exposure}

The current modeling effort addresses the battlefield setting in which an RDD is deemed the most likely threat scenario. Persons involved in an RDD event may be exposed to a significant amount of radioactive particulates, which would potentially result in skin contamination and inhalation of radioactive nuclides. Since the focus of the current work is the development of models for assessing medical countermeasures for internalized radionuclides, the primary route of exposure for internalization of radionuclides is assumed to be through inhalation. Some of the inhalation exposure will result in the eventual transfer of material to the gastrointestinal tract and is addressed through the inhalation model. Ingestion is not currently considered a stand-alone route of exposure for the battlefield scenario.

The amount of $\mathrm{Pu}$ internalized as a result of dermal absorption from skin contamination is assumed to be negligible. Only in cases of heavy contamination of a soluble radionuclide would absorption through the skin result in any significant internalized contamination (NCRP 2008a). Plutonium dioxide $\left(\mathrm{PuO}_{2}\right)$, the chemical form used in this modeling effort, is fairly insoluble. Personnel clothing provides significant protection from skin contamination, and external decontamination can be readily performed.

External exposure to radionuclides from an RDD-type scenario can potentially result in a significant contribution to radiation dose but it depends on the specific radionuclides involved. For the radionuclides $\mathrm{Pu}-238$ and $\mathrm{Pu}-239$, the primary contribution to radiation dose is from the alpha emission with a minor contribution from low energy photons or electrons. The alpha particle cannot penetrate past the epidermis and therefore does not pose a significant external hazard. Furthermore, any countermeasure treatment for the external dose contribution would be targeted toward acute radiation syndrome rather than decorporation. As stated previously, this particular modeling effort addresses internal contamination and decorporation treatment. Although modeling the impact of treatment on the dose contributed from external radionuclide sources would be valuable in number of scenarios, it is outside of the scope of the current work.

\subsubsection{Physical and Chemical Form}

As will be demonstrated in the results section, the physical and chemical form of plutonium particles are critical to accurately estimating the plutonium distribution and resultant radiation dose from an inhalation exposure. Although National Planning Scenario estimates particle sizes of 1-150 microns $(\mu \mathrm{m})$ result from an RDD (DHS 2004), only particles less than $10 \mu \mathrm{m}$ are considered respirable (ICRP 1994a). Larger particles, up to $30 \mu \mathrm{m}$, may be inhaled in still air and even larger particles may be inhaled during high wind speeds. However, very large particles settle from the air quickly or if inhaled are lodged in the nasal region (ICRP 1994a). There is insufficient data for development of models for particle sizes greater than $100 \mu \mathrm{m}$ (ACGIH 1999, ICRP 1994a). The inhalation model adopted for this work (as described in section 4.2) can potentially model mono-dispersed particle sizes ranging from $1-100 \mu \mathrm{m}$. In the stand-alone 
GUI, only 1 and 5 micron particle sizes were implemented to minimize the computational demand. These particle sizes are currently implemented in other radiological models (ICRP 1994a and NCRP 2008b) that can serve as reference for our outputs. ICRP (1994b) regards 1 micron-sized particles to represent indoor environmental exposures and 5 micron-sized particles more representative of occupation exposures. Recent research on modeling parameters for an RDD that included particle size distributions from blast was reviewed. Findings indicated that particle sizes from 1-3 $\mu \mathrm{m}$ were the most important with regard to eventual inhalation dose, with a peak dose at $2.6 \mu \mathrm{m}$ (Srimok 2006). Therefore, the default values of 1 and 5 microns for particles implemented in our work should be sufficient for this modeling effort.

Particles will deposit in different areas of the respiratory tract; larger particles will preferentially deposit in the upper respiratory tract and extrathoracic region, while small particles can reach the lower respiratory tract and pulmonary regions. These deposition parameters are estimated using the respiratory model described below. This approach allows the user to examine the influence of particle size on deposition, Pu distribution, and dose.

The chemical form chosen for this work, $\mathrm{PuO}_{2}$ is justified by the text presented in Section 3.1: "The primary form of plutonium used in industrial applications is in the oxide form, plutonium dioxide $\left(\mathrm{PuO}_{2}\right)$, which is considered insoluble. The metal oxide is used in RTGs (NRC 2008), and DOE indicates that "Plutonium dioxide $\left(\mathrm{PuO}_{2}\right)$ may now be the most important and most thoroughly studied of all plutonium compounds. Due to its chemical stability and relative inertness, it is the preferred form for shipping and storing plutonium at the present time" (DOE 2006). Since plutonium readily oxidizes in air (DOE 2006) and in an RDD, an explosion would likely be used to disperse a plutonium monolith (further facilitating oxidation); any form of plutonium used would likely oxidize into $\mathrm{PuO}_{2}$."

It should be noted that while $\mathrm{PuO}_{2}$ is relatively insoluble, differences in solubility of $\mathrm{Pu}-238$ and $\mathrm{Pu}-239$ have been observed and reflected in the ultimate dissolution and uptake of $\mathrm{Pu}$ from the respiratory tract (NCRP 2008b). Such variances depend greatly on the specific activity in the particulate, the chemical composition of the particulate as a whole (i.e. presence of carrier material) and size and shape of particulates. Therefore, the outputs generated by this model should be considered representative of $\mathrm{PuO}_{2}$ in general.

\subsubsection{Inhalation Exposure}

As described above, inhalation exposure was considered the primary route for plutonium intake for the modeling scenario chosen for this work. In the case of $\mathrm{PuO}_{2}$, which has quite limited solubility, the precise deposition in the respiratory tract will greatly impact the rate and amount of plutonium reaching the systemic circulation. The inhalation model described below can estimate the regional deposition location of plutonium in the respiratory tract if key variables, such as particle size and wind speed are known. Reasonable default parameters are provided when specific scenario information is not available. We compare our results against other established models, dose coefficients, or case studies, by choosing parameters that most closely resemble the specific comparison presented.

\subsubsection{Ingestion Exposure}

Given the RDD scenario, ingestion is not considered a stand-alone route of exposure. A portion of the plutonium deposited in the respiratory tract will be eventually mechanically cleared to the GI tract from the lungs via ciliary action or swallowing. $\mathrm{PuO}_{2}$ is not readily 
absorbed by the GI tract (0.001\%, ICRP 1993), but the fraction of plutonium reaching the systemic circulation from the GI tract is included.

\subsection{Inhalation Exposure Model: Calculation of Plutonium Body Burden}

Medical planners determine the plutonium body-burden after an exposure to a given air concentration of plutonium by either assumption or the use of a transport and dispersion model. The plutonium body-burden is calculated by considering the inhaled fraction of that exposure and the amount of the inhaled fraction that gets deposited into the different respiratory regions. Both of these parameters depend on particle size and can provide an accurate representation of the amount of plutonium retained from the exposure (ICRP 1994a). An overview of the inhalation model used to calculate the plutonium body burden is provided in Figure 3. The deposition refers to respiratory deposition in the extrathoracic, tracheobronchial, and pulmonary regions.
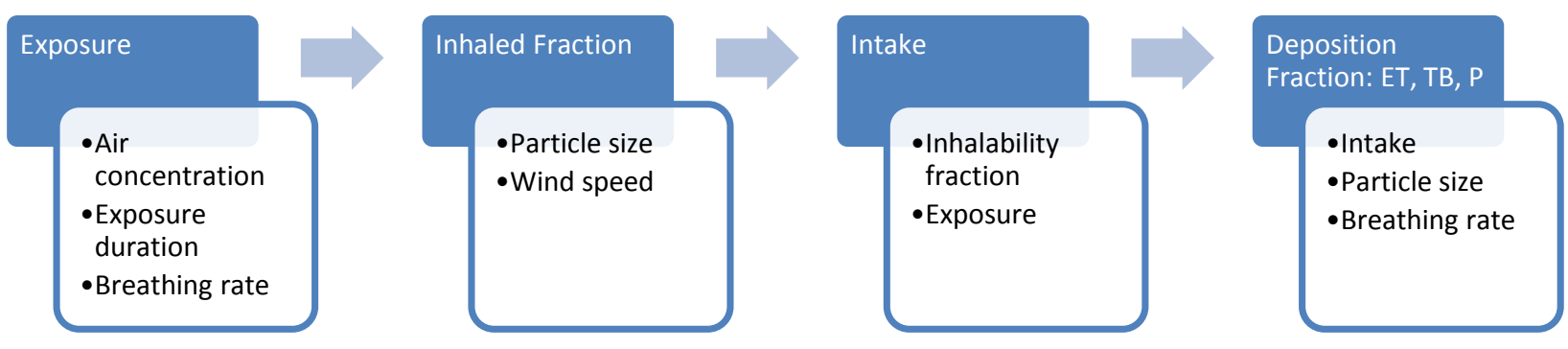

Figure 3. Inhalation Exposure Model Overview

\subsubsection{Exposure}

The exposure (Exp) is a necessary input for the inhalation model and is calculated simply by multiplying the air concentration of plutonium in the environment (AirConc), the exposure duration (ExpDur), and the breathing rate.

$$
\text { Exp }=\text { AirConc } \times \text { ExpDur } \times \text { BreathingRate }
$$

The air concentration is a user-defined input parameter in units of activity. In the final software implementation, variable activity inputs will be possible and subsequently converted, as needed. However, for the basic mathematical construct in this phase, microcuries $(\mu \mathrm{Ci})$ per unit volume (liters) are used. Also, exposure duration and breathing rate are user-defined inputs in units of time (minutes) and liters per minute $(\mathrm{L} / \mathrm{min})$, respectively. The user may want to examine different levels of activity and the impact on overall calculations. However, for this phase, default values of $15 \mathrm{~L} / \mathrm{min}$ for a breathing rate at rest and $25 \mathrm{~L} / \mathrm{min}$ for light activity (Niinimaa 1981) are implemented.

\subsubsection{Inhaled Fraction}

Inhalability is a measure of the fractional concentration of material that is inhaled relative to the concentration in the ambient air. Inhalability refers to the intake process and is defined as a function of particle size. A recent review (Millage 2010) examined the data from inhalability 
measurements and current mathematical models of inhalability. Based on this review, the proposed mathematical model provides the best description of the data across a variety of conditions, while minimizing mathematical inconsistencies. The inhalability model, which provides the inhaled fraction, is a function of both particle size and wind speed; wind speed can play a significant role in how much particulate material can be inhaled.

The inhaled fraction, $I(d)$, is determined by the particle size $(d)$ and particle concentration $(C)$.

$$
I(d)=C_{\text {inspired }}(d) / C_{\text {ambient }}(d)
$$

Inhalability is a function of particle size and ambient wind speed and is best described by three different equations, each describing different wind speed regimes. The first equation is for still air, i.e. wind speed is zero (Millage 2010).

$$
I_{\text {still }}(d)=f_{N}\left[1-\left(\frac{1}{\left(1+6.809 \times 10^{3} \times d^{-2.736}\right)}\right)\right]+f_{o}\left[\frac{1.44}{(1+0.44 \exp (0.0195 d))}\right]
$$

where $I_{\text {still }}$ is the inhaled fraction in still air and $f_{N}$ is the nasal fraction as defined below.

The next equation is for winds speeds $(U)$ greater than zero, but less than or equal to 4 meters per second (m/s) (Millage 2010).

$$
\begin{aligned}
I_{U \leq \frac{4 m}{S}}(d)=(1 & -J)\left\{f_{N}\left[\frac{1}{1-(1+\exp (8.826-2.73 \ln (d)))}\right]+f_{o}\left[\frac{1.44}{1+0.44 \exp (0.0195 d)}\right]\right\} \\
+J & {\left[1-0.5\left(1-\left(\frac{1}{7.6 \times 10^{-4} d^{2.8}+1}\right)\right)+1 \times 10^{-5} U^{2.75} \exp (0.055 d)\right] }
\end{aligned}
$$

where: $J=\frac{U^{2.75}}{4^{2.75}}$

The final equation is for wind speeds greater than $4 \mathrm{~m} / \mathrm{s}$ and less than or equal to $9 \mathrm{~m} / \mathrm{s}$ (Millage 2010).

$$
\frac{I_{4 m}}{s}<U \leq \frac{9 m}{s}(d)=1-0.5\left(1-\left(\frac{1}{7.6 \times 10^{-4} d^{2.8}+1}\right)\right)+1 \times 10^{-5} U^{2.75} \exp (0.055 d)
$$

Note that data is not available for estimating the inhaled fractions during wind speeds greater than $9 \mathrm{~m} / \mathrm{s}$ and the model is not valid for particle sizes greater than $100 \mu \mathrm{m}$ in aerodynamic diameter. Therefore, the inhalability function is limited to wind speeds of $9 \mathrm{~m} / \mathrm{s}$ or less and to particles sizes of $100 \mu \mathrm{m}$ or less. Often particles larger than a few microns are ignored because the general thought is that they will not be inhaled; however, larger particles can be inhaled and while they may not reach the pulmonary region, they can deposit in the extrathoracic region and 
be absorbed into the bloodstream. As an example, based on the equation shown above, in a moderate wind environment of $4 \mathrm{~m} / \mathrm{s}$ approximately $60 \%$ of $22 \mu \mathrm{m}$ particles will be inhaled.

\subsubsection{Nasal Fraction}

According to Niinimaa 1981, the majority of people breathe through their nose until their breathing rate reaches a threshold level. The nasal fraction, $f_{N}$, defined by Niinimaa is illustrated in Figure 4. The nasal fraction is 1 until the breathing rate reaches greater than $35 \mathrm{~L} / \mathrm{min}$, which is the transition point to heavier activity. The oral fraction, $f_{o}$, is simply $1-f_{N}$. The estimates established by Niinimaa are considered to be representative of the general population and are the best estimates outside of individual data. Note that this approach is valid only for normal augmentors (i.e. the general population). In the final software implementation of the model, values will be implemented in a look-up table for simplicity.

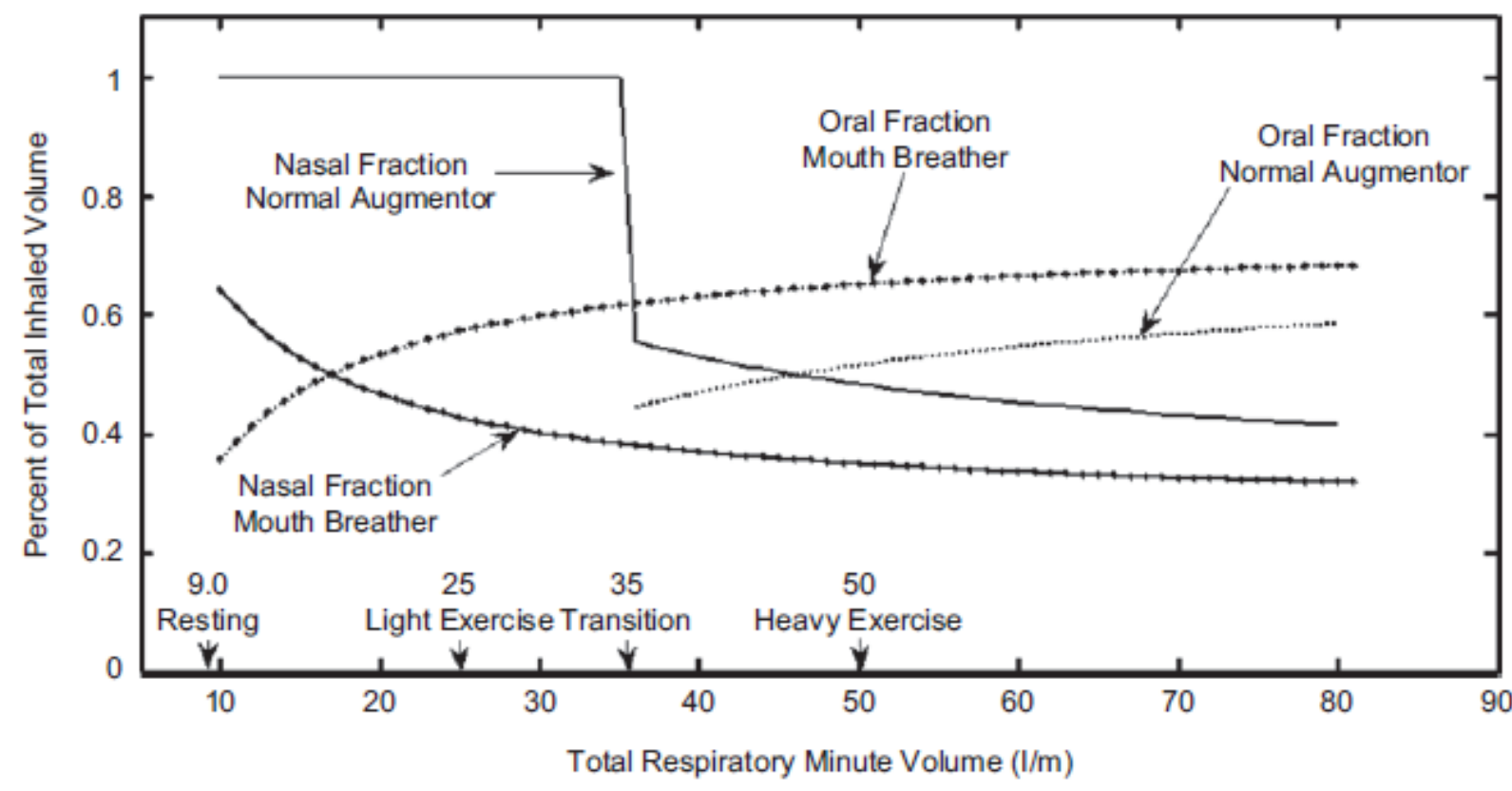

Figure 4. Nasal Fraction as a Function of Breathing Rate (According to Niinimaa 1981, reproduced from Millage 2010).

\subsubsection{Wind Speed, $U$}

If wind speed conditions are known, the model will allow a user to enter the specified value; otherwise a default ambient air speed value of $4 \mathrm{~m} / \mathrm{s}$ will be used. We have successfully accounted for varying wind speeds in our implementation of the particle deposition model in the Hazard Prediction \& Assessment Capability (HPAC), so the final implementation of the model will be able to account for more complex weather profiles.

\subsubsection{Intake}

The intake is simply exposure (in activity and as calculated in 4.2.1) of radionuclide particulates multiplied by the inhaled fraction as calculated according to the inhalability function: 


$$
\text { Intake }=\operatorname{Exp} \times I(d)
$$

Where Exp is the exposure and $I(d)$ is the particle size and wind speed-dependent inhaled fraction which valid for normal augmentors (i.e. the general population).

The resultant intake is the radioactive material concentration that actually enters the nasal or oral cavities. It does not take into account the fraction of the material that is actually deposited in the respiratory tract or the fraction that is breathed out again. The final body-burden will be determined by the deposition in the respiratory tract as described below.

\subsubsection{Deposition Fraction}

The deposition fraction is the fraction of the inhaled radioactive material that is deposited in specific regions of the respiratory tract. We used the Multiple-Path Particle Dosimetry (MPPD) model to estimate the deposition fraction. MPPD is a widely used, fast-running, GUI-driven, Java-based set of algorithms that can calculate the deposition and retention of both monodispersed and poly-dispersed particulates and aerosol droplets in human respiratory tracts based on user-defined inhalation rates (see Asgharian 2006a, Asgharian 2006b, and Asgharian 2006c for complete details). The human respiratory model includes both single-path symmetrical calculations as well as several multi-path variations of limited-asymmetric, asymmetric, and stochastic models. The limited-asymmetric model uses a 5-lobed model with subsequent symmetric airways. An age-dependent set of lung morphologies is available. The model can calculate deposition in three regions, extrathoracic (ET), tracheobronchial (TB) and pulmonary (P), or by specific airway generation, shown in Figure 5. Clearance pathways and time frames are significantly different in each region and since $\mathrm{Pu}$ is relatively insoluble, the estimated fractional deposition in these regions can significantly impact the projected clearance, uptake, and resultant radiation dose. Therefore, precise deposition calculations are critical in making accurate estimations in the Pu model.

Since MPPD does not rely entirely on a simple, symmetrical model, such as that used in the International Commission on Radiological Protection (ICRP) Publication 66 (1994a), the model can account for specific lobal deposition in the asymmetric model as well as generation-bygeneration deposition throughout the respiratory tract. Results of the deposition and retention calculations using MPPD have been favorably compared with experimental data from both rats and humans (Raabe 1976, Heyder 1986, Asgharian 2006b). Results were published that indicate the asymmetrical model used in the MPPD is effective at modeling clearance (Asgharian 2001). In addition, MPPD includes a set of stochastically generated lung models that can be used to provide an estimate of the uncertainty associated with respiratory tract deposition. 
Head (or extra-thoracic, ET) airways

- Nose and mouth to the larnyx

- Nasal airways and the oral cavity

Tracheobronchial (TB) region

- Larynx to the terminal bronchioles

- Ciliated epithelium, mucous-secreting

Pulmonary $(\mathrm{P})$ region

- Respiratory bronchioles to the terminal alveoli

- Gas-exchange epithelium, non-ciliated

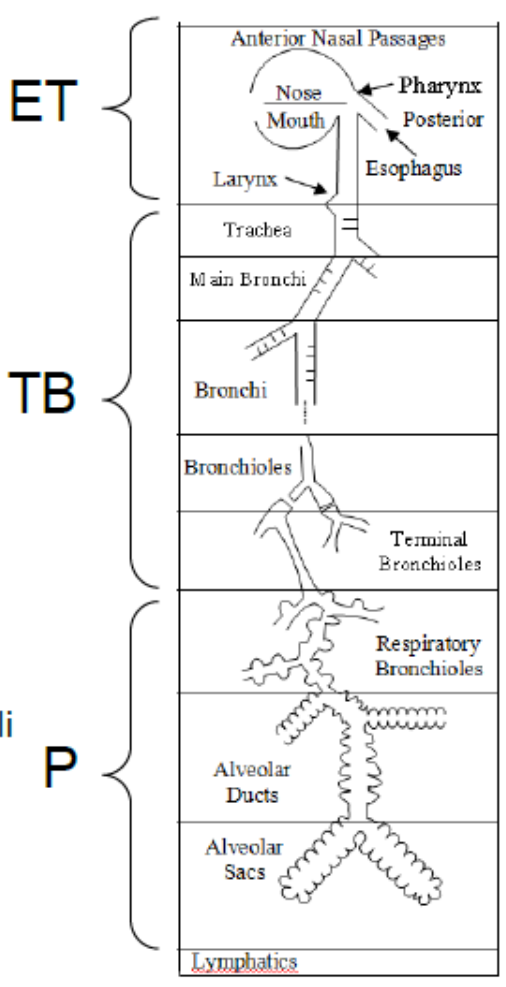

Figure 5. TheTthree Functional Regions of the Respiratory Tract (Asgharian 2006a)

As an example, we noted previously that in an area with an ambient wind of $4 \mathrm{~m} / \mathrm{s}$, approximately $60 \%$ of particles of $22 \mu \mathrm{m}$ would be inhaled. Using MPPD, we calculated that of the particles that were inhaled and assuming a breathing rate of $15 \mathrm{~L} / \mathrm{min}$, approximately $94 \%$ would deposit in the ET region, 5.4\% would deposit in the TB region, $0.0002 \%$ would deposit in the pulmonary region, and the remaining $0.59 \%$ exhaled without depositing.

In much of the published data, $5 \mu \mathrm{m}$ particles are used as a standard for inhalation exposure scenarios. In cases with $5 \mu \mathrm{m}$ particles, $100 \%$ of the particles would be inhaled. Based on MPPD calculations, we calculate that approximately $31 \%$ would deposit in the ET region, 39\% would deposit in the TB region, and 30\% would deposit in the $\mathrm{P}$ region, assuming a breathing rate of 20 L/min. ${ }^{1}$

Please refer to the references used in this section for a comprehensive description of the model and algorithms included in MPPD. MPPD has been adopted by the Environmental Protection Agency (EPA), other US government agencies, and the international risk assessment community to precisely estimate respiratory deposition (TERA 2012, Gangwal 2011, Wichers 2006, RIVM 2002). As noted above, the model in MPPD has been documented extensively in peer-reviewed publications and outputs of MPPD have been transitioned to DTRA programs of record, such as HPAC.

\footnotetext{
${ }^{1}$ The breathing rate $(20 \mathrm{~L} / \mathrm{min}$, average breathing rate for a worker) and particle size ( 5 micron) were chosen for scenario calculations so that comparisons could be made with other published data that use these parameters (ICRP 1994, NCRP 2008b).
} 
Since MPPD is stand-alone software, a more comprehensive look-up table using MPPD will be implemented in the final software developed by this project, to ensure that all components of the model are linked together in a seamless fashion. Users will not be required to run MPPD separately to evaluate variations in breathing rate and particle size in the final implementation. A look-up table provides a simpler and faster running tool than implementation of the MPPD engine itself. However, for illustrative purposes, Appendix I provides an example of the outputs generated by MPPD. Note that the fractional respiratory deposition depends upon both particle size and breathing rate.

\subsubsection{Respiratory Clearance and Systemic Uptake}

The size-dependent deposition profile of plutonium particles, along with other key attributes, will impact the observed clearance and systemic uptake of plutonium. For example, larger particles are less likely to reach the pulmonary region in which absorption into blood predominately occurs. Deposition in the extrathoracic and tracheobronchial regions of the respiratory tract will primarily result in clearance to the GI tract or back into the environment (via nose blowing, coughing, etc.). Larger particles will take longer to dissolve, which is necessary for systemic uptake, thus will demonstrate very slow absorption into the bloodstream. Other factors which impact the rate of uptake include the chemical form of plutonium, composition of the matrix material of the particles, and presence of other radionuclides (Ménétrier 2005). These factors, together with individual variation, contribute to the large variability in the data available on the respiratory clearance and uptake of plutonium.

Since $\mathrm{PuO}_{2}$ is relatively insoluble, a fairly small amount of the plutonium deposited in the respiratory tract will enter the systemic circulation; studies indicate that plutonium is absorbed into the circulation in two phases. A small fraction, less than $1 \%$, of the deposition is absorbed within about a day. The remaining plutonium is mechanically cleared from the respiratory tract, sequestered, or transformed and absorbed into the blood, with a half-time on the order of years. The rate of transfer of plutonium out of the respiratory tract can vary between ${ }^{238} \mathrm{PuO}_{2}$ and

${ }^{239} \mathrm{PuO}_{2}$ as demonstrated by bioassay data from accidental worker exposures (Hickman 2005 and James 2003) and from animal studies (Bair 1973 and Mewhinney 1983). The relatively high specific activity of $\mathrm{Pu}-238$, which makes it amenable for use as a RTG can cause radiolytic fragmentation of Pu particles, increasing solubility and facilitating transfer (NCRP 2008b). However, due to limited quantitative data, separate values for $\mathrm{Pu}-238$ are not currently implemented in our model, but it is important to note this source of uncertainty.

Considerable evidence exists that indicates the transfer of $\mathrm{Pu}$ particles is slower than the generic ICRP (1994a) respiratory uptake/transfer model calculates for "insoluble" radionuclides (Khokhryakov 2005, Birchall 2010, and Davesne 2010). The impact on the risk to pulmonary tissue doses (and estimated health effects) is significantly different, depending on which model parameters implemented. The ICRP (1994a) parameters for respiratory clearance have been critically evaluated since additional knowledge has been obtained and improvements to the model were made (Bailey 2007). The guidance suggests using radionuclide specific parameters for the respiratory tract model whenever possible. Plutonium specific parameters were estimated in a couple of studies, since the ICRP (1994a) model did not adequately predict values obtained in long-term evaluation of exposed plutonium workers (Khokhryakov 2005, Birchall 2010). Likewise, the data on systemic uptake of a wide variety of chemical forms of plutonium particulates from human and animal studies have been critically evaluated and specific uptake 
parameters proposed (Davesne 2010). However, each of the referenced studies recommends different parameters, depending on the specific data evaluated or the approach used.

The generic structure of ICRP respiratory tract model for respiratory clearance, as illustrated in Figure 6, was implemented for this work. The clearance parameters are listed in Table 1 below and the values, shown in Figure 6, refer to the compartmental transfer rates (in day ${ }^{-1}$ ).

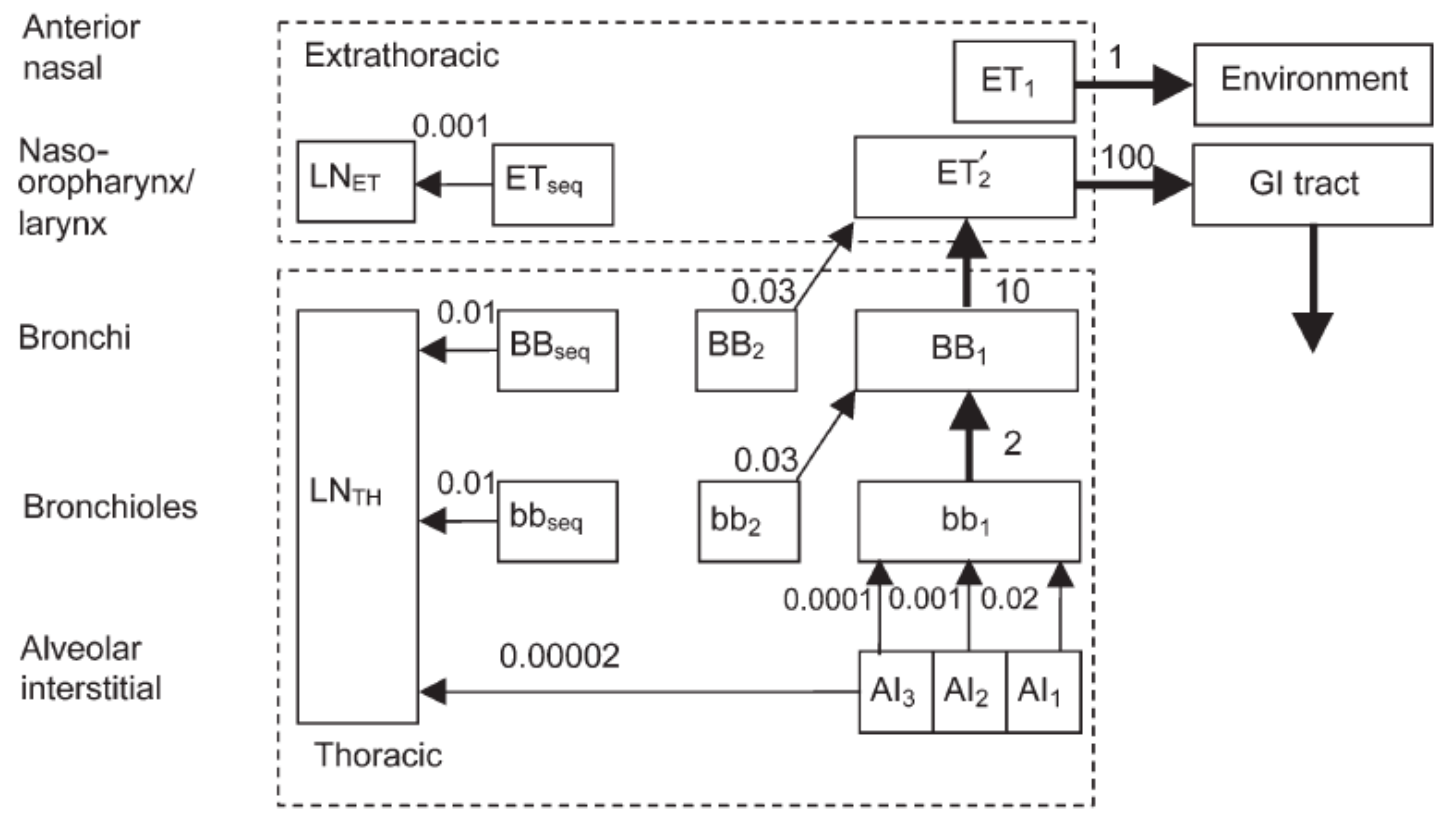

Figure 6. ICRP Respiratory Tract Model: Mechanical Clearance (Bailey 2007) ${ }^{2}$

The ICRP publication provides a detailed description of the respiratory tract clearance and uptake model. The clearance parameters are defined in Table 1, with the fraction of regional deposition in each compartment provided. To correlate with outputs from the MPPD model described previously, the ET region is the same, the TB region is defined as bronchi and bronchioles, and the pulmonary region is the alveolar interstitial. Greater detailed outputs from MPPD can be obtained in terms of generations, that split the TB region into bronchi (generation 1-9) and bronchioles (generation 10-16). These outputs from MPPD will be included in the lookup table in the final software implementation.

\footnotetext{
${ }^{2}$ Bailey (2007) uses a prime to denote the portion of the ET2 compartment that transitions quickly to the GI tract. $0.05 \%$ of the initial ET2 deposition is retained in the wall of the region and is described by the ETseq compartment.
} 
Table 1. Respiratory Compartments for Clearance Calculations

\begin{tabular}{|c|c|c|c|}
\hline Compartment & Symbol & $\begin{array}{c}\text { Fraction of deposition in each } \\
\text { compartment }\end{array}$ & $\begin{array}{c}\text { Term for } \\
\text { calculation }\end{array}$ \\
\hline $\begin{array}{c}\text { Extrathoracic }- \text { mainly nasal } \\
\text { deposition }\end{array}$ & $\mathrm{ET}_{1}$ & 0.15 & $\mathrm{ET}_{1 \mathrm{frac}}$ \\
\hline $\begin{array}{c}\text { Extrathoracic - lower, cleared to } \\
\text { GI }\end{array}$ & $\mathrm{ET}_{2}$ & $0.85 * 0.9995$ & $\mathrm{ET}_{2 \text { frac }}$ \\
\hline $\begin{array}{l}\text { Extrathoracic - sequestered, } \\
\text { "bound" }\end{array}$ & $\mathrm{ET}_{\text {seq }}$ & $0.85 * 0.0005$ & $\mathrm{ET}_{\text {seq frac }}$ \\
\hline Bronchi - faster clearance & $\mathrm{BB}_{1}$ & $0.993-f_{s}$ & $\mathrm{BB}_{1 \text { frac }}$ \\
\hline Bronchi - slower clearance & $\mathrm{BB}_{2}$ & $f_{s}$ & $\mathrm{BB}_{2 \text { frac }}$ \\
\hline Bronchi - sequestered, "bound" & $\mathrm{BB}_{\text {seq }}$ & 0.007 & $\mathrm{BB}_{\text {seq frac }}$ \\
\hline Bronchioles - faster clearance & $\mathrm{bb}_{1}$ & $0.993-f_{s}$ & $\mathrm{bb}_{1 \text { frac }}$ \\
\hline Bronchioles - slower clearance & $\mathrm{bb}_{2}$ & $f_{s}$ & $\mathrm{bb}_{2}$ frac \\
\hline $\begin{array}{l}\text { Bronchioles - sequestered, } \\
\text { "bound" }\end{array}$ & $\mathrm{bb}_{\text {seq }}$ & 0.007 & $b b_{\text {seq frac }}$ \\
\hline $\begin{array}{l}\text { Alveolar interstitial - faster } \\
\text { clearance }\end{array}$ & $\mathrm{AI}_{1}$ & 0.3 & $\mathrm{AI}_{1 \text { frac }}$ \\
\hline $\begin{array}{l}\text { Alveolar interstitial - moderate } \\
\text { clearance }\end{array}$ & $\mathrm{AI}_{2}$ & 0.6 & $\mathrm{AI}_{2}$ frac \\
\hline $\begin{array}{c}\text { Alveolar interstitial - slower } \\
\text { clearance }\end{array}$ & $\mathrm{AI}_{3}$ & 0.1 & $\mathrm{AI}_{3}$ frac \\
\hline Lymph nodes & $\mathrm{LN}$ & & $\mathrm{LN}_{\text {frac }}$ \\
\hline
\end{tabular}

The term $f_{s}$ refers to the slow-cleared fraction in the "mechanical" clearance (i.e. clearance mechanisms besides absorption/uptake into the blood) of the respiratory tract, which is particle size-dependent, according to the following functions:

$$
\begin{gathered}
f_{s}=0.5 \text { for } d \leq 2.5 \sqrt{\rho / \chi} \mu \mathrm{m} \\
f_{s}=0.5 e^{-0.63\left(d \sqrt{\frac{\rho}{\chi}}-2.5\right)} \text { for } d>2.5 \sqrt{\rho / \chi} \mu \mathrm{m}
\end{gathered}
$$

where $d$ is the particle size diameter, $\rho$ is the particle density $\left(3 \mathrm{~g} / \mathrm{cm}^{3}\right.$ is used as a default value), and $\chi$ is the particle shape factor (1.5 is used as a default value; ICRP 1994a).

The implementation for the clearance values in our model follow that of the ICRP model, except for the fraction allocated in the ET region for clearance to the environment (via nose blowing or coughing) versus clearance to the GI tract or sequestration. ICRP had originally used an arbitrary value of $50 \%$ clearance to the environment; however, more recent data indicates that the fraction cleared to the environment is no more than about 15\% (Bailey 2007). Therefore, our model assumes a $15 \%$ fraction cleared to the environment. 
The ICRP model assumes that absorption into the bloodstream occurs in all regions, besides the $\mathrm{ET}_{1}$ compartment, at a rate specified according to the solubility of the radionuclide (soluble, moderately soluble, or insoluble). However, the revised guidance recommends using radionuclide-specific parameters for absorption/uptake rates, when available (Bailey 2007). Table 2 details the absorption/uptake parameters obtained for a generic insoluble radionuclide as well as from different studies specifically on $\mathrm{PuO}_{2}$. A couple of studies have proposed radionuclide-specific parameters for the clearance model, depicted in Figure 6, together with radionuclide-specific parameters for systemic uptake (Khokhryakov 2005, Birchall 2010). However, these studies are based on a selected case or experiment. A recent review by Davesne 2010 compiled uptake parameters on a wide variety of chemical forms of plutonium which includes data on $\mathrm{Pu}-238,-239$, and -240 as well as mixtures.

Table 2. Respiratory Tract Absorption Values for Generic Insoluble Materials and $\mathrm{PuO}_{2}$

\begin{tabular}{|c|c|c|c|c|}
\hline & $\begin{array}{c}\text { ICRP 1994; } \\
\text { Insoluble }\end{array}$ & $\begin{array}{c}\text { Bailey 20073; } \\
\text { Insoluble }\end{array}$ & $\begin{array}{c}\text { Birchall 2010; } \\
\text { PuO }_{2}\end{array}$ & $\begin{array}{c}\text { Davesne 2010; } \\
\text { PuO2 }_{2}\end{array}$ \\
\hline $\mathrm{f}_{\mathrm{sr}}$ & 0.001 & 0.01 & 0.0026 & 0.064 \\
\hline $\mathrm{s}_{\mathrm{r}}\left(\mathrm{day}^{-1}\right)$ & 100 & 3 & 1 & 3 \\
\hline $\mathrm{s}_{\mathrm{s}}\left(\right.$ day $\left.^{-1}\right)$ & 0.0001 & 0.00008 & 0.0001 & 0.0019 \\
\hline
\end{tabular}

where $f_{s r}$ is the percent of the radionuclide rapidly absorbed at rate $s_{r}\left(\right.$ day $\left.^{-1}\right)$ and the remaining amount of radionuclide, referred to as $f_{s s}$, is equal to $\left(1-f_{r}\right)$, and is absorbed at a slower rate, $s_{s}\left(\right.$ day $\left.^{-1}\right)$.

To determine an appropriate set of parameters for the model to be implemented in our work, the outputs from the model, using each of the different absorption parameters listed in Table 2 , were compared in Figure 7.

\footnotetext{
${ }^{3}$ This reference uses geometric diameter rather than aerodynamic diameter for particles in their estimate. The authors use these values, there may be differences
} 


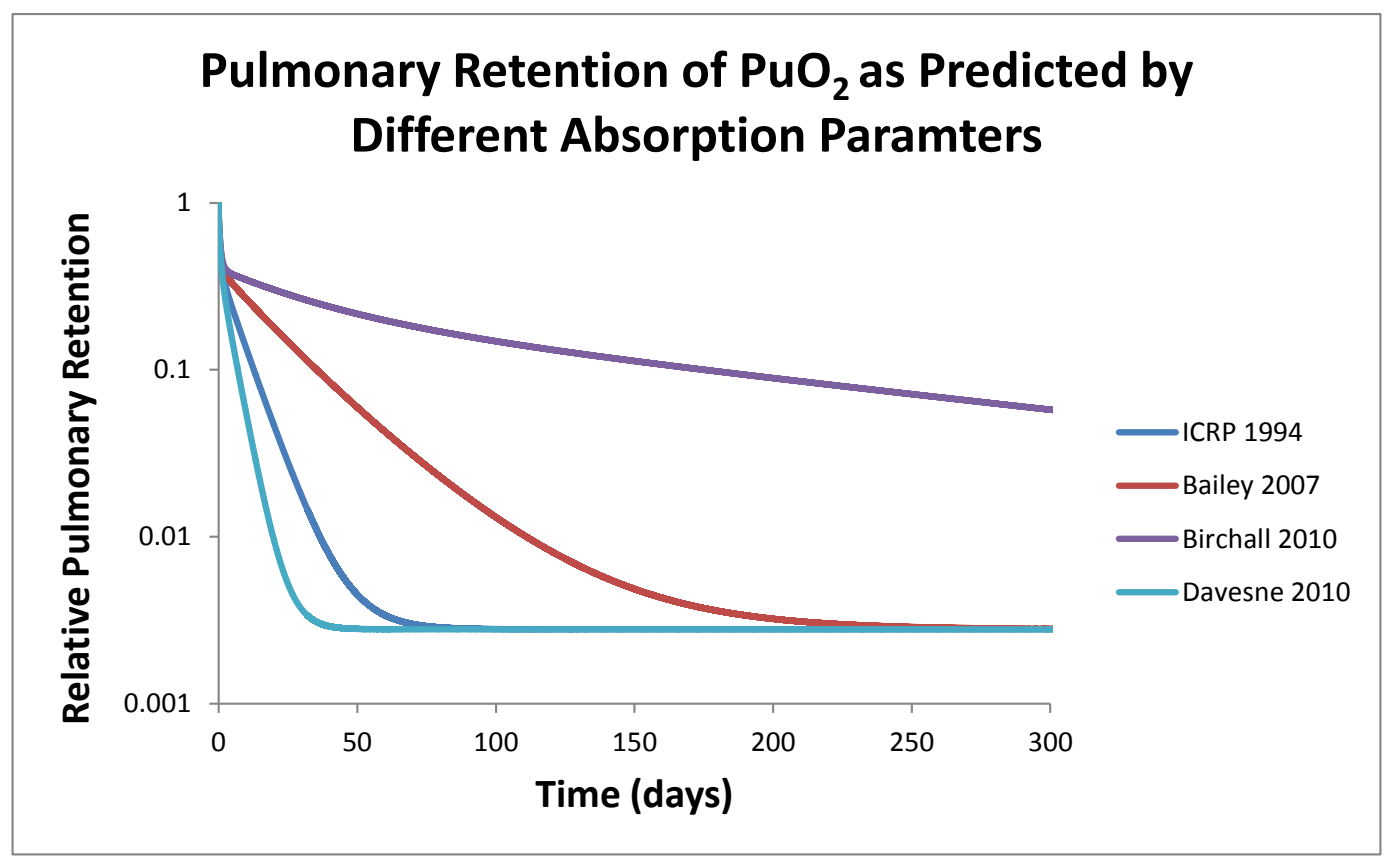

Figure 7. Pulmonary Retention of $\mathrm{PuO}_{2}$ as Predicted by Different Absorption Parameters

A number of specific parameters impact the observed behavior of plutonium in the respiratory tract such as:

- Particle size

- Exposure parameters such as wind speed

- Inhalation parameters such as breathing rate

- Chemical form of the matrix material

- Physical form

- Presence of other radionuclides

- Individual variability

Considering that all of the very specific parameters (i.e. particle size, presence of other radionuclides, breathing rate) are often not known- and for the purpose of scenario testing- a general approach that encompasses some of the variability is warranted. The model parameters provided by Bailey, 2007, offer a more general response as compared to parameters obtained in the specific studies. We adopted these values for incorporation into our model.

The portion of plutonium transferred to the GI tract from the respiratory tract via mechanical clearance (see Figure 6 and Appendix II) is primarily excreted directly through fecal elimination, although a small fraction of the plutonium can be absorbed into the systemic circulation from the GI tract. Uptake from the GI tract is described in more detail below, but in short, studies indicate that plutonium oxides have very limited absorption from the GI tract, with uptakes ranging from $10^{-7}$ to $10^{-5}$. A GI uptake value of $1 \times 10^{-5}$ has been adopted by the ICRP (1994b) as a conservative estimate for insoluble plutonium uptake. This value will be implemented in our model for consistency. 
The implementation of the clearance and uptake parameters along with a complete mathematical description of the model is provided in Appendix II.

\subsubsection{Uptake from the GI Tract}

The portion of plutonium transferred to the GI tract is primarily excreted directly through fecal elimination, although a small fraction of the plutonium can be absorbed into the systemic circulation from the GI tract. In case studies and experimental studies, plutonium has exhibited very limited absorption from the GI tract. According to human data (from Sellafield releases (Hunt 1986) and from a review of GI absorption of radionuclides (Harrison 2001)) from individuals who consumed seafood contaminated with plutonium and americium, 0.00001-0.01\% of plutonium absorption from the GI tract was observed. Based on the data reviewed for $\mathrm{PuO}_{2}$, ICRP (1994b) adopted a conservative value of $0.001 \%$ absorption for $\mathrm{PuO}_{2}$, due to its low solubility. Therefore, we use the conservative GI uptake parameter value, recommended by ICRP of $0.001 \%$ in our model. However, it is important to note that Harrison, et al. (2001) recommended a median value of $0.05 \%$ for generic $\mathrm{Pu}$. A recent review evaluating uncertainties associated with $\mathrm{Pu}$ dose estimates highlights the discrepancy in the GI absorption parameters to be a major source of uncertainty in current modeling (Puncher 2012).

\subsection{Plutonium Biokinetic Model}

The distribution of plutonium throughout the body's tissues is calculated according to $\mathrm{Pu}$ biokinetic model based on the ICRP (1993), but updated and modified by Leggett (2005), as shown in Figure 8. The modifications made by Leggett (2005) include refinements in the tissue compartments (such as blood and liver) to more accurately reflect data obtained from autopsy analyses and long-term follow-up of occupationally-exposed $\mathrm{Pu}$ workers. The biokinetic model implements the transfer coefficients detailed in Table 3.

The physiologically-based model developed by Leggett was chosen because it was the most detailed model available for Pu. The physiologically-based model allows more detailed and accurate dosimetry calculations to be made for the whole body and enables the calculation of doses to specific tissues. Specific tissue doses are critical in determining acute effects from radiation for which dose to critical organs must be examined. Detailed tissue transport data, obtained from the biokinetic model, enables the calculation of the amount of $\mathrm{Pu}$ available for removal by DTPA treatment. 


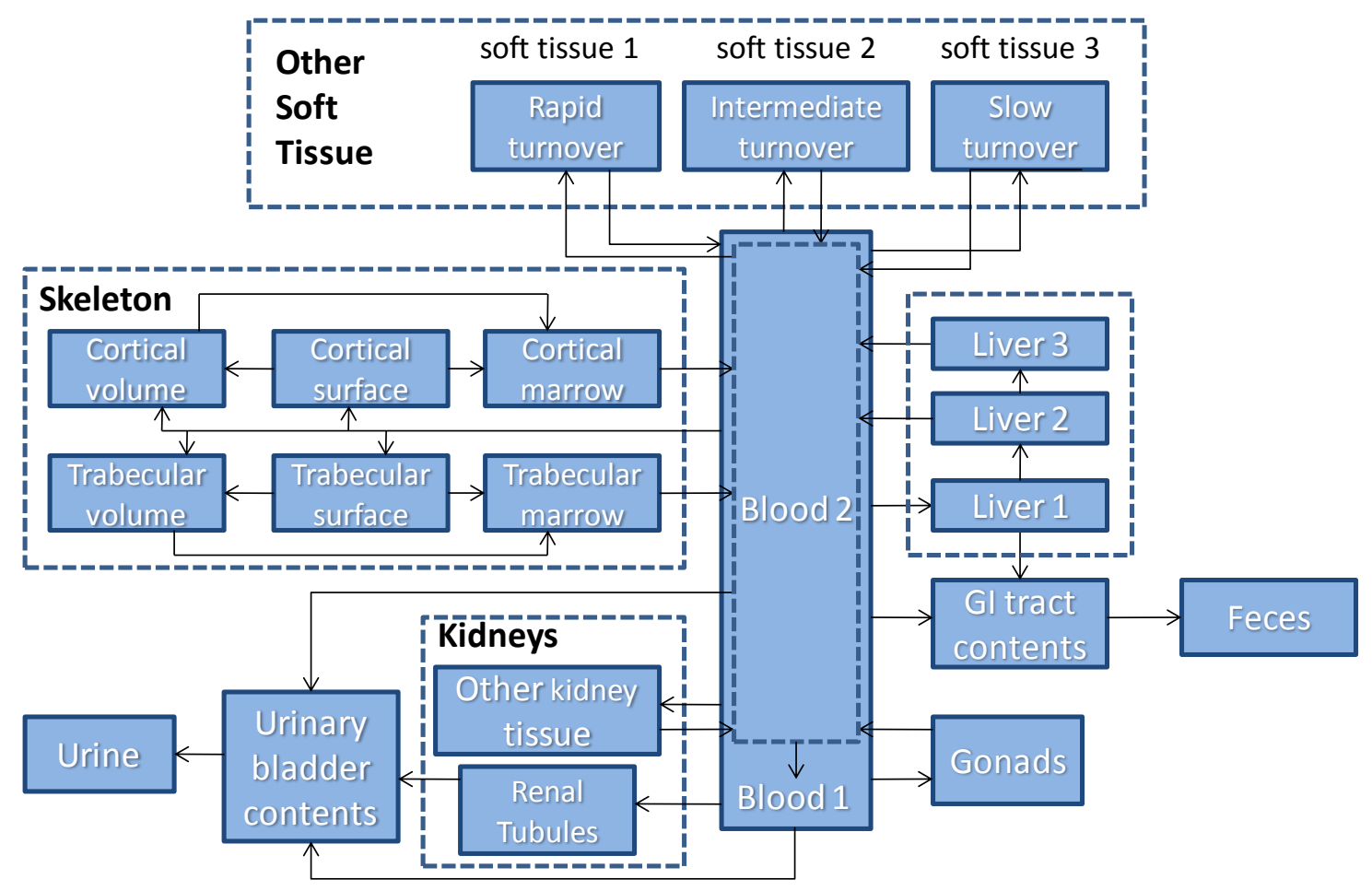

Figure 8. Plutonium Biokinetic Distribution Model (Leggett 2005)

The plutonium biokinetic model obtains input from the inhalation model to ascertain the amount of Pu entering the bloodstream from the respiratory tract, either by direct absorption into the blood or indirect respiratory clearance to the GI tract and subsequent absorption (which contributes minimally). Due to the low solubility of $\mathrm{PuO}_{2}$, systemic uptake is relatively small. However, significant doses to internal organs may still be obtained from the portion of the $\mathrm{Pu}$ absorbed, particularly from Pu immobilized in the bone compartment. Therefore, the biokinetic model is required for calculating those doses and the risk of subsequent adverse health effects.

\subsubsection{Transfer Coefficients for Plutonium}

The plutonium biokinetic model allows incomplete, tissue-dependent extraction of material during passage through the circulation and return of material from tissues to blood. The model performs this function by accounting for the blood flow rate to different tissues, estimated tissue retention times, and subsequent transfer coefficients.

Table 3. Transfer Coefficients (Leggett 2005)

\begin{tabular}{|c|c|c|}
\hline From & To & $\begin{array}{c}\text { Transfer coefficient } \\
\left(\mathbf{d}^{\mathbf{- 1}} \mathbf{)}\right.\end{array}$ \\
\hline Blood 1 & Liver 1 & 0.462 \\
\hline Blood 1 & Cortical surface & 0.08778 \\
\hline Blood 1 & Cortical volume & 0.00462 \\
\hline Blood 1 & Trabecular surface & 0.12474 \\
\hline
\end{tabular}




\begin{tabular}{|c|c|c|}
\hline From & To & $\begin{array}{c}\text { Transfer coefficient } \\
\left(d^{-1}\right)\end{array}$ \\
\hline Blood 1 & Trabecular volume & 0.01386 \\
\hline Blood 1 & Urinary bladder contents & 0.0154 \\
\hline Blood 1 & Renal tubules & 0.0077 \\
\hline Blood 1 & Other kidney tissue & 0.000385 \\
\hline Blood 1 & Upper large intestine contents & 0.01155 \\
\hline Blood 1 & Gonads & 0.0002695 \\
\hline Blood 1 & Ovaries & 0.0000847 \\
\hline Blood 1 & Soft tissue 2 & 0.018511 \\
\hline Blood 1 & Soft tissue 3 & 0.0231 \\
\hline Soft tissue 1 & Blood 1 & 0.099 \\
\hline Blood 2 & Urinary bladder contents & 3.5 \\
\hline Blood 2 & Blood 1 & 67.55 \\
\hline Blood 2 & Soft tissue 1 & 28.95 \\
\hline Renal tubules & Urinary bladder contents & 0.017329 \\
\hline Other kidney & Blood 2 & 0.0001266 \\
\hline Soft tissue 2 & Blood 2 & 0.001386 \\
\hline Soft tissue 3 & Blood 2 & 0.0001266 \\
\hline Liver 1 & Small intestines & 0.0009242 \\
\hline Liver 1 & Liver 2 & 0.045286 \\
\hline Liver 2 & Blood 2 & 0.00152 \\
\hline Liver 2 & Liver 3 & 0.00038 \\
\hline Liver 3 & Blood 2 & 0.0001266 \\
\hline Gonads & Blood 2 & 0.00038 \\
\hline Ovaries & Blood 2 & 0.00038 \\
\hline Cortical surface & Cortical marrow & 0.0000821 \\
\hline Cortical surface & Cortical volume & 0.0000205 \\
\hline Cortical volume & Cortical marrow & 0.0000821 \\
\hline Trabecular surface & Trabecular marrow & 0.000493 \\
\hline Trabecular surface & Trabecular volume & 0.000123 \\
\hline Trabecular volume & Trabecular marrow & 0.000493 \\
\hline Cortical marrow & Blood 2 & 0.0076 \\
\hline Trabecular marrow & Blood 2 & 0.0076 \\
\hline Urinary bladder contents & Urine & 7 \\
\hline GI tract & Feces & 0.5 \\
\hline
\end{tabular}


The transfer coefficients for the flow of $\mathrm{Pu}$ from blood to different tissue compartments and its return to the circulation were mathematically derived from the fractional blood flow to the tissues and knowledge concerning the tissue-specific retention of $\mathrm{Pu}$ in the compartments. The knowledge is based on accidental, worker, and even experimental human exposure case studies and autopsies, as well as detailed experimental animal studies, which were reviewed by ICRP (1993), Leggett (2005), Durbin (2006), and NCRP (2008b).

\subsection{DTPA Treatment Model}

Since DTPA is not readily absorbed from the GI tract into the blood stream and little Pu is secreted into the GI tract, DTPA must be administered intravenously for effective decorporation. Inhaled DTPA may be absorbed up to $20 \%$ from the lung into the circulation and is a potential mode of administration. Based on data from animal studies and one human tracer study using ${ }^{14}$ carbon-labeled DTPA, the chelate uniformly distributes throughout the body via circulation. It remains in the extracellular space and is not metabolized to any significant degree (Volf 1978, Stather 1983). A basic biokinetic model for DTPA has been proposed, as shown in Figure 9 (Stather 1983, Breustedt 2009 and 2010). The transfer coefficients proposed for this model are listed in Table 4 below.

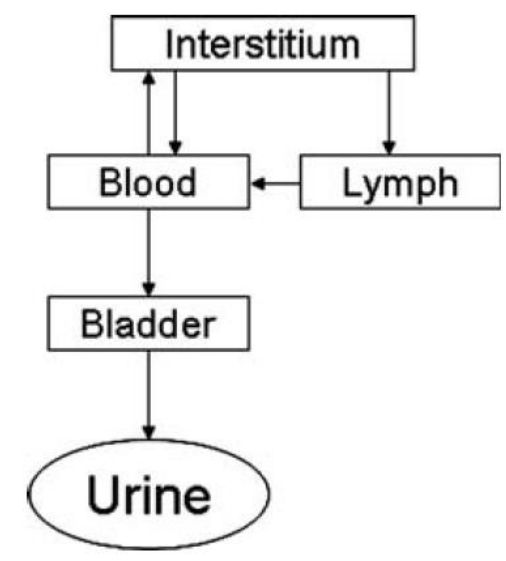

Figure 9. DTPA Biokinetic Model (Breustedt 2010)

Breustedt and colleagues through the European consortium, EURODOS, have tried to use the biokinetic model to develop a mathematical model for DTPA on the molecular level. To date, these efforts have had moderate success, since simulation could not accurately reproduce data for several validation cases (Breustedt 2009 and 2010). Due to these limitations, we adopted a simplified approach to modeling the removal of plutonium by DTPA. Since DTPA does not concentrate in any specific tissues or transfer to intracellular space, we assume that DTPA removes $\mathrm{Pu}$ by chelating $\mathrm{Pu}$ primarily in the circulation (i.e. the blood compartment of the $\mathrm{Pu}$ biokinetic model). 
Table 4. Transfer Coefficients for the DTPA Biokinetic Model (Breustedt 2009)

\begin{tabular}{|c|c|c|}
\hline From & To & Transfer coefficient $\left(\mathbf{d}^{\mathbf{- 1}}\right)$ \\
\hline Blood & Interstitium & 145 \\
\hline Interstitium & Blood & 64 \\
\hline Interstitium & Lymph & 0.123 \\
\hline Lymph & Blood & 0.405 \\
\hline Blood & Urinary bladder & 45.7 \\
\hline
\end{tabular}

The process of decorporation is limited by the rate of mobilization from the lungs to the circulation and the rate of release of Pu back into the circulation from tissues that have sequestered it, such as the liver and bone. While the Pu biokinetic model calculates the amount of Pu in the circulation at any given time, the DTPA biokinetic model developed by Stather (1983), indicates that nearly all of the DTPA injected into the bloodstream (99\%) clears via renal excretion in about 24 hours. The recommended dose of DTPA results in a vast excess of DTPA in the circulation, as compared to the amount of Pu in the circulation. Also, the binding affinity of DTPA for Pu is quite strong. Both of these qualities assume that all of the Pu in the blood stream will be bound by DTPA during its circulation and is subsequently removed by renal clearance.

\subsubsection{Route of Administration}

The primary route of administration for DTPA is intravenous administration and is considered a fixed parameter in the model (FDA 2004). This route of administration will quickly reach an equilibrium concentration of DTPA in the circulation (Stather 1983).

\subsubsection{Formulation, Dose, and Time Course}

Ca- and Zn-DTPA are formulated in a $5 \mathrm{ml}$ hyperosmolar solution, containing 1 gram of the respective salt. adjusted to physiological $\mathrm{pH}$ with sodium hydroxide provided in sterile, nonpyrogenic ampoules, suitable for intravenous administration (FDA 2004, Hameln 2004). This is a standard formulation, which is designed as a fixed parameter in the treatment model.

Although nebulized DTPA may be administered with an inhaler, there is insufficient data to adequately model this route of administration. The evidence that is available does not indicate any improved chelation for $\mathrm{PuO}_{2}$ (Ménétrier 2005). In addition, nebulized chelation therapy may exacerbate asthma (Hameln 2004); therefore, intravenous injection is the preferred method of treatment and is treated as a fixed parameter in the model.

The optimal dosing regimen for an adult is $1 \mathrm{~g}$ of Ca-DTPA on the initial day of treatment followed by $1 \mathrm{~g}$ Zn-DTPA per day for subsequent treatments, until the radionuclide burden is adequately reduced (FDA 2004). The transition from Ca-DTPA to Zn-DTPA is recommended due to toxicity issues and is briefly discussed later is this report. The model assumes that the recommended dosing regimen is followed, although the mathematical implementation of the decorporation model, as described below, does not discriminate between Ca- and Zn-DTPA. 
The duration of treatment, in days, is an input variable for the treatment model. The effect of treatment duration can be examined with the model, with longer treatment courses having a greater impact on total radiation dose.

\subsubsection{Time from Exposure to Treatment}

The time from exposure to initiation of treatment is an input variable parameter in the model. Using the plutonium biokinetic model enables the dose calculation to be made as a function of $\mathrm{Pu}$ concentration in the body integrated over time. When DTPA treatment begins, $\mathrm{Pu}$ concentration is reduced from the systemic circulation (the blood compartment). Re-equilibration is achieved over time according to the tissue transfer coefficients in the biokinetic model. Since radiation dose is calculated based on the $\mathrm{Pu}$ concentration as a function of time, it can be calculated seamlessly using the model, regardless of DTPA treatment start time or duration. The impact of time from exposure to initiation of treatment can be examined with the model. The greatest impact on dose reduction is observed when treatment begins soon after exposure. This is particularly important for $\mathrm{Pu}$, as it is absorbed into the bloodstream, where it can be sequestered by the liver and incorporated into bone, which is particularly difficult to mobilize.

\subsubsection{Plutonium Decorporation}

The binding affinity of DTPA for Pu is quite strong, as demonstrated by its stability constant of 23.4, at physiological conditions (Volf 1978, Anderegg 2005). The stability constant is the equilibrium constant for the formation of a metal complex (a chelate bound to a metal) in a solution and reflects the affinity a chelate has for a specific metal. For comparison, the stability constant of DTPA with calcium is about 2 and for zinc about 4 (Anderegg 2005). Thus, DTPA will more readily exchange zinc or calcium ions, allowing for the opportunity to bind to $\mathrm{Pu}$. DTPA binding of $\mathrm{Pu}$ is stronger than with other competing metal ions and DTPA does not readily release $\mathrm{Pu}$ once it is bound.

As described above, the recommended dose of DTPA results in an initial vast excess of DTPA in the circulation as compared to the amount of $\mathrm{Pu}$ in the circulation. Given the strong affinity of DTPA for Pu and its excess, we can assume that all of the Pu in the blood stream will be bound by DTPA during its circulation and subsequently removed by renal clearance.

For each DTPA treatment, the total amount of Pu entering the circulation (blood compartment) from all contributing tissues is integrated over the established "effective" residence time, to determine the total Pu bound or chelated by DTPA for each treatment. The amount of Pu chelated by DTPA is deducted from the total body burden of Pu and added to the amount of $\mathrm{Pu}$ excreted. The Pu remaining in the tissue compartments is then re-equilibrated according to the plutonium biokinetic model. The effective residence time refers to the period of time that DTPA can efficiently remove Pu from the body. The effective residence time was developed as described below.

\subsubsection{Optimizing DTPA Effective Residence Time}

Different effective residence times for $\mathrm{Pu}$ in the circulation (i.e. blood compartment) were examined in the treatment model. The model (described above) is constructed such that all of the $\mathrm{Pu}$ entering the blood compartment during the effective residence time for DTPA, after administration, is removed. The rate of Pu chelated from the circulation during DTPA treatment is the sum of $\mathrm{Pu}$ in the blood that would normally move to tissue compartments, and the amount 
of $\mathrm{Pu}$ being released from each organ back into the circulation, over the specified effective residence time for each treatment:

$$
\frac{d}{d t}\left(P u_{\text {chelated }}\right)=\sum\left(P u_{\text {blood }} * T C_{{\text {blood } \rightarrow \text { organ }_{i}}}+P u_{\text {organ }_{i}} * T C_{\text {organ }_{i} \rightarrow \text { blood }}\right)
$$

where $P u_{\text {chelated }}$ is the amount of Pu chelated by DTPA, $P u_{\text {blood }}$ is the amount of Pu in blood, $P u_{\text {organ }}$ is the amount of $\mathrm{Pu}$ in each organ (or tissue) that will transfer within the blood (see Figure 8), and $T C$ is the transfer coefficient (in units per day; Table 3) for the respective flow of $\mathrm{Pu}$. The amount of Pu chelated by DTPA is added to the amount of Pu excreted in the urine.

The transfer of $\mathrm{Pu}$ in and out of the blood during untreated periods is represented as:

$$
\frac{d}{d t}\left(P u_{\text {blood }}\right)=\sum\left(-P u_{\text {blood }} * T C_{\text {blood } \rightarrow \text { organ }_{i}}+P u_{\text {organ }_{i}} * T C_{\text {organ }_{i} \rightarrow \text { blood }}\right)
$$

The transfer of $\mathrm{Pu}$ in the blood compartment during treatment changes to:

$$
\frac{d}{d t}\left(P u_{\text {blood }}\right)=\sum\left(-P u_{\text {blood }} * T C_{\text {blood } \rightarrow \text { organ }_{i}}\right)
$$

Plutonium retention under DTPA treatment was examined assuming a maximum residence time of 24 hours, based on the biokinetic model for DTPA (Stather 1983). Data was generated on effective residence times for DTPA ranging from 2 to 24 hours, as shown in Figure 10. For this scenario, treatment was initiated one day after exposure to $5 \mu \mathrm{m}$ particles. Treatment was continuous for 30 days. The simulation shows how effective continuous treatment can be when initiated early. In this scenario, $\mathrm{Pu}$ is removed nearly as soon as it enters the bloodstream. Since a slower absorption of Pu into the blood occurs as particle size increases, DTPA treatment can be very effective if administered early (before Pu becomes lodged in the bone and liver) and continuous. Since Pu moves into the bloodstream relatively slowly, different effective residence times for $\mathrm{Pu}$ do not have a large impact on the amount of $\mathrm{Pu}$ that can be removed with each treatment. 


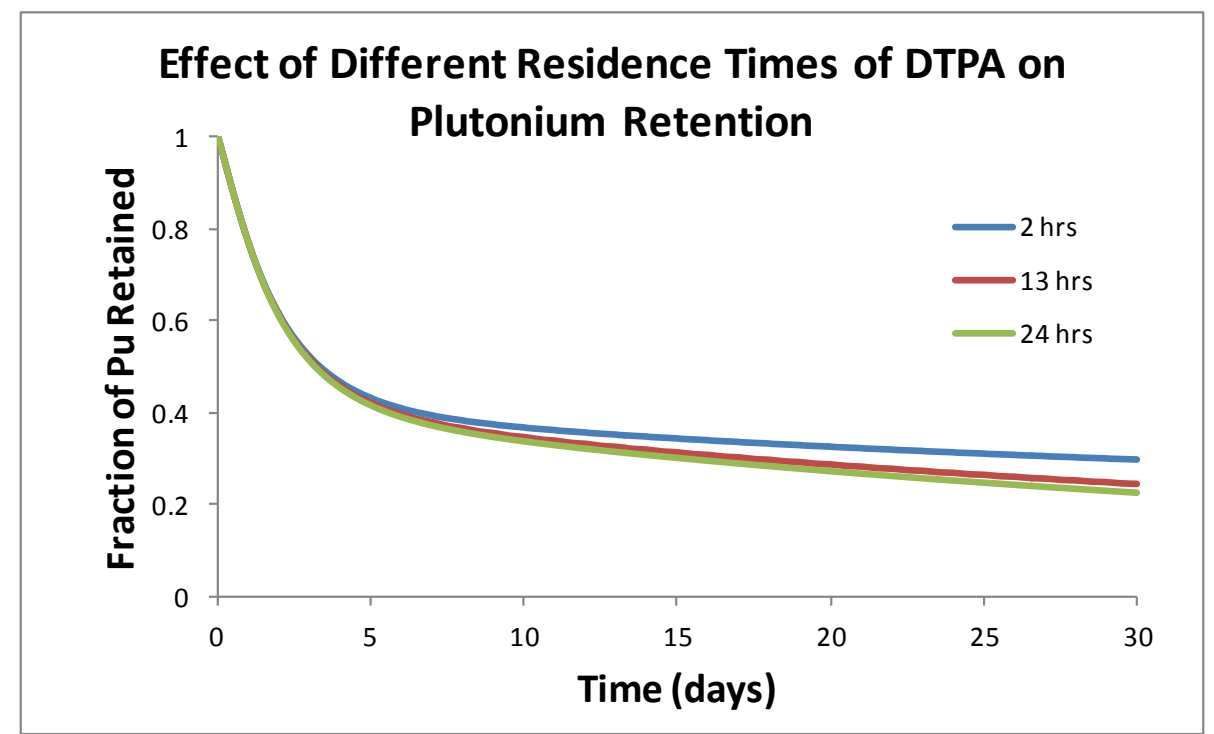

Figure 10. Effect of Different Effective Residence Times of DTPA in the Blood

Using the plutonium biokinetic and decorporation model, the maximum effective residence time for 24 hours provides an initial increase of approximately 71 times the daily urinary excretion of Pu during treatment. This effectiveness of the chelation treatment using DTPA is evaluated by considering the excretion enhancement factor (EEF). DTPA has been reported to increase urinary excretion of Pu with an EEF of 5 to 150 with DTPA treatment (Jech 1972, Jolly 1972, Schofield 1974, Hall 1978, Volf, 1978, Wood 2000, Ménétrier 2005, Grappin 2007, Bertelli 2010). The effectiveness of DTPA in six patients with inhalation exposure of ${ }^{239} \mathrm{Pu}$ (chemical form not reported) was examined five years after exposure with intermittent treatment. The EEFs ranged from 45-120, with decreasing effectiveness over time. The output of the DTPA decorporation model (EEF 71) falls well within these reported values for enhanced urinary excretion.

Studies on the treatment of Pu and Am with DTPA in animal models have indicated that DTPA can effectively remove actinides from tissues in the extracellular/interstitial space and possibly competitively bind nuclides from cellular surfaces (Phan 2005, 2006a, 2006b; Fritsch 2008, 2009, 2010). Based on these studies' findings, researchers hypothesized that a small amount of DTPA can actually enter intracellular spaces and bind to and remove actinides. This intracellular attachment mechanism is plausible and can explain the observation of a continued elevated excretion for a period of time after treatment ends. Although the vast majority of DTPA clears the blood in 24 hours (99.9\%), a small amount of DTPA clears more slowly (Stather 1983) and therefore this hypothesized mechanism needs to be validated. Sufficient evidence exists to support interstitial removal of actinides via DTPA treatment; however, all of the reported studies were conducted on soluble species of $\mathrm{Pu}$ and $\mathrm{Am}$.

To account for an elevated increase in Am excretion after DTPA treatment via chelation in the interstitial space, removal of interstitial Am was approximated by using existing transfer coefficients from the different tissue compartments and estimating an interstitial removal fraction (IRF). However, in the plutonium model provided here, model outputs provide an EEF (71) of the same magnitude as observed in human case studies, indicated above. Sérandour et al. (2008) proposed that the reason for the differential behavior of $\mathrm{Am}$, compared to $\mathrm{Pu}$, indicates a lower 
affinity of DTPA for Am as compared to Pu. However, the composite data suggests that a larger intracellular contribution to decorporation of Am excretion under DTPA treatment, as compared to $\mathrm{Pu}$.

It is worth noting that a decline in the enhanced excretion is observed over time, as tissue reservoirs with faster transfer coefficients (reflecting tissues that bind plutonium less tightly) are depleted. In turn, the excretion enhancement obtained from DTPA declines. Case studies show that upon cessation of treatment, whole-body re-distribution of Pu from slower tissue transfer compartments occurs and other soft tissue levels rise upon re-equilibration. Therefore, intermittent treatment with DTPA is warranted for overall effectiveness. The current model code is constrained by the software used, (see section 4.1) such that scenarios with intermittent treatments are not easily evaluated. Future implementation may include this feature.

\subsubsection{Toxicity/Side Effects}

Treatment with DTPA can deplete endogenous metals, which is why the $\mathrm{Zn}$ salt is preferred for long-term treatment. However, other endogenous metals may be depleted if treatment spans several months. During prolonged treatments, serum levels of essential metals should be monitored including the use of mineral replacements, as needed. Otherwise, DTPA has not been reported to have any significant adverse effects. Approximately 6\% of patients in the registry of DTPA-use reported side effects, such as headache and lightheadedness. The use of nebulized DTPA for inhalation dosing reported patients experiencing coughing and wheezing and exacerbated asthma (FDA 2004, Hameln 2004). Patients with renal impairment do not need dose adjustment; however, if renal insufficiency or renal failure is present, Ca-DTPA should not be used. If patients with renal impairment are heavily contaminated, using dialysis increases the rate of elimination. Dialysis fluid will become radioactive and appropriate radiation safety measures should be instituted (NCRP 2008a).

Although long-term treatment with Zn-DTPA in healthy adults does not cause any serious side effects, the route of administration is through intravenous injection. This is, to some degree, invasive under continuous treatment and must be considered in the overall regimen adopted.

\subsection{Radiation Dose Model}

The radiation dose delivered to the critical target organs (RBM and lungs) for acute effects must account for the Pu burden in each of the tissues. The amount of energy absorbed in the critical target organ must account for the energy emissions from all sources. The method used for this calculation is sometimes referred to as the Medical Internal Radiation Dose (MIRD) method. The method utilizes tabularized data that are computational estimates of the amount of energy deposited in a specific organ, based on the amount of energy emitted from radioactive material within another organ (Snyder 1978). Due to the complex nature of the human anatomy, these specific absorbed fractions (SAFs) in each of the tissues, require detailed radiation transport calculations, as described below. The dose to specific target organs requires an integrated calculation, based on the dose rate as a function of time, resulting from the time-dependent $\mathrm{Pu}$ 238 or $\mathrm{Pu}-239$ body-burden. Since $\mathrm{Pu}-238$ and $\mathrm{Pu}-239$ both emit low-energy photons and electrons (with a given percent per disintegration) and an $\alpha$-particle, the dose to the red bone marrow and lungs will include contributions from photons emitted from other organs. Also, plutonium within the RBM and lungs will further emit photons, electrons, and $\alpha$-particles. 
The local energy deposition from the $\alpha$-particle is modified by a Quality Factor (QF) of 20 to convert to dose equivalent. The high linear energy transfer (LET) of the $\alpha$-particle causes a higher level of localized damage than a low LET energy deposition from photons. To quantify the increase in potential biological damage, multiply the energy deposition by a QF. For $\alpha-$ particles in the 5 mega-electron Volts (MeV) range, the accepted QF is 20 (ICRP 1991).

In addition to the organ-specific dose calculation, we present a method for approximating the 50-year committed effective dose equivalent (CEDE). The CEDE is the dose calculation that is commonly used for radiation protection associated with internal hazards and it is the unit upon which most long-term complications or cancer incidence rates are based. Acute dose calculations are generally considered to be associated with the dose accumulated over the first thirty days; the majority of the total dose accumulated will occur during this time period. The body-burden, and the associated dose accumulation rate, will decrease with time as a result of radioactive decay, natural elimination, and accelerated elimination resulting from DTPA treatment.

\subsubsection{Organ Specific Acute Doses}

The decay characteristics of $\mathrm{Pu}-238$ and $\mathrm{Pu}-239$ are listed in Table 5 and provide the total energy of their emissions. The predominant mode of decay for $\mathrm{Pu}-238$ is with a $5.49 \mathrm{MeV}$ (average energy) $\alpha$-particle emission, accompanied by low-energy photons and electrons (12\% and $38 \%$ per disintegration, respectively) to uranium-234. Pu-239 decays with a $5.15 \mathrm{MeV}$ (average energy) $\alpha$-particle emission, accompanied by low-energy photons and electrons (4\% and $32 \%$ per disintegration, respectively) to uranium-235 (Shleien 1992). Since plutonium will be distributed by the bloodstream to most organs throughout the body, determining how much energy is absorbed by specific organs is complex. The dose delivered to each given organ is a result of energy emitted from all organs, including self-absorption in the same organ. Highfidelity phantoms were created to facilitate calculating these doses and both Monte Carlo and discrete calculation methods were implemented. Oak Ridge National Laboratory (Christy 1987) generated a set of Specific Absorbed Fractions (SAFs) that provides an energy-dependent means of calculating the dose absorbed by an organ, as a function of the energy emitted by another organ. For example, an average decay of Pu-238 emits a single $5.49 \mathrm{MeV} \alpha$-particle (average energy). In addition, Pu-238 decay emits a photon (average energy $14 \mathrm{keV}$ ) $12 \%$ of the time, and $38 \%$ of the time an electron (average energy $22 \mathrm{keV}$ ). Therefore, for every Becquerel (1 disintegration per second) of activity in a given organ, the $5.49 \mathrm{MeV}$ of energy from the alpha particle, together with 2 and $8 \mathrm{keV}$ (on average) of photon and electron energy, are emitted per second.

Table 5. Decay Properties of Pu-238 and Pu-239 (NCRP 2008b)

\begin{tabular}{|c|c|c|c|c|}
\hline & Half-life (years) & $\begin{array}{c}\text { Average Alpha } \\
\text { Emission per } \\
\text { Decay (MeV) }\end{array}$ & $\begin{array}{c}\text { Average Photon } \\
\text { Emission per } \\
\text { Decay (MeV) }\end{array}$ & $\begin{array}{c}\text { Average } \\
\text { Electron } \\
\text { Emission per } \\
\text { Decay (MeV) }\end{array}$ \\
\hline $\mathrm{Pu}-238$ & 87.7 & 5.49 & 0.002 & 0.008 \\
\hline
\end{tabular}




\begin{tabular}{|c|c|c|c|c|}
\hline $\mathrm{Pu}-239$ & 24,110 & 5.15 & 0.001 & 0.005 \\
\hline
\end{tabular}

By interpolating the SAF tables, the fraction of the energy, from a given emission, deposited in another (or the same) organ can be calculated. The contributions from all organs to a specific target organ are summed. For Pu isotopes, the RBM and lungs are considered the most critical target organs for predicting acute radiation effects, specifically hematopoietic syndrome and pneumonitis leading to lung fibrosis. The equations for the calculation of bone marrow and lung doses are summarized below (note these are generalized equations and must be evaluated for each radiation type and the total deposited dose summed):

$$
\begin{aligned}
D_{B M}(t) & \left.=\sum_{t_{o}}^{t}\left[\sum_{j=1}^{3} \sum_{i=1}^{N}\left(A_{P u}^{i}(t) \times \overline{E_{j}} \times S A F_{j}\left(O_{i}=>B M\right) / M_{B M}\right)\right)\right] \times \Delta t \\
D_{L}(t) & \left.=\sum_{t_{o}}^{t}\left[\sum_{j=1}^{3} \sum_{i=1}^{N}\left(A_{P u}^{i}(t) \times \overline{E_{j}} \times S A F_{j}\left(O_{i}=>L\right)\right) / M_{L}\right)\right] \times \Delta t
\end{aligned}
$$

where:

$D_{B M}(t)=$ Dose delivered to bone marrow at time $t$

$D_{L}(t)=$ Dose delivered to lung at time $t$

$A_{P u}^{i}=$ Activity of Pu in organ $i$

$\bar{E}_{J}=$ Average energy emitted per decay with $j$ equal to the radiation types 1 (alpha), 2 (photon), or 3 (electron)

$\Delta t=$ Time step increment

$S A F_{j}\left(O_{i}=>B M\right)=$ Specific Absorption Fraction from organ $i$ to bone marrow with $j$ equal to the radiation types 1 (alpha), 2 (photon), or 3 (electron)

$S A F_{j}\left(O_{i}=>L\right)=$ Specific Absorption Fraction from organ $i$ to lungs with $j$ equal to the radiation types 1 (alpha), 2 (photon), or 3 (electron)

$M_{B M}=$ Mass of bone marrow

$M_{L}=$ Mass of the lungs

The SAF values for the low-energy photons and electron are approximated according to 10 $\mathrm{keV}$ photons. The values are shown in Table 6 for each source organ, with the RBM or lungs as the target organ. The electron SAF is approximated to $10 \mathrm{keV}$ photon, since it is the closest relevant SAF available for use. Some assumptions were necessary to harmonize the SAF values given by Christy (1987), with the Pu tissue content provided by the Leggett (2005) model. For the three soft tissue compartments, the median SAF value among the remaining tissues (skin, heart, spleen, etc.) represents soft tissues 1,2 , and 3. 
Table 6. Photon SAF Values for Pu-238/239 for Red Bone Marrow (RBM) and Lungs

\begin{tabular}{|c|c|c|}
\hline Source Organ & SAF Values - RBM & SAF Values - Lungs \\
\hline Blood & 0.000447 & 0.00193 \\
\hline Lungs & 0.0000177 & 0.913 \\
\hline Liver & 0.0000291 & 0.000132 \\
\hline Kidneys & 0.0000154 & 0 \\
\hline Urinary bladder contents & 0.0033358 & 0 \\
\hline Cortical bone & 0.0251 & 0.00000944 \\
\hline Trabecular bone & 0.0639 & 0.0000187 \\
\hline Red marrow & 0.0639 & 0.0000187 \\
\hline GI contents & 0 & 0 \\
\hline Soft tissue 1 & 0.0000162 & 0.000123 \\
\hline Soft tissue 2 & 0.0000162 & 0.000123 \\
\hline Soft tissue 3 & 0.0000162 & 0.000123 \\
\hline Gonads & 0 & 0 \\
\hline Ovaries & 0 & 0 \\
\hline
\end{tabular}

The mean free path of an $\alpha$-particle in the $5 \mathrm{MeV}$ range (as is the case with both $\mathrm{Pu}-238$ and $\mathrm{Pu}-239)$ is measured in microns. Thus, it is assumed that the alpha particles will deposit all of their energy exclusively within the organ of uptake. The RBM is a complicated case because of the intricate nature of the structure, in and around the blood forming region. The model assumes the $\alpha$-particle energy is deposited locally in the portion of bone structure where the $\mathrm{Pu}$ is retained. Therefore, for the RBM and the lungs, it is assumed that all of the alpha particles deposit all of their energy within those organs. Likewise, the low-energy electrons have a very short range in tissue and their energy is assumed to be absorbed in the tissue of origin.

\subsubsection{Effective Whole Body Equivalent}

While it is imperative to understand doses to specific organs for acute effects, most predictors of long-term effects, such as cancer induction from internally deposited radioactive material, are based on the concept of a 50-year committed whole-body dose. In other words, the model considers the radiation dose that the body will accumulate over a 50-year period, following the uptake. This dose value is based on the estimated dose delivered to specific organs or tissues. The resultant dose is then multiplied according to a specified tissue weighting factor (ICRP 1991). While our model approximates the calculation of dose to a specific organ as a function of activity in other organs, performing this calculation from all organs, to all organs, and appropriately weighting the results is not practical, SAF values are not available for all tissue contributions in the biokinetic model. A large number of assumptions would be required for the calculation, and the resulting uncertainty in this calculation would be significant. However, we approximate the dose using tabulated estimates of 50-year committed doses from inhalation 
uptakes of insoluble forms of $\mathrm{Pu}-238$ and $\mathrm{Pu}-239$. By using some basic assumptions, we developed a method of approximating the incremental accumulation of whole-body equivalent dose, thereby estimating the whole-body effective dose over time and the 50-year committed dose.

The NCRP estimates a 50-year effective dose equivalent of 1.1E-05 Sv/Bq (NCRP 2008b) for inhalation of $5 \mu \mathrm{m}$ insoluble $\mathrm{Pu}-238$ particulates and $8.4 \mathrm{E}-06 \mathrm{~Sv} / \mathrm{Bq}$ for inhalation of $5 \mu \mathrm{m}$ insoluble Pu-239 particulates (NCRP 2008b). We can show the accumulation of this dose from the following equation:

$$
D(50)=\int_{0}^{50} \dot{D}(t) d t
$$

We can approximate this equation with:

$$
D(50) \approx \sum_{i=1}^{N} \dot{D}\left(t_{i}\right) \cdot \Delta t_{i}
$$

where:

$$
\dot{D}(t)=\text { Dose rate at time } t
$$

If we assume the dose rate at time $t$ is proportional to the amount of $\mathrm{Pu}-238 / 239$ in the body at time $t$, then we can rewrite the previous equation to:

$$
D(50) \approx \sum_{i=1}^{N} C \cdot A_{P u}\left(t_{i}\right) \cdot \Delta t_{i}
$$

where:

$$
\begin{gathered}
A_{P u}\left(t_{i}\right)=\text { Plutonium activity retained at time } t_{i} \\
C=\text { Constant to convert } A_{P u} \text { to dose rate }
\end{gathered}
$$

Using the initial retention from the inhalation, we use this retention equation and assume the plutonium delivers a "dose equivalent rate" in proportion to the amount of $\mathrm{Pu}$ retained in the body at time $t$. We further assume the $\mathrm{Pu}$ is in equilibrium throughout the body at all times. In other words, the proportion of $\mathrm{Pu}$ in any given organ is constant at all times. We then calculate a dose-rate conversion factor. The equilibrium assumption is reasonable for the majority of the 50year period with the exception of the period immediately following the uptake. We calculate the proportionality constant, $C$, by numerically integrating the results from our model of $\mathrm{Pu}$ distribution with no treatment. Based on the NCRP equivalent dose estimates for the 50-year committed dose equivalent, the $C$ for Pu-238 is 2.3E-09 Sievert/Becquerel/day (Sv/Bq/day) and $\mathrm{Pu}-239$ is $1.75 \mathrm{E}-09 \mathrm{~Sv} / \mathrm{Bq} /$ day.

Using this conversion factor, we can estimate the accumulation of dose equivalent as a function of the $\mathrm{Pu}$ retained in the body at any given time, regardless of the elimination rate. This allows us to compare accumulated doses at any given time with and without DTPA treatment. 


\subsubsection{Calculation of Acute Health Effects Severity}

Acute injury may be possible from inhalation exposure to plutonium particulates. Early $\mathrm{Pu}$ workers at the Mayak Production Association in the former Soviet Union were exposed to high levels of $\mathrm{Pu}$ through inhalation, and radiation pneumonitis/pulmonary fibrosis lead to many of the workers' deaths (Claycamp 2000). Pneumonitis and pulmonary fibrosis are considered acute, deterministic effects; however, the time scale in which these illnesses manifest are longer than many other acute effects. Furthermore, the onset of these effects is dose and dose-rate dependent. However, the precise response of lung tissue to $\mathrm{Pu}$ deposited in the lung with regard to dose and dose-rate is not well characterized. Therefore, a precise model for acute pulmonary effects is not possible due to limitations in data. However, a severity level for pulmonary effects can be roughly estimated. Development of a more precise injury model for pulmonary effects is warranted.

There is little guidance on the development of severity levels for pulmonary effects as mentioned previously. Allied Medical Publication 8 (AMedP-8(C)) does not address casualties from internalized radionuclides. Cutaneous and external whole-body-injury severity ranges are not applicable to the effects from lung doses received from internalized radionuclides; however, whole-body ranges will be used as guidance in estimating tissue-specific dose ranges for the severity levels. Mettler, 2008, reviews of the impact of radiation on all organ systems provides limited data for making quantitative assessments on predicting incidence of pulmonary effects. However, such data is needed to map lung dose estimates to plausible injury severity levels. Data from radiation oncology (Marks 2010) and from occupational exposures (Claycamp 2000) were evaluated for estimating dose ranges for pulmonary tissue effect and assigning severity levels 1-3.

Based on the literature reviewed, the symptomatic incidence in $50 \%$ of the population for pneumonitis leading to fibrosis is assumed to be approximately $8 \mathrm{~Gy}$ prompt exposure. However, the data from clinical radiology is highly variable, greatly dependent on dose rate, and possibly has confounding factors due to disease and treatment (Marks 2010). The acute radiation dose which causes lethality in $50 \%$ of the population (LD50) for the RBM is 2.9 Gy (Anno 2003); accumulating the dose over a longer period of time will increase this value. For very high dose scenarios, the model can be used to look at how aggressive and/or effective treatment can be.

Based on the literature reviewed, the following cumulative dose severity levels proposed for pulmonary effects are:

\section{Severity level 0: $0-<1$ Gy}

Although some exposure to an agent or effect may have occurred, no observable injury (as would be indicated by manifested symptoms) has developed." (AMedP-8(C))

\section{Severity level 1: $1-<5$ Gy}

Slightly reduced respiratory capacity in a portion of the population

\section{Severity level 2: 5 - <8 Gy}

Transient pneumonitis resulting in some respiratory decline

\section{Severity level 3: $\geq 8$ Gy}

Significant pneumonitis leading to fibrosis and eventual pulmonary failure 
Note that the proposed ranges have considerable uncertainty associated with them, since data is limited, and observed effects are dependent on a number of factors, such as uniformity of dose, dose rate, etc. A separate effort specifically aimed at establishing reliable ranges for pulmonary effects from inhaled radionuclides is warranted. Additional uncertainty can arise from extrapolating the anticipate range of effects from prompt doses to the effects anticipated from radiation delivered over a long period of time. It is not clear whether chronic effects of fibrosis and organ impairment would occur at lower or higher pulmonary doses. It has been noted that the Mayak worker cumulative pulmonary doses ranged from 5-37 Gy and pneumosclerosis was observed in several participants of the cohort (Claycamp 2000).

As mentioned above, the $\mathrm{LD}_{50}$ for the bone marrow is about $2.9 \mathrm{~Gy}$ (Anno 2003). In the case of inhaled insoluble $\mathrm{Pu}$ radionuclides, only a relatively small amount of $\mathrm{Pu}$ is absorbed into the systemic circulation. This absorbed $\mathrm{Pu}$ would become fixed in the bone, but the total bone marrow dose over 50 years (from a $1 \mu \mathrm{Ci}$ intake) would be less than $1 \mathrm{mGy}$. The exposure would need to be significantly larger or prolonged, in order to result in acute effects in the hematopoietic system. Based on the data provided by this modeling effort, acute effects to the red marrow are not likely; however, increased risk to long-term health effects, such as cancer is still a valid concern. Therefore, the dose to the red marrow is required to estimate carcinogenic risk.

\subsubsection{Calculation of Long-Term Carcinogenic Risk}

A primary concern from inhaled and internalized radionuclides is the increased risk to long term health consequences such as cancer induction. The Biological Effects of Ionizing Radiation VII (BEIR VII) carcinogenic models for ionizing radiation are the current standards used in several countries, including the United States. The risk model developed by the BEIR VII committee is what is used by all U.S. government agencies. The methodology takes into account the current population baseline risk to cancer and projects for a given exposure (radiation dose), the increased risk of cancer fatality over a lifetime (assumed 50-year). However, the BEIR VII risk models were developed for external ionizing radiation. To apply this to doses received over time by internalized radionuclides, additional methodology must be applied. In this case, the EPA established methodology for the calculation of risk (USEPA 1999). Federal Guidance Report (FGR) No. 13 establishes a method for calculating the dose from internalized radionuclides, which uses the integrated dose for each decade with the age-respective risk coefficients provided by BEIR VII. Using the guidance as established in EPA FGR No. 13 and the risk models from BEIR VII, iterative calculations can be made using the doses received over time, with and without treatment. While detailed risk analysis can be conducted, the initial implementation will assume the exposure occurs for a 20 -year-old healthy male or female (risk coefficients vary between genders) and the projected risk refers to the increased relative risk over 50-years.

$$
I R R=\sum D_{i} * R C_{i}
$$

where $I R R$ is the increased relative risk to cancer mortality over 50 years. $D_{i}$ is the integrated dose from each decade after exposure using the effective whole-body dose calculation, described in section 4.5.2, and obtaining the incremental dose for each of 5 decades. $R C$ is the risk coefficient for the corresponding age range. 


\subsection{Efficacy}

The efficacy of DTPA treatment can be evaluated in terms of overall dose reduction and the reduction of risk to acute and long-term health effects. A dose reduction factor is calculated by dividing the absorbed dose from a given intake of $\mathrm{Pu}-238$ or $\mathrm{Pu}-239$, with a specified treatment regimen, by the absorbed dose from same intake without treatment:

$$
\text { Dose reduction factor }=D_{\text {treated }} / D_{\text {untreated }}
$$

where $D_{\text {untreated }}$ is the radiation dose without treatment and $D_{\text {treated }}$ is the radiation dose with DTPA treatment. Note that the two doses must be compared at the same time post exposure. Since the reduction of carcinogenic risk is the predominate goal, the 50-year whole-bodycommitted effective dose is suggested for comparison (see section 5.2.7 for further discussion).

The efficacy is then calculated by:

$$
\text { Efficacy }=1-D_{\text {treated }} / D_{\text {untreated }}
$$

where $D_{\text {untreated }}$ is the radiation dose without treatment and $D_{D T P A}$ is the radiation dose with treatment.

It is important to note that DTPA has only partial efficacy in the treatment of inhaled $\mathrm{PuO}_{2}$, due to its limited and slow absorption of $\mathrm{PuO}_{2}$ into the systemic circulation from the lungs (Henge-Napoli 2000). However, $\mathrm{PuO}_{2}$ remains the most available form of plutonium for use in a radiological weapon and understanding the fate of $\mathrm{Pu}$ within the body is necessary to estimate radiation dose received by an exposed individual, potential health effects, and long-term health risks. 
This page is intentionally left blank. 


\section{Section 5.}

\section{Preliminary Model Results}

The results obtained from the preliminary implementation of the model are presented in this section. Final results may vary upon final implementation in stand-alone code and software, due to the precise numerical solutions used in the final code for the integrations required within the various models.

\subsection{Preliminary Implementation}

A number of the calculations required in the Pu decorporation model involve several sets of differential equations and the integration of values over time. Many of the differential equations are interconnected and certain calculations require simultaneous numerical solutions to provide the appropriate outputs. Therefore, Berkeley Madonna ${ }^{\mathrm{TM}} \mathrm{v}$. 8.3.18 software, licensed by Robert Macey and George Oster of the University of California, was used to solve the differential equations contained within the overall model. The integration method used was the $2^{\text {nd }}$ order Runge-Kutta method and a time-step interval of 0.0001 days was employed for most calculations. For 50 -year calculations, a smaller time step of 0.05 days was used for optimal model performance.

Final software will have the model coded autonomously from Berkeley Madonna ${ }^{\mathrm{TM}}$ and incorporate numerical solutions for the differential equations independently.

\subsection{Model Outputs}

The plutonium decorporation model can be used to calculate a number of time dependent parameters. The initial conditions currently assumed are that $\mathrm{Pu}$ intake is through inhalation with a given air concentration of $\mathrm{Pu}$, wind speed, breathing rate, and average particle size. The inhalation and uptake model requires these inputs. If values are not known, default parameters may be used for wind speed, breathing rate, and average particle size. The outputs from this portion of the model describe the levels of Pu in tissues or excretion in units, to use as the input dose, and the rate is per day (ex. milicurie/day: $\mathrm{mCi} / \mathrm{day}$ ):

- Amount of plutonium deposition in the three major areas of the respiratory tract

- Subsequent plutonium in blood, lungs, GI tract, liver, kidneys, six separate bone compartments, RBM, urinary bladder, three soft tissue compartments, gonads (or ovaries)

- Total plutonium retained in the body

- Plutonium excretion in urine and feces

- Total plutonium excreted

Certain tissue values are used as input parameters for the radiation dose calculations. For radiation dose calculations, the input dose must be in radioactive units (e.g. $\mu \mathrm{Ci}$ ), providing an output in absorbed radiation dose ( $\mu \mathrm{Gy}$ or $\mu \mathrm{Sv}$ ). If mass is used as the input, the specific activity of the exposure material can be used to convert the input into activity. The lung and RBM 
calculations are derived from the summation of the high and low LET dose contributions from relevant target organs, using SAFs as described in section 4.5.1 and integrated over the time period specified. The whole-body effective dose is calculated based on the decay-corrected total $\mathrm{Pu}-238$ or $\mathrm{Pu}-239$ activity and the constant for the whole-body effective dose over the time period specified, as described in section 4.5.2. The lung and RBM acute doses are used to estimate risk of acute health effects (pulmonary pneumonitis/fibrosis and hematopoietic syndrome) and the whole body effective dose is used to calculate the 50-year dose for evaluating long-term carcinogenic health risk.

Treatment with DTPA is modeled using the following input parameters: dose of DTPA (1 gram, fixed parameter) material, which results in a vast excess of DTPA in the systemic circulation as compared to $\mathrm{Pu}$, treatment start-time, relative to the initial intake of $\mathrm{Pu}$, and the duration of DTPA treatment. The same model outputs as described above may be calculated with adjustments for the amount of Pu chelated by DTPA during treatment.

Untreated and treated courses, as well as different treatment initiation times and durations, can be evaluated and compared to determine doses and dose reductions that may be obtained in different scenarios. The data generated from different scenarios are detailed below to illustrate the reliability and utility of the Pu decorporation model developed in this work.

\subsubsection{Impact of Particle Size on Plutonium Biokinetics and Dose Estimates}

As discussed in Section 4.2.5, the particle size or average particle size distribution of the exposure will significantly impact the observed biokinetic profile after an intake. Smaller particle sizes will be more easily inhaled and a larger fraction of that exposure will reach the pulmonary region, which can lead to systemic uptake. The model may be used to examine the impact of particle size on lung and systemic body burdens and clearance. A sample evaluation of 1 and 5 $\mu \mathrm{m}$ particle sizes with two different breathing rates are presented in Figure 11 and Figure 12.

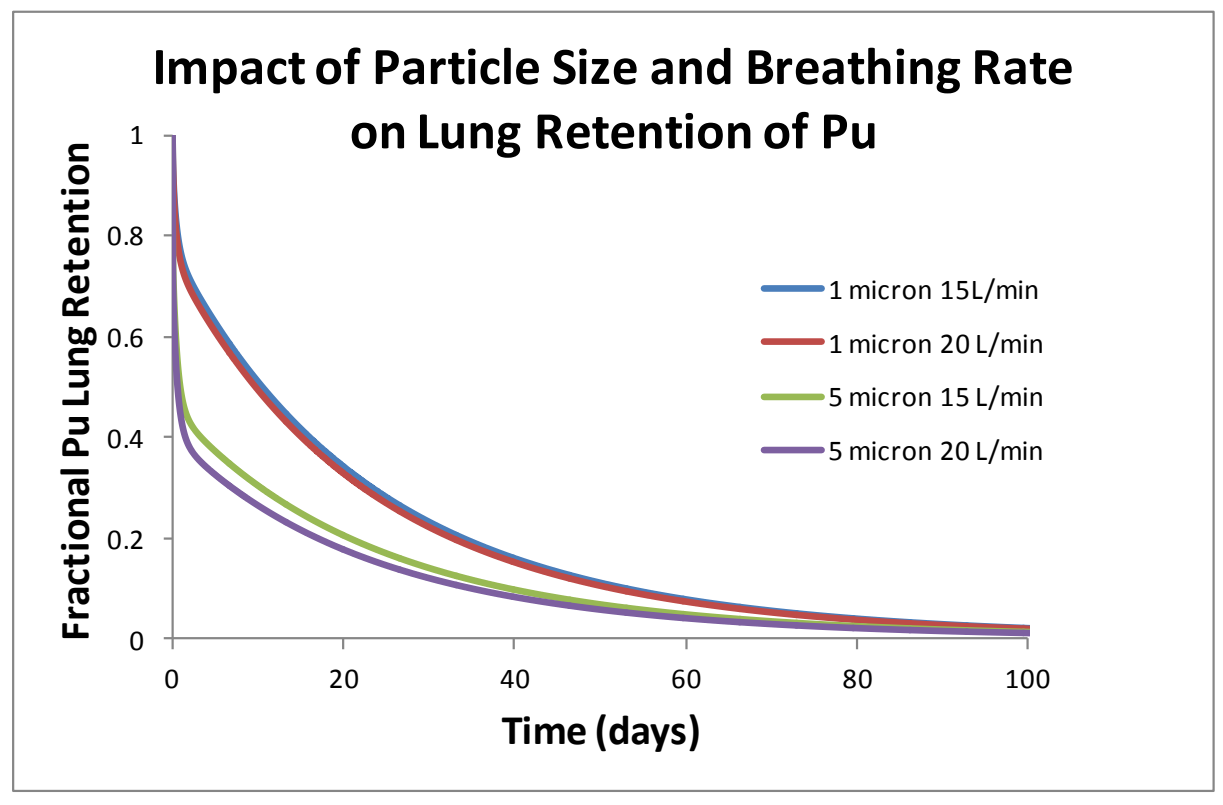

Figure 11. Pu Burden in the Lung as a Function of Particle Size and Breathing Rate 


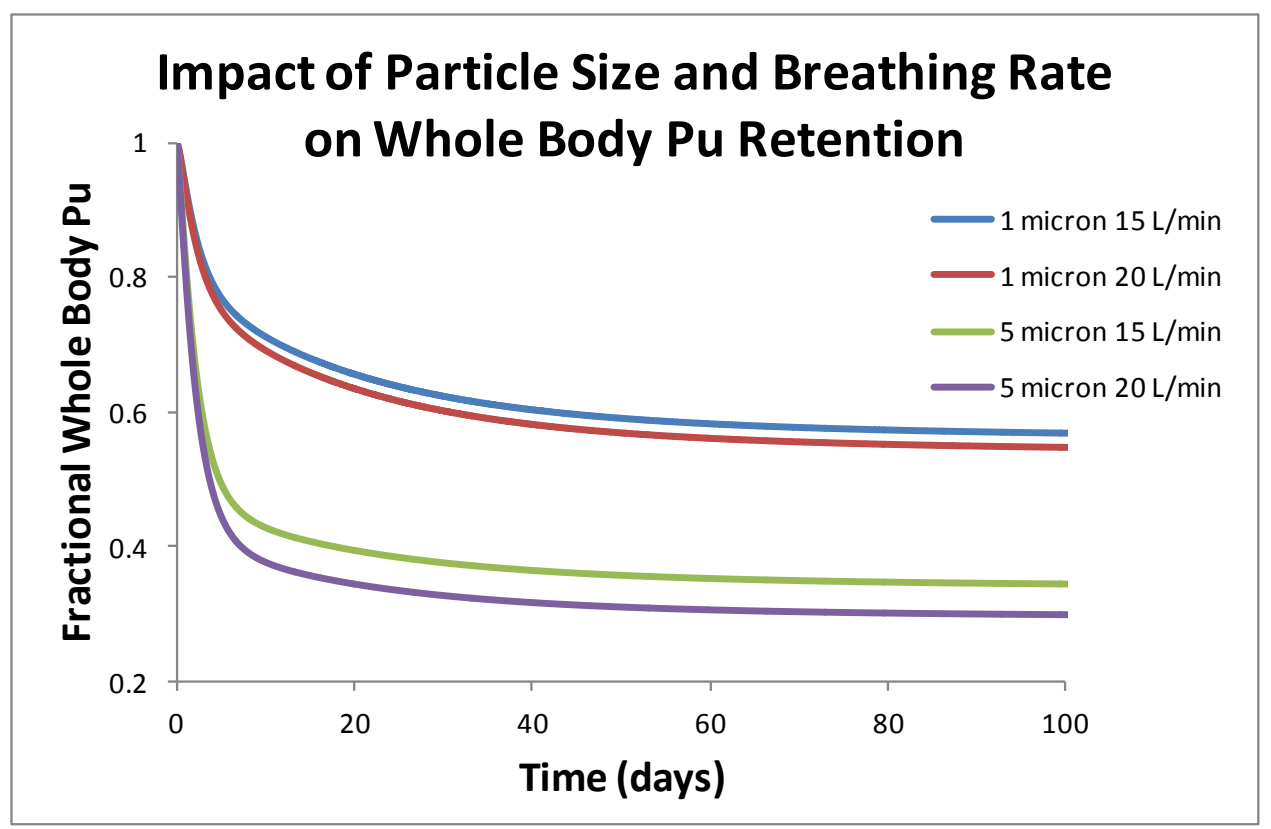

Figure 12. Pu Retention as Function of Particle Size and Breathing Rate

Since particle size has such a significant impact on the precise deposition and resulting clearance of the plutonium intake, the particle size distribution will significantly impact radiation dose. While faster clearance with smaller particle sizes may increase the systemic body burden of $\mathrm{Pu}$, larger particle sizes that clear more slowly will result in a higher localized exposure to radiation in the lung. The model allows one to examine the impact of particle size on target organ doses as well as whole-body effective doses. The impact of particle size $(1$ and $5 \mu \mathrm{m}, 20 \mathrm{~L} / \mathrm{min}$ breathing rate) on radiation dose to the lung from a $1 \mu \mathrm{Ci}$ intake is illustrated in Figure 13.

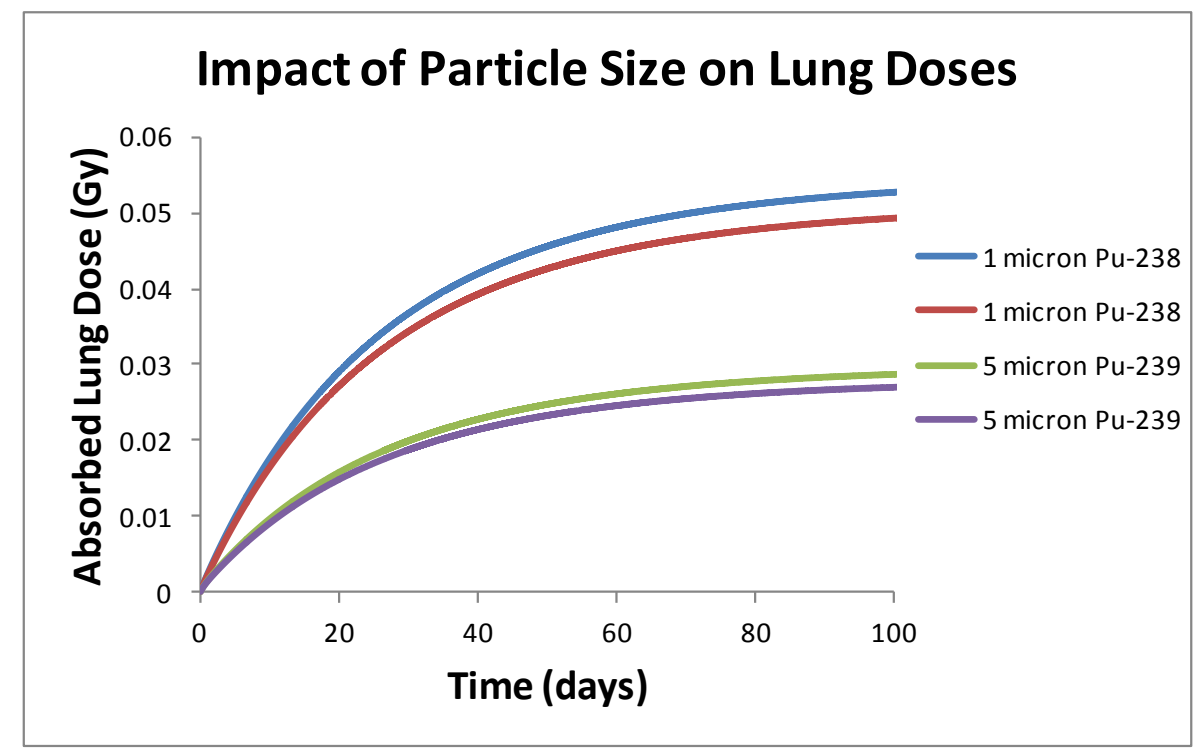

Figure 13. Radiation Dose to the Lung from Different Particle Sizes 


\subsubsection{Plutonium Tissue Distribution}

The model allows for an examination of the biodistribution of Pu throughout the body over time. Figure 14 illustrates Pu distribution in selected tissues over 30 days, in an untreated scenario, with an intake of $1 \mu \mathrm{Ci} \mathrm{Pu}$ (inhalation exposure to $\mathrm{PuO}_{2}, 5 \mu \mathrm{m}$ particles, $20 \mathrm{~L} / \mathrm{min}$ breathing rate). Pu has an affinity for the liver and bone compared to other tissues. This illustration also shows how Pu has an initial fast clearance from the respiratory tract for a portion of the intake, which then slows dramatically. Pu absorbed from the lungs redistributes and then accumulates in the liver and bone.

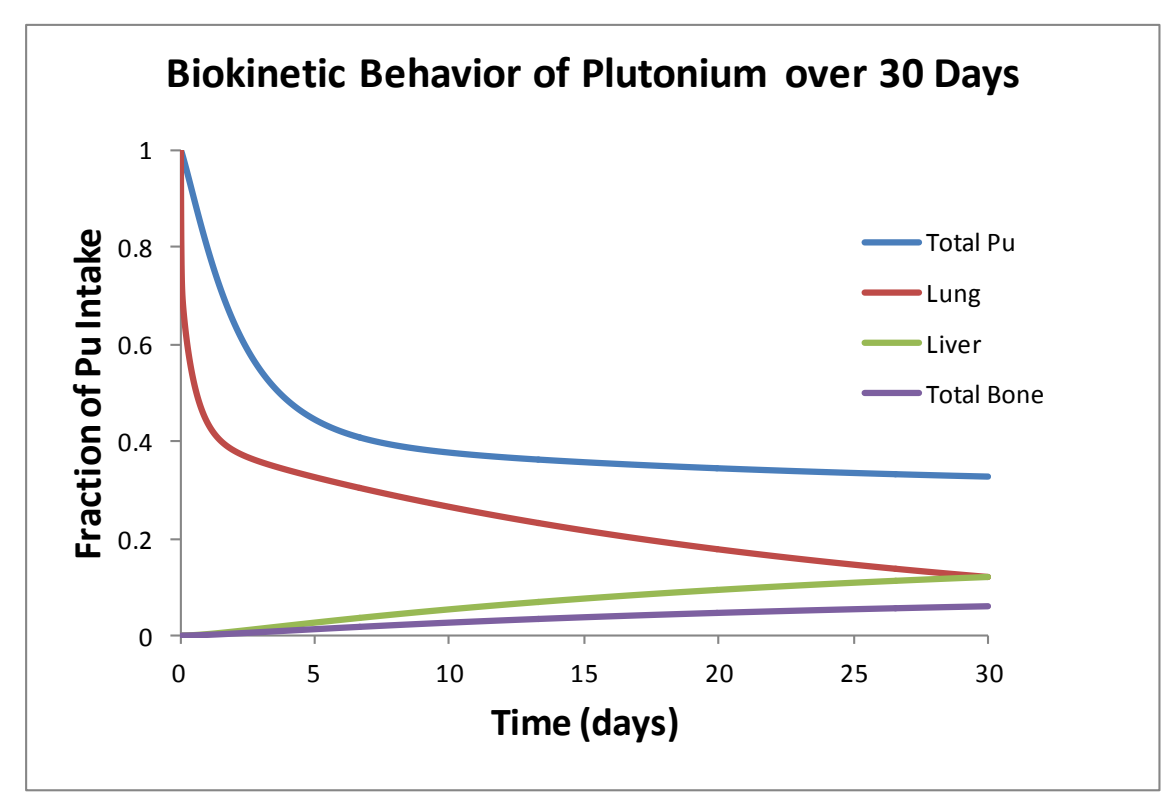

Figure 14. Plutonium Retention in Selected Tissues Over 30 Days

The total Pu in Figure 14 is calculated by summing the Pu present in all of the tissues represented in the model for each time step. Additional organ and tissue distributions that could not be easily displayed in Figure 14 are illustrated in Figure 15 and their distribution is extended out to 180 days to show the cross-over in soft tissue distributions. Figure 15 illustrates that the blood has a minimal amount of $\mathrm{Pu}$, having been redistributed to tissues, which retain the $\mathrm{Pu}$ to varying degrees. The different soft tissue compartments represent tissues that have rapid, intermediate, and slow turnover. 


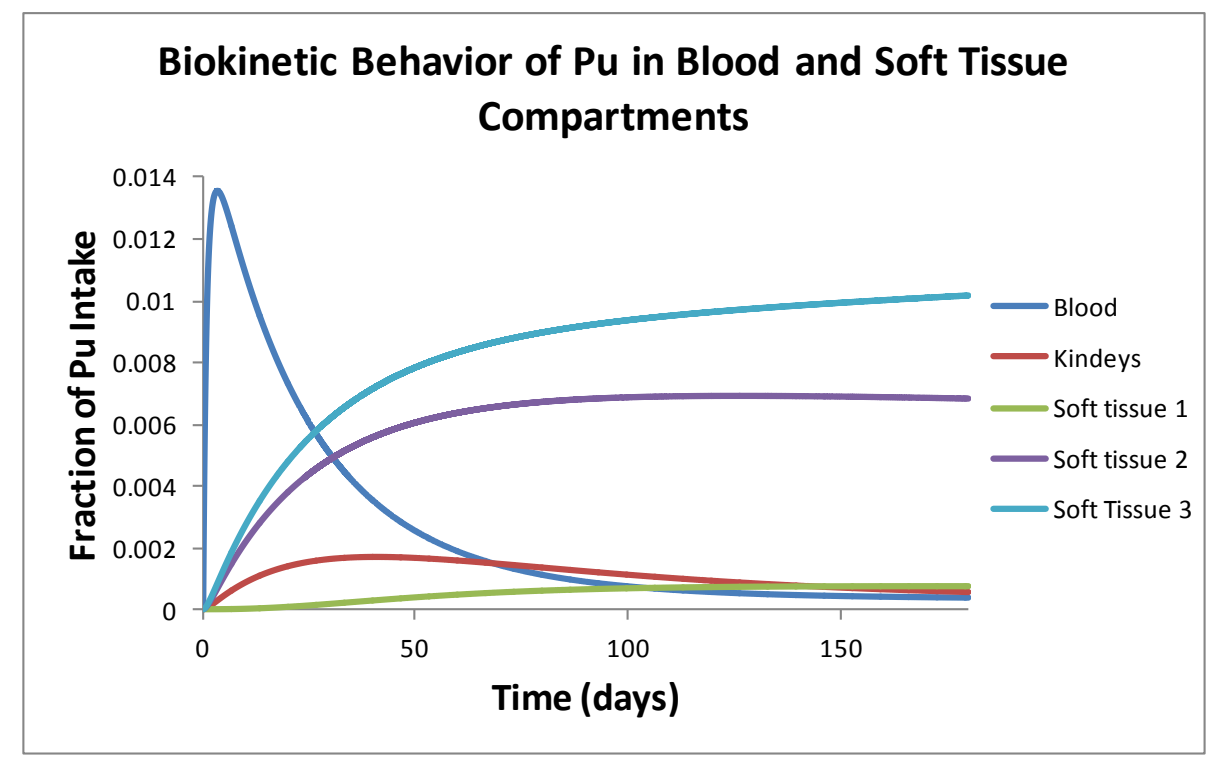

Figure 15. Pu Distribution for Selected Tissues Over 180 Days

\subsubsection{Comparison of Predicted Plutonium Retention to Experimental and Human Data}

Data collected on humans indicates large variability in Pu retention and biokinetics. The precise distribution can be dramatically influenced by the chemical form of $\mathrm{Pu}$, the particle size distribution of the exposure, and breathing rate. Age, gender, and body weight can also impact the outcome.

The biokinetic model for Pu developed by Leggett (2005) and implemented in our model has been compared to experimental animal data and human case studies (Leggett 2005, NCRP 2008b). Figure 16 shows Pu retention data from injection studies and are compared to the Leggett 2005 and ICRP 1993 models simulation results.

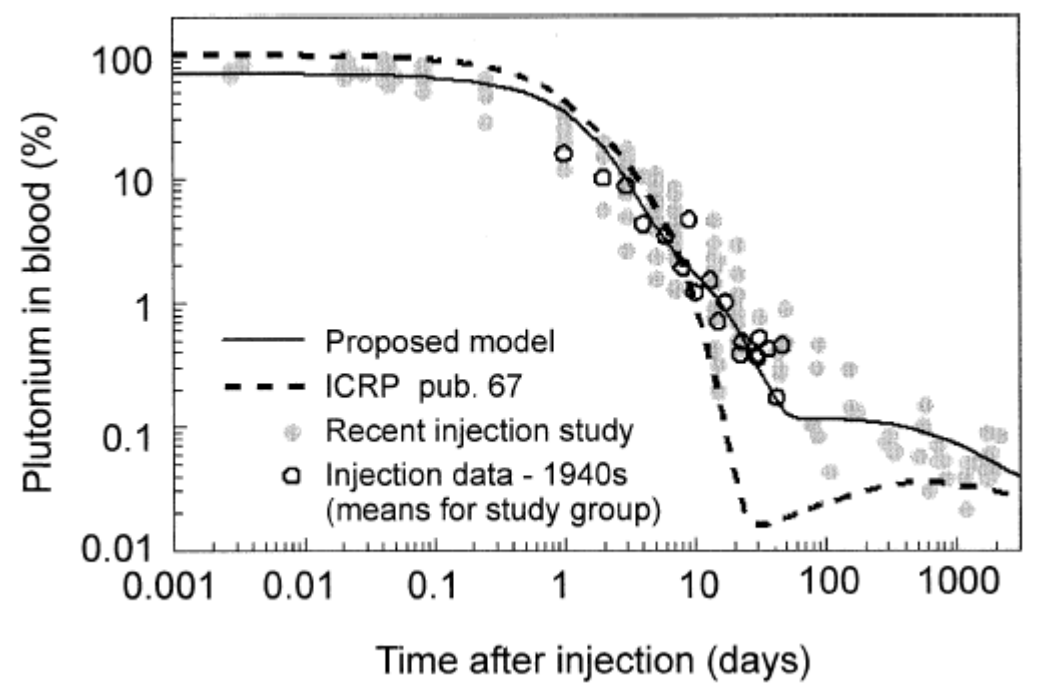

Figure 16. Model Predictions of Pu Retention (Leggett 2005) 


\subsubsection{DTPA Decorporation of Plutonium}

DTPA treatment can reduce the amount of $\mathrm{Pu}$ in the body by binding the $\mathrm{Pu}$ in the circulation, as described in section 4.4.4. DTPA predominately binds $\mathrm{Pu}$ in the systemic circulation. $\mathrm{Pu}$ is then re-equilibrated according to the variable transfer rates of the different tissues. The impact of DTPA on Pu whole-body retention is illustrated in Figure 17. This figure shows $\mathrm{Pu}$ retention over 60 days after $1 \mu \mathrm{Ci}$ lung deposition in the untreated case and with DTPA treatment beginning at day 14 after exposure, with standard dosing ( $1 \mathrm{~g}$ daily) for a duration of 30 days ( $5 \mu \mathrm{m}$ particle size, $20 \mathrm{~L} / \mathrm{min}$ breathing rate).

The red curve shows a rapid decline of $\mathrm{Pu}$ after treatment is initiated. When treatment is discontinued after 30 days, the slope of the treated curve resumes the shape of the untreated curve and is parallel to it.

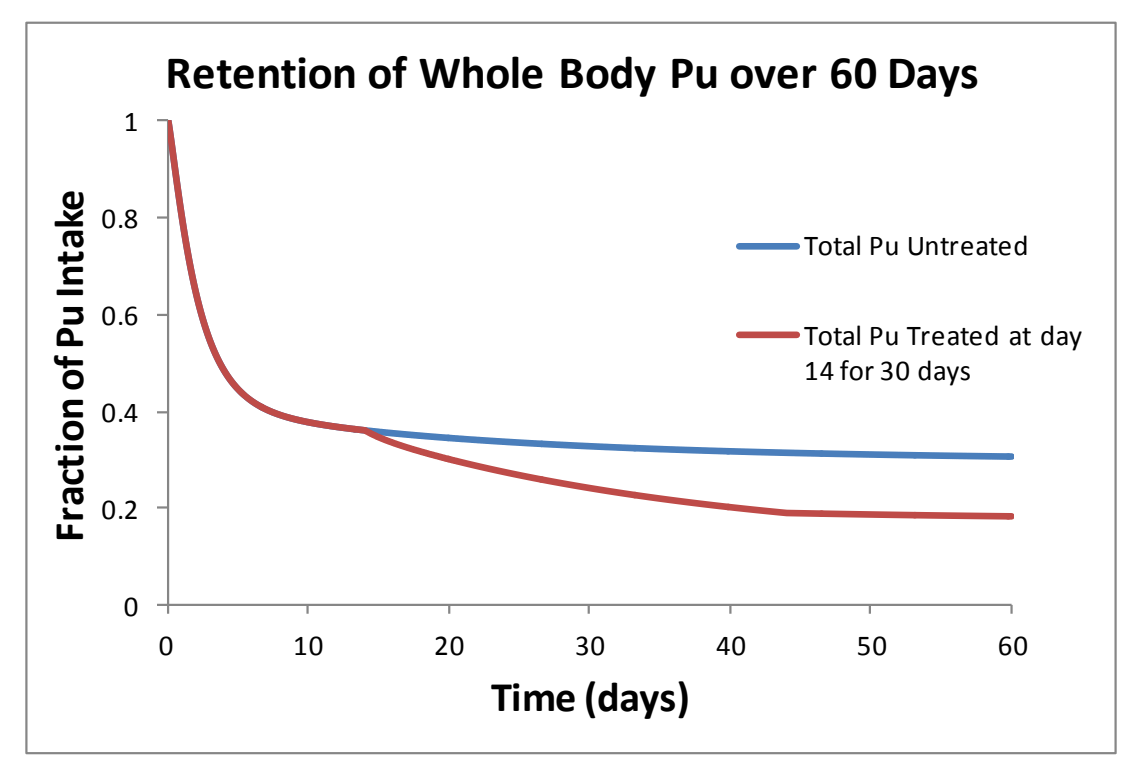

Figure 17. Plutonium Retention With and Without Treatment

Large individual variability is observed in the retention and excretion of Pu with DTPA treatment, comparable to the variability observed with Pu biokinetics in individuals. Increased urinary excretion under DTPA treatment ranges from 5-fold to as much as 150-fold, depending on the exposure conditions, in particular the chemical form of $\mathrm{Pu}$ involved in the initial exposure (Jech 1972, Jolly 1972, Schofield 1974, Hall 1978, Volf, 1978, Wood 2000, Ménétrier 2005, Grappin 2007, Bertelli 2010).

\subsubsection{Plutonium Excretion}

The composite model estimates cumulative excretion as a function of time. The excretion rate of $\mathrm{Pu}$ changes over time as it is cleared from the respiratory tract by different modes with different clearance rates. The cumulative excretion over 60 days from the scenario presented in the previous section $(5.2 .4 ; 5 \mu \mathrm{m}$ particle size and $20 \mathrm{~L} / \mathrm{min}$ breathing rate; treatment beginning day 14 and lasting for 30 days) is shown in Figure 18. Total excretion is dominated by fecal excretion early in time due to the rapid clearance from the ET and TB regions via the GI tract. 


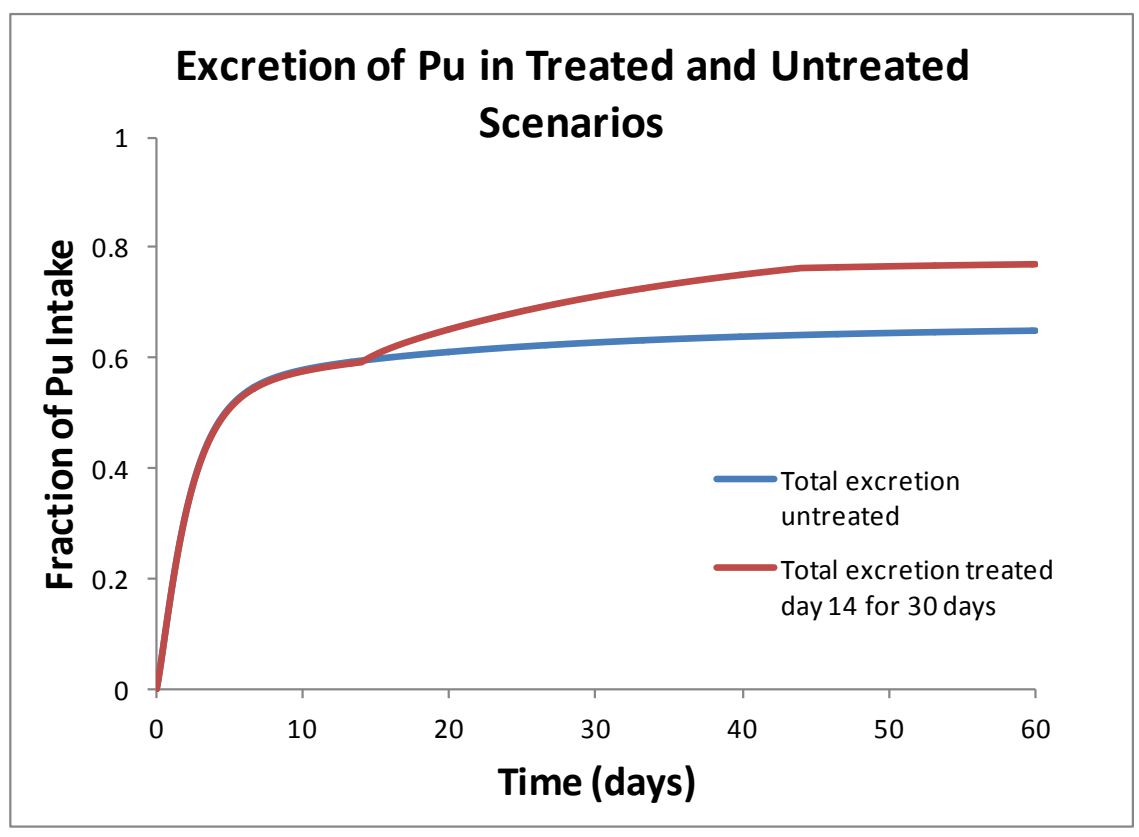

Figure 18. Plutonium Excretion With and Without Treatment

The impact on urinary excretion during treatment for this scenario is shown in Figure 19. The urinary output quickly declines after treatment ends. The output after treatment is stopped is less than pre-treatment values, at least immediately after treatment ceases, due to the time required for re-equilibration from slow transfer tissue compartments to the circulation.

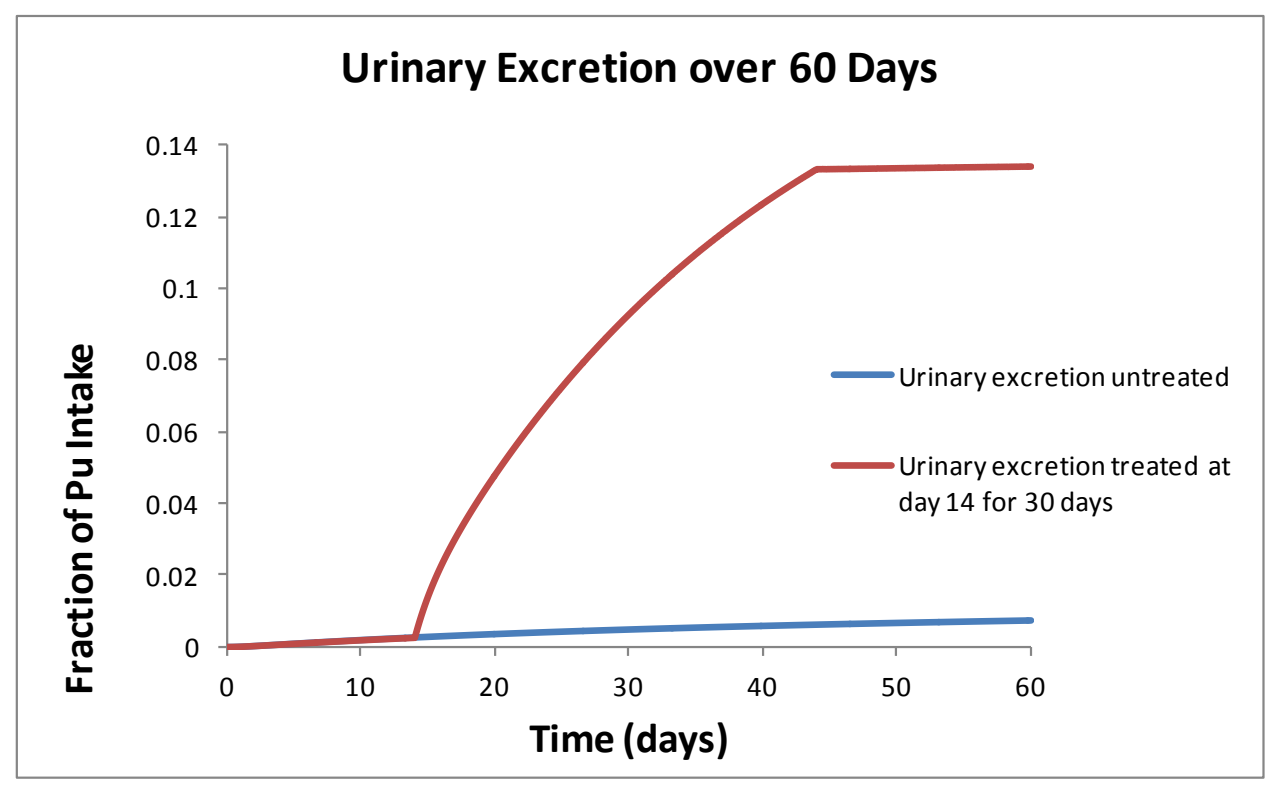

Figure 19. Urinary Excretion of Plutonium With and Without Treatment 
Figure 20 compares the total cumulative excretion to fecal excretion in the treated and untreated case. The amount of Pu cleared through the GI tract is significant, as illustrated by the magnitude of fecal excretion. Urinary excretion is modest without DTPA treatment (initiated on day 14 for 30 days), but dramatically increases upon treatment, as evidenced by the sharp rise in the total excretion shown in the graph below. The rate of increase excretion quickly returns to that of pre-treatment after treatment ceases. A slightly lower fecal excretion during treatment is due to the decrease in systemic plutonium being cleared via the GI tract (and being excreted in the bile) during treatment.

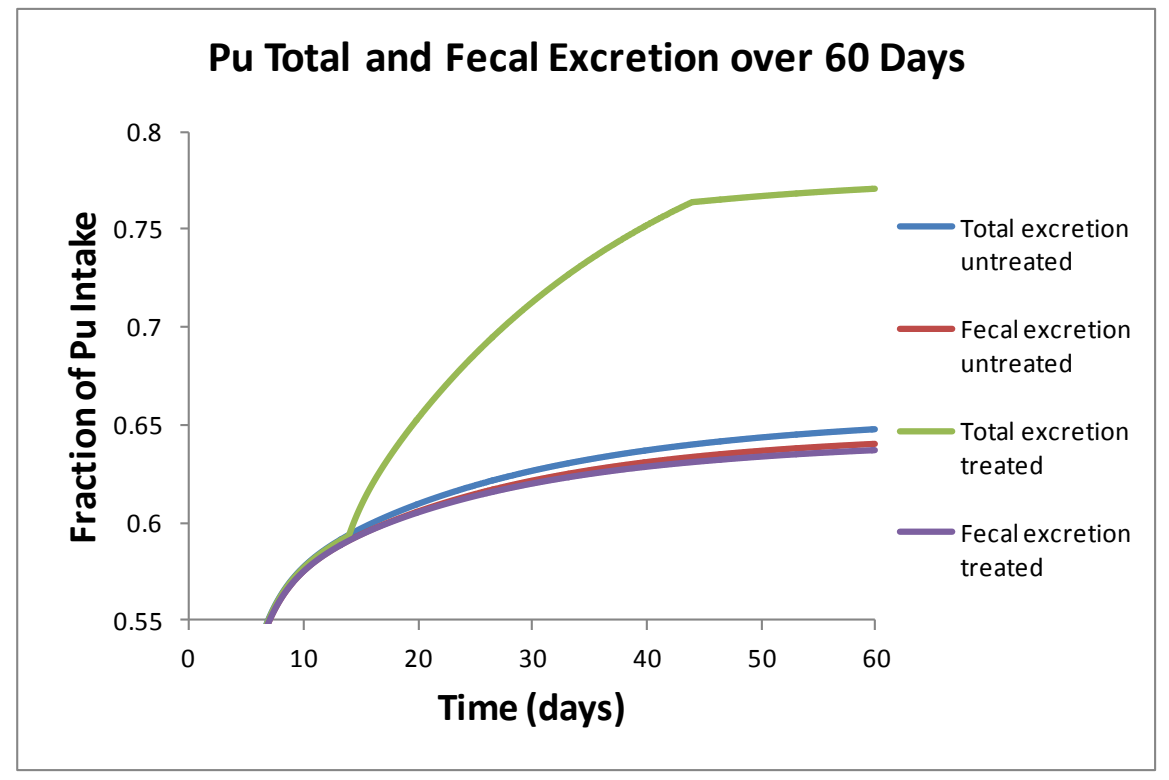

Figure 20. Plutonium Total and Fecal Excretion Over 60 Days

\subsubsection{Plutonium Acute and Whole Body Effective Doses}

The model may be used to calculate acute doses to the critical target organs (RBM and lung) and the whole-body effective dose. Since both $\mathrm{Pu}$ isotopes have $\alpha$-emissions, high radiation doses delivered directly to the lung tissue is possible. The RBM is one of the more sensitive organs for acute effects and $\mathrm{Pu}$ is immobilized in bone RBM exposure to radionuclides may cause acute affects, such as the hematopoietic radiation syndrome. Our model can determine the dose to these critical organs as a function of time as well as the committed effective whole body dose.

The acute lung and red marrow doses for a respiratory deposition of $1 \mu \mathrm{Ci}$ of $\mathrm{Pu}-238$ or $\mathrm{Pu}-$ 239 ( 5 micron particles with a breathing rate of $20 \mathrm{~L} / \mathrm{min}$ ) in untreated cases are shown in Figure 21 . The acute dose refers to the total energy deposited in a particular organ and potentially subsequent acute effects (i.e. cell death, which results in organ dysfunction leading to morbidity and mortality). The dose to the lung begins to decline as activity is cleared from the region. The dose to the red marrow accumulates as Pu is redistributed from the lung and incorporated into the bone compartments. Since redistribution is slow, the red marrow dose becomes more critical later in time. 

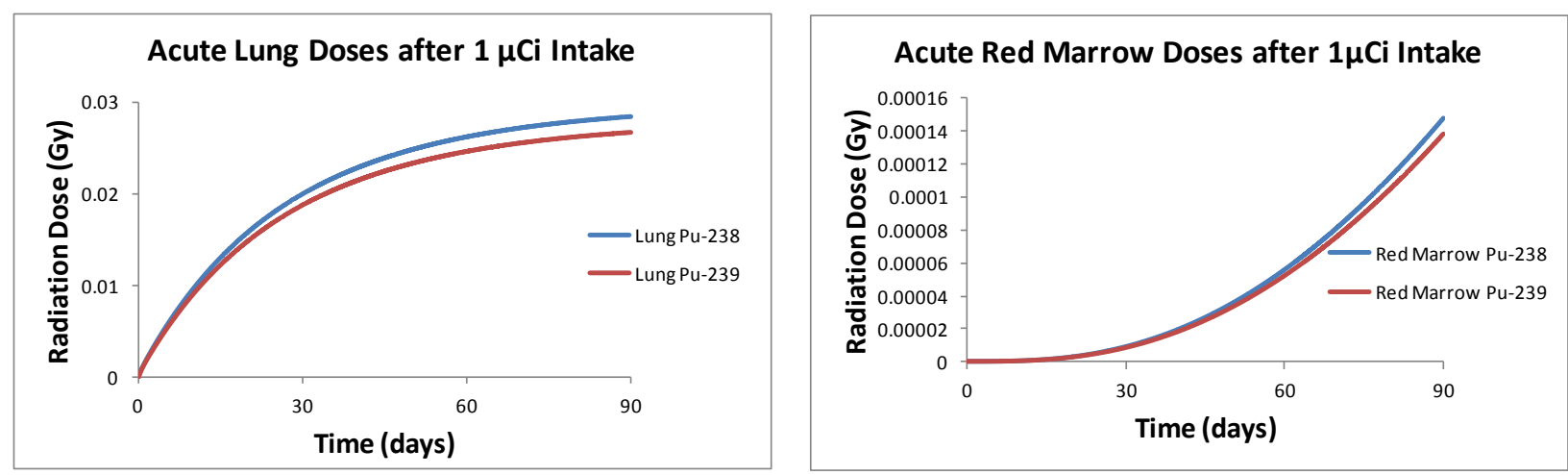

Figure 21. Acute Doses to Critical Organs from Pu-238 and Pu-239 Over 90 Days

The concept of committed effective dose was developed to relate long-term health effects such as carcinogenesis. For this relationship, tissues must be weighted, since different tissues have different dose responses to carcinogenesis. This weighting results in an averaging of the dose over the whole body, according to tissue-specific sensitivities and provides an effective whole-body dose that can be used to relate to overall carcinogenic risk.

The long-term health risk to cancer is most often evaluated calculating the 50-year committed whole-body effective dose. Table 7 shows the predicted 50-year committed wholebody effective dose in treated and untreated scenarios after exposure to $1 \mu \mathrm{Ci}$ of $\mathrm{Pu}-238$ and $\mathrm{Pu}$ 239, $5 \mu \mathrm{m}$ particulates (assuming $20 \mathrm{~L} / \mathrm{min}$ breathing rate). The treated scenarios involve a treatment start time of 14 days post-exposure with treatment durations of 60,120, and 180 days. 
Table 7. The 50-Year Committed Effective Whole Body Radiation Doses from Pu-238 and Pu-239 in Untreated and Treated Cases

\begin{tabular}{|l|c|c|c|c|}
\hline \multicolumn{1}{|c|}{ Dose } & Untreated & $\begin{array}{c}\text { DTPA Day 14, } \\
\text { 60-day Course }\end{array}$ & $\begin{array}{c}\text { DTPA at Day } \\
\text { 14, 120-day } \\
\text { Course }\end{array}$ & $\begin{array}{c}\text { DTPA at Day } \\
\text { 14, 180-day } \\
\text { Course }\end{array}$ \\
\hline $\begin{array}{l}\text { Effective Whole Body, Sv } \\
\text { for Pu-238 }\end{array}$ & 0.29 & 0.13 & 0.11 & 0.10 \\
\hline $\begin{array}{l}\text { Effective Whole Body, Sv } \\
\text { for Pu-239 }\end{array}$ & 0.26 & 0.12 & 0.10 & 0.09 \\
\hline
\end{tabular}

The data in Table 7 illustrates reduction in the 50-year committed dose by approximately 55 , 62 , and $66 \%$, with DTPA treatment beginning day 14 and continuing for 60, 120, or 180 days, respectively. DTPA treatments afford substantial dose reduction from Pu radionculides, allowing substantial reduction in long-term health risks. However, given limited resources, the calculations may help optimize treatment regimens for maximum reduction in $\mathrm{Pu}$ body-burden and dose. In this scenario, treating an individual continuously for 3 times as long (180 days) does not result in three times the reduction in dose. In fact, the need for re-equilibration of $\mathrm{Pu}$ after an initial treatment has been recognized for optimal treatment effectiveness.

The acute dose calculations from our model were compared to the current approach used by the ICRP and adopted by the NCRP (ICRP 1993, NCRP 2008b). Our model uses the same biokinetic model as the referenced models; however, the respiratory clearance model differs and is specific to Pu with particle size dependence. The ICRP and NCRP approaches use a standard, generic respiratory clearance model developed by ICRP (ICRP 1994). Neither of these approaches is up-to-date according to more recent recommendations. For $\mathrm{PuO}_{2}$, the ICRP generic model has not reliably predicted clearance for insoluble Pu radionuclides (Bailey 2007, Birchall 2010). The model implemented in this work uses an initial clearance of Pu greater than the ICRP model (as recommended by Bailey 2007). This results in lower lung dose and greater red marrow dose in our model, as compared to the calculations reported by the NCRP (2008b). Even small differences in respiratory absorption parameters (shown in Table 2) can result in significant differences in estimated radiation doses. The range of values referenced in the literature for respiratory absorption of relatively insoluble plutonium highlights the degree of uncertainty associated with current plutonium models. 
Table 8. Comparison of Doses at 365 Days (Gy/Bq of Pu-238 or Pu-239 Intake) by Different Models

\begin{tabular}{|l|l|l|l|l|}
\hline & \multicolumn{1}{|c|}{$\begin{array}{c}\text { Lung - Low } \\
\text { LET }\end{array}$} & \multicolumn{1}{|c|}{$\begin{array}{c}\text { Lung - High } \\
\text { LET }\end{array}$} & $\begin{array}{c}\text { Red Marrow - } \\
\text { Low LET }\end{array}$ & $\begin{array}{c}\text { Red Marrow - } \\
\text { High LET }\end{array}$ \\
\hline $\begin{array}{l}\text { NCRP 2008b } \\
\text { Pu-238 }\end{array}$ & $1.3 \times 10^{-9}$ & $1.5 \times 10^{-6}$ & $3.9 \times 10^{-12}$ & $1.6 \times 10^{-9}$ \\
\hline $\begin{array}{l}\text { Model Simulation } \\
\text { Pu-238 }\end{array}$ & $1.4 \times 10^{-9}$ & $8.1 \times 10^{-7}$ & $1.3 \times 10^{-10}$ & $6.1 \times 10^{-8}$ \\
\hline $\begin{array}{l}\text { NCRP 2008b } \\
\text { Pu-239 }\end{array}$ & $8.7 \times 10^{-10}$ & $1.3 \times 10^{-6}$ & $2.7 \times 10^{-12}$ & $1.5 \times 10^{-9}$ \\
\hline $\begin{array}{l}\text { Model Simulation } \\
\text { Pu-239 }\end{array}$ & $7.5 \times 10^{-10}$ & $7.6 \times 10^{-7}$ & $6.5 \times 10^{-11}$ & $5.7 \times 10^{-8}$ \\
\hline
\end{tabular}

NCRP model simulations were based on inhalation of $5 \mu \mathrm{m}$ particulate for workers (not stated, but assuming ICRP breathing rate of $20 \mathrm{~L} / \mathrm{min}$ for workers was used).

\subsubsection{Evaluation of Efficacy}

The efficacy of DTPA treatment can be evaluated based on the concept of dose reduction. The example above, in Table 7, is a good illustration of how the comparison of doses after DTPA treatment can be used to evaluate efficacy. This type of analysis can allow an end-user to determine how long DTPA treatment administration is justified. The dose reduction from treatment is further illustrated in Figure 22, which shows the dose accumulated over 90 days in untreated and treated cases from a $1 \mu \mathrm{Ci}$ intake of $\mathrm{Pu}-238$ or $\mathrm{Pu}-239$ (inhalation exposure to $\mathrm{PuO}_{2}, 5 \mu \mathrm{m}$ particles, $20 \mathrm{~L} / \mathrm{min}$ breathing rate). The treated cases assume treatment starting day 14 after the exposure and continuing for 45 or 90 days. A significant reduction in dose is observed with treatment for 45 days. Dose is further reduced marginally with longer treatment times but does not become evident until longer times post-exposure. Over time, as the dose continues to accumulate, the difference becomes more apparent.
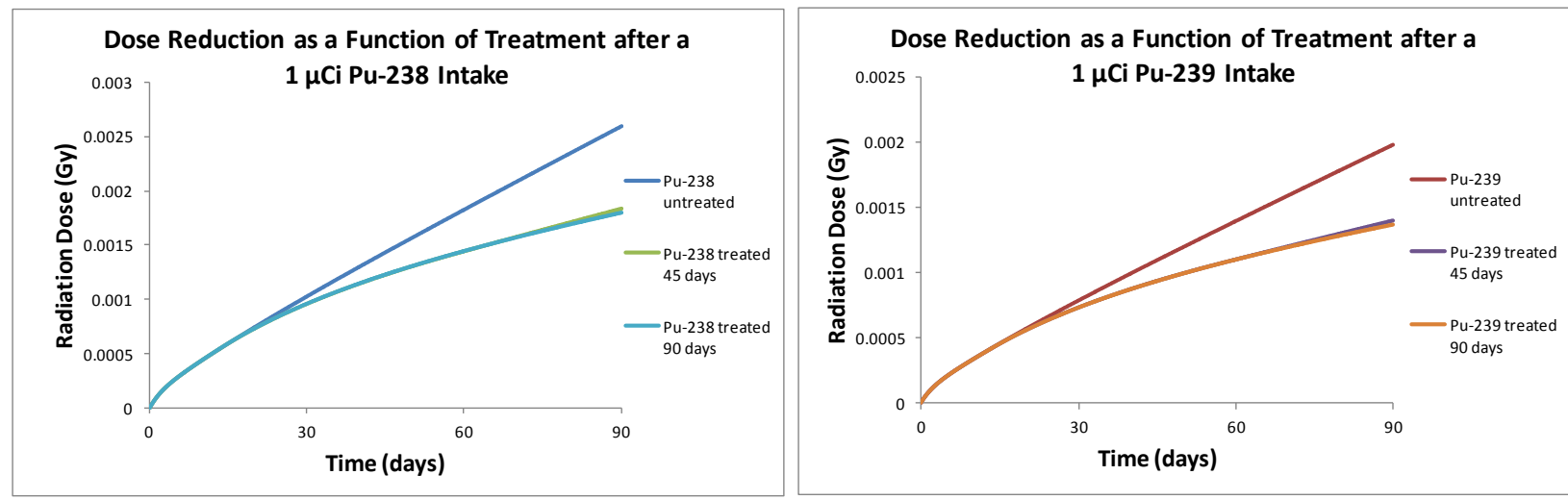

Figure 22. Doses from Pu-238 and Pu-239 Over 90 Days in Treated and Untreated Cases 
The dose saving reduces with time, which illustrates that the majority of the dose absorbed by the body is received very early after an exposure. The time of treatment with DTPA can have a significant impact on the overall dose resulting from $\mathrm{Pu}$ exposure. This is particularly important for actinides such as $\mathrm{Pu}$ and Am because of their incorporation into bone. After $\mathrm{Pu}$ is absorbed into the systemic circulation from the lungs, a portion can quickly be retained in the bone where DTPA has minimal ability to remove it. Having DTPA present in the circulation can help bind $\mathrm{Pu}$ as soon as it is absorbed from the lung and reduces the amount available for incorporation into the bone. It is worth noting that extended and intermittent treatment times are often necessary due to the slow clearance fractions of Pu from the lungs. Unfortunately, DTPA injections have not consistently been shown to effectively increase the absorption of $\mathrm{Pu}$ from the lungs. Therefore, a significant portion of the dose observed in Figure 22 arises from the $\mathrm{Pu}$ lodged in the respiratory tract.

The impact of the different delays in treatment initiation after an exposure is examined in the efficacy of decorporation. In the example shown in Table 9, the 90-day dose from $1 \mu \mathrm{Ci}$ of $\mathrm{Pu}-$ 238 is reduced more dramatically the sooner treatment initiation occurs. Efficacy of treatment reduces with an increase in treatment initiation. However, because DTPA has little or no influence on absorption of $\mathrm{Pu}$ from the lungs, no significant dose reduction is afforded to that tissue compartment. Note that results for $\mathrm{Pu}-239$ are comparable to the data on $\mathrm{Pu}-238$.

Table 9. Doses After 90 Days from $1 \mu \mathrm{Ci}$ Pu-238 Exposure in Untreated and 30-Day DTPA Treated Subjects with Different Treatment Initiation Times

\begin{tabular}{|c|c|c|c|c|c|}
\hline Dose & Untreated & $\begin{array}{c}\text { DTPA at day } \\
\text { 1, 30-day } \\
\text { course }\end{array}$ & $\begin{array}{c}\text { DTPA at day } \\
\text { 14, 30-day } \\
\text { course }\end{array}$ & $\begin{array}{c}\text { DTPA at day } \\
\text { 27, 30-day } \\
\text { course }\end{array}$ & $\begin{array}{c}\text { DTPA at day } \\
\text { 40, 30-day } \\
\text { course }\end{array}$ \\
\hline Lung, mGy & 28.3 & 28.3 & 28.3 & 28.3 & 28.3 \\
\hline $\begin{array}{c}\text { Red Marrow, } \\
\text { mGy }\end{array}$ & 0.1 & 0.02 & 0.09 & 0.12 & 0.14 \\
\hline $\begin{array}{c}\text { Effective } \\
\text { Whole Body, } \\
\text { mSv }\end{array}$ & 2.6 & 1.3 & 1.9 & 2.3 & 2.4 \\
\hline
\end{tabular}

Dose reduction is further examined in Table 10 where the 50-year effective whole-body dose versus treatment initiation time and duration of treatment are presented. 
Table 10. 50-Year Committed Whole Body Effective Doses (Sv)

\begin{tabular}{|c|c|c|c|c|c|c|c|c|}
\hline $\begin{array}{c}\text { Duration of } \\
\text { DTPA, days }\end{array}$ & \multicolumn{6}{|c|}{ Treatment Initiation Times (days post exposure) } \\
\hline 0 & 0.29 & - & - & - & - & - & 180 \\
\hline 30 & 0.096 & 0.22 & 0.26 & 0.27 & 0.28 & 0.28 & 0.28 \\
\hline 60 & 0.037 & 0.20 & 0.25 & 0.26 & 0.27 & 0.27 & 0.27 \\
\hline 90 & 0.017 & 0.18 & 0.24 & 0.25 & 0.26 & 0.26 & 0.27 \\
\hline 120 & 0.009 & 0.18 & 0.23 & 0.25 & 0.26 & 0.26 & 0.26 \\
\hline 150 & 0.006 & 0.17 & 0.22 & 0.24 & 0.25 & 0.25 & 0.25 \\
\hline 180 & 0.005 & 0.17 & 0.22 & 0.24 & 0.24 & 0.25 & 0.25 \\
\hline
\end{tabular}

The data illustrate that earlier treatment initiation enables greater reduction of dose. Likewise, longer courses of DTPA generally provide greater dose reduction. However, at later treatment initiation times, dose reduction is not as significant even with longer treatment durations. The dose reduction factors for these same data may be calculated by dividing the treated dose by the untreated dose. For dose reduction and efficacy, the estimated doses of treated and untreated cases must be compared at the same time post-exposure for a scenario. For all the scenarios provided, differences in the 50-year committed whole-body effective doses are compared. These are the primary endpoints for estimating long-term health risk (carcinogenesis), which is the primary concern for internalized $\mathrm{Pu}$.

$$
\text { Dose reduction factor }=\text { Dose }_{\text {Treated }} / \text { Dose }_{\text {Untreated }}
$$

The dose reduction factors for the different treatment courses, summarized in Table 10, are listed in Table 11.

Table 11. Dose Reduction Factors for Different Treatment Regimens

\begin{tabular}{|c|c|c|c|c|c|c|c|}
\hline $\begin{array}{c}\text { Duration of } \\
\text { DTPA, days }\end{array}$ & \multicolumn{7}{|c|}{ Treatment Initiation Times (days post exposure) } \\
\hline 30 & 0.33 & 0.76 & 0.90 & 0.93 & 0.97 & 0.97 & 0.97 \\
\hline 60 & 0.13 & 0.69 & 0.86 & 0.90 & 0.93 & 0.93 & 0.93 \\
\hline 90 & 0.06 & 0.62 & 0.83 & 0.86 & 0.90 & 0.90 & 0.93 \\
\hline 120 & 0.03 & 0.62 & 0.79 & 0.86 & 0.90 & 0.90 & 0.90 \\
\hline 150 & 0.02 & 0.59 & 0.76 & 0.83 & 0.86 & 0.86 & 0.86 \\
\hline 180 & 0.02 & 0.59 & 0.76 & 0.83 & 0.83 & 0.86 & 0.86 \\
\hline
\end{tabular}

The values in Table 11 may be converted to estimates of efficacy by subtracting the dose reduction factors from one.

$$
\text { Efficacy }=1-\text { Dose reduction factor }
$$


The efficacy values are shown in Table 12. The higher values indicate more effective treatment and greater efficacy. Earlier treatment combined with longer duration affords the greatest dose reduction and efficacy.

Table 12. Efficacy of Different Treatment Regimens

\begin{tabular}{|c|c|c|c|c|c|c|c|}
\hline $\begin{array}{c}\text { Duration of } \\
\text { DTPA, days }\end{array}$ & \multicolumn{7}{|c|}{ Treatment Initiation Times (days post exposure) } \\
\hline 30 & 0.67 & 0.24 & 0.10 & 0.07 & 0.03 & 0.03 & 0.03 \\
\hline 60 & 0.87 & 0.31 & 0.14 & 0.10 & 0.07 & 0.07 & 0.07 \\
\hline 90 & 0.94 & 0.38 & 0.17 & 0.14 & 0.10 & 0.10 & 0.07 \\
\hline 120 & 0.97 & 0.38 & 0.21 & 0.14 & 0.10 & 0.10 & 0.10 \\
\hline 150 & 0.98 & 0.41 & 0.24 & 0.17 & 0.14 & 0.14 & 0.14 \\
\hline 180 & 0.98 & 0.41 & 0.24 & 0.17 & 0.17 & 0.14 & 0.14 \\
\hline
\end{tabular}

It is of note that since $\mathrm{PuO}_{2}$ is insoluble and is lodged in the respiratory tract, a considerable portion of the dose from inhaled insoluble radionuclides of Pu cannot be alleviated by the use of DTPA treatment. The use of DTPA is still beneficial, but the study highlights that a medical countermeasure able to mobilize and remove insoluble $\mathrm{Pu}$ radionuclides from the respiratory tract would be greatly beneficial in the reduction of dose from $\mathrm{Pu}$ inhalation exposures.

\subsubsection{Acute Injury from Plutonium}

Section 3.5.3 describes, in detail, how acute injury to the respiratory region is possible from inhalation exposure to plutonium particulates. Estimates made from our composite model show intakes of $\mathrm{Pu}-238 / 239$ in the $\mathrm{mCi}$ range would be required to develop radiation pneumonitis/pulmonary fibrosis in the severity ranges 2 or 3.

\subsubsection{Long-term Health Effects}

At lower radiation doses, protection from long-term health effects, such as carcinogenesis, is the primary concern of internalized radionuclides. Each branch of the United States Department of Defense sets guidance and recommended dose limits. As an example, the U.S. Navy limits the 50 -year whole-body committed effective dose to $0.05 \mathrm{~Sv}$ or $0.5 \mathrm{~Sv}$ for any specific organ or tissue, whichever is more limiting (NAVMED P-5055). The model can help to resolve the treatment duration required, to lower the committed dose within these limits. The recommended threshold for decorporation treatment is any exposure resulting in a 50-year whole body committed effective dose greater than $200 \mathrm{mSv}$ (Rojas-Palma 2009). Therefore, the model can help to determine whether treatment is necessary.

Using this approach, the increased relative risk from the $1 \mu \mathrm{Ci}$ scenario, presented in this section, is approximately $0.35 \%$ for $\mathrm{Pu}-238$ and $0.28 \%$ for $\mathrm{Pu}-239$. In the case of prolonged treatment (180 days), the risk is reduced to $0.12 \%$ and $0.09 \%$ for $\mathrm{Pu}-238$ and $\mathrm{Pu}-239$, respectively. 


\section{Section 6.}

\section{Limitations of the Model}

The composite model described in this report is based on the best, currently available data; however, as with all models, it has a number of limitations. The purpose of this section is to highlight the major limitations of the model and identify possibilities for addressing them rather than provide a comprehensive review of uncertainties associated with the models.

Large variability in intake, clearance, and biokinetics after Pu exposures has been observed among individuals as well as in animal experiments. Furthermore, intake, clearance, and biokinetics vary significantly, depending on the specific particle size, breathing rate, and chemical form of the exposure. The model can only provide a tool for evaluating specific scenarios and testing different treatment regimens with fixed assumptions. For an actual exposure, observed bioassay data for each individual must be used to determine the clearance, biokinetics, and resulting dose for that person.

Application of the inhalation model is limited to wind speeds less than or equal to $9 \mathrm{~m} / \mathrm{s}$ and to individuals that are considered normal breathers. The biokinetic model is currently limited by the data available on tissue distribution of Pu. It assumes three generic soft tissue compartments, which clear at varying rates. If actual data on the other organs were available, more precise dose estimates would be possible. More detailed data on specific organ burdens may become available in the future, as autopsy samples from the United States Transuranium and Uranium Registries (USTUR) are analyzed. Based on animal data, it is known that a fraction of the less soluble Pu in the pulmonary region is transferred to the lymph nodes and eventually to the blood stream with a long half-life. In our model, the lymph nodes are not treated as a compartment that releases $\mathrm{Pu}$, due to a lack of human data and the minor contribution of this transfer mode.

Finally, our model's removal of Pu with DTPA is an approximation, based on the physiological distribution of DTPA and Pu, the observed data, and assumptions concerning the DTPA binding. The approach developed in this work affords reliable results within the limitations and uncertainties of any of the existing approaches available today. Another approach to model decorporation with DTPA was conducted with Pu and was based on molecular chelation kinetics (Breustedt 2009, 2010). In this approach, the molecular ratios of Pu, DTPA, and their binding affinities were used to calculate Pu-DTPA formation and subsequent excretion. The investigators reported that this approach did not provide suitable results when modeling repeat DTPA administration over a short time period. Also, the challenge with modeling molecular chelation kinetics when the components (Pu and DTPA) are present on vastly different scales was discussed. This approach may still afford a plausible model given further development and experimental data. 
This page is intentionally left blank. 


\section{Section 7.}

\section{Next Steps}

Each of the components of the $\mathrm{Pu}$ decorporation model will be consolidated into a single set of codes and integrated into user-friendly software for use in scenario simulations. These components include the inhalation exposure model, the Pu biokinetic model, the DTPA treatment model, and the radiation dose models. The results presented here provide an indication of the utility of the composite model and a sample of the type of data that can be generated.

As mentioned previously, large individual variability was observed in human data collected, to date, regarding $\mathrm{Pu}$ absorption, retention, and response to treatment. Although, beyond the scope of the current effort, certain aspects of individual variability could be addressed in the $\mathrm{Pu}$ decorporation model presented here. For example, the distribution of $\mathrm{Pu}$ is known to be dependent on age, gender, and body size/composition. Distribution is partially due to the differences in the relative size of the tissues and partially due to differences in metabolism. Physiological data exists for age and gender specific physiological variances (Richardson 2010 and ICRP 1995) as well as differences in long-term effects of exposure (BEIR VII 2006). Extrapolations can be made mathematically for some parameters, to account for body size and composition. Therefore, the physiological model for Pu as well as the DTPA treatment model could be refined to account for physiological differences in distribution and retention of $\mathrm{Pu}$, so that additional age and gender specific data could be generated. Likewise, the absorption of radiation is impacted by the differential tissue distribution of radioactivity. Furthermore, long-

term health risks vary among different ages and between genders. Model refinements would also enable more precise health risk assessments outside of the "healthy, adult male".

As mentioned in the previous section, modeling decorporation of $\mathrm{Pu}$ on the level of molecular chelation might afford a more precise description of the rate of removal of $\mathrm{Pu}$ under DTPA treatment. However, this level of modeling would require more detailed data on $\mathrm{Pu}$ and DTPA distribution and kinetics in tissues than is currently available. The effort would also involve more complex modeling. However, with additional data and resources, this may prove a viable approach to resolving some of the uncertainty in the current model. 
This page is intentionally left blank. 


\section{Section 8.}

\section{Conclusions}

The DTPA decorporation model presented in this work estimates Pu absorption, distribution, retention, excretion, and response to DTPA treatment in adult healthy males after an inhalation exposure. The model is easily adapted for a direct ingestion route of exposure, which may be included in the final GUI. The model further estimates the acute lung and RBM dose and the whole-body effective dose as a function of time.

The results of the model compare favorably with both human data and alternative models developed by the ICRP and NCRP (Figure 16 and Table 8).

Calculations from the model may be used to analyze consequences of exposure to $\mathrm{Pu}-238$ and $\mathrm{Pu}-239$ (dioxide) and the effect of treatment based on initiation and duration times. The model may facilitate interpretation of Pu bioassay data and aid in treatment planning. The $\mathrm{Pu}$ decorporation model is a valuable tool for assessing the effect of exposure to $\mathrm{Pu}-238 / 239$, in the form of $\mathrm{PuO}_{2}$ and subsequent DTPA treatment.

The model could be further improved by incorporating age and gender specific parameters and data, which would enable more precise calculations for additional segments of the population. 
This page is intentionally left blank. 


\section{Section 9.}

\section{References}

American Conference of Governmental Industrial Hygienists (ACGIH). 1999. Particle sizeselective sampling for particulate air contaminants (Vincent, J.H., Ed.). Cincinnati, OH: ACGIH Worldwide.

Anderegg G, et al. 2005. Critical evaluation of stability constants of metal complexes or complexones for biomedical and environmental applications. IUPAC Technical Report. Pure Appl Chem, 77(8):1445-1495.

Anno GH, et al. 2003. Dose response relationships for acute ionizing-radiation lethality. Health Physics 84(5): 565-575.

Argonne National Laboratory, EVS, Human Health Factsheet, August 2005.

Asgharian B, et al. 2001. Mucociliary clearance of insoluble particles from the tracheobronchial airways of the human lung. Aerosol Science 32:817-832.

Asgharian B, et al. 2006a. Dosimetry of particles in humans: from children to adults. In Gardner, D.E., Toxicology of the Lung, 4th ed. Boca Raton: CRC Press, pp. 151-194.

Asgharian B, et al. 2006b. Prediction of particle deposition in the human lung using realistic models of lung ventilation. Journal of Aerosol Science 37:1209-1221.

Asgharian B, et al. 2006c. Airflow distribution in the human lung and its influence on particle deposition. Inhalation Toxicology 18:795-801.

Bailey MR, et al. 2007. Updating the ICRP human respiratory tract model. Radiat Prot Dosimetry 127:31-34.

Bair et al. 1973. Plutonium in soft tissues with emphasis on the respiratory tract. pp. 503-568 in Uranium, Plutonium, Transplutonic Elements. Hodge, Stannard, and Hursh, Eds. Springer, New York.

BEIR VII. Committee to Assess Health Risks from Exposure to Low Levels of Ionizing Radiation, National Research Council. 2006. Health Risks from Exposure to Low Levels of Ionizing Radiation: BEIR VII Phase 2. Washington, D.C.: The National Academies Press.

Bertelli L, et al. 2010. Three plutonium chelation cases at Los Alamos National Laboratory. Health Phys 99:532-538.

Birchall AM, et al. 2010. Plutonium worker dosimetry. Radiat Env Biophys 49(2):203-212.

Breustedt BE, et al. 2009. Biokinetic modelling of DTPA decorporation therapy: the CONRAD approach. Radiation Protection Dosimetry 134(1): 38-48.

Breustedt B, et al. 2010. The CONRAD approach to biokinetic modeling of DTPA decorporation therapy. Health Phys 99(4):547-552.

Bureau of Medicine and Surgery. 2011. Radiation Protection Manual. U.S. Navy Publication: NAVMED P-5055. 
Cassatt DR, et al. 2008. Medical countermeasures against nuclear threats: Radionuclide decorporation agents. Radiat Res, 170(4):540-548.

Chang TP, et al. 2011. Iron poisoning: a literature-based review of epidemiology, diagnosis, and management. Pediatr Emerg Care, 27(10):978-985.

Christy M and Eckerman KF (1987) Specific Absorbed Fractions of Energy at Various Ages from Internal photon Sources. I. Adult Male. ORNL/TM-8381/VII, Oak Ridge National Laboratory.

Claycamp HG, et al. 2000 Deterministic effects from occupational radiation exposure in a cohort of Mayak PA workers: Data base description. Health Phys. 79(1):48-54.

Davesne E, et al. 2010 Absorption of plutonium compounds in the respiratory tract. J Radiol Prot 30(1):5-21.

Department of Energy (DOE). 2006. DOE Standard: Guide of good practices for occupational radiological protection in plutonium facilities. DOE-STD-1128-98.

Department of Homeland Security (DHS). 2004. Homeland Security Council, Planning Scenarios Executive Summaries.

Durbin PW. 2006. Actinides in animals and man. pp 3330-3440 in The Chemistry of the Actinides and Transactinide Elements. $3^{\text {rd }}$ ed. Vol. 5, Morss, Edelstein and Fuger, Eds., Springer, New York.

Food and Drug Administration (FDA) CaDTPA and ZnDTPA package inserts: NDA 21-749 and 21-751; approved 8/11/2004. Accessed on September 21, 2011 at: http://www.fda.gov/Drugs/EmergencyPreparedness/Bioterrorismand DrugPreparedness/ucm130311.htm

Food and Drug Administration (FDA). 2009. Questions and answers on Prussian Blue. http://www.fda.gov/Drugs/EmergencyPreparedness/BioterrorismandDrugPreparedness/u cm130314.htm Accessed on September 17, 2012.

Food and Drug Administration (FDA). 2011. Questions and answers on Prussian Blue. http://www.fda.gov/Drugs/EmergencyPreparedness/BioterrorismandDrugPreparedness/u cm130337.htm\#4 Accessed on September 17, 2012.

Fritsch P, et al. 2010. Structure of a single model to describe plutonium and americium decorporation by DTPA treatments. Health Physics 99(4):553-559.

Fritsch P,et al. 2009. Simplified structure of a new model to describe urinary excretion of plutonium after systemic, liver or pulmonary contamination of rats associated with CaDTPA treatments. Radiat Res 171(6):674-686.

Fritsch P, et al. 2008. Intracellular Pu Decorporation in Rat by Different DTPA Formulations. Radioprotection 43(5):173-173.

Gangwal S, et al. 2011. Informing selection of nanomaterial concentrations for ToxCast in vitro testing using the Multi-Path Particle Dosimetry model. Presented at Annual Meeting of the Society of Toxicology, Washington , DC, March 06 - 10, 2011.

Hameln Pharmaceuticals. 2004. Pharmaceutical insert for pentate zinc trisodium injection (ZnDTPA). 
Hall RM, et al. 1978. A mathematical model for estimation of plutonium in the human body from urine data influenced by DTPA therapy. Health Phys 34:419-431.

Harrison JD, et al. 2001. Reliability of the ICRP's dose coefficients for members of the public, II. Uncertainties in the absorption of ingested radionuclides and the effect on dose estimates. Radiat Prot Dosim 95, 295-308.

Henge-Napoli MH, et al. 2000. Decorporation of radionuclides from the human body. Radiat. Prot. Dosim 87 (1), 1-58.

Heyder J, et al. 1986. Deposition of particles in the human respiratory tract in the size range 0.005 - $15 \mu \mathrm{m}$. J Aerosol Sci 17: 811-825.

Hickman AW, et al. 1995. Application of a canine ${ }^{238} \mathrm{Pu}$ biokinetic/dosimetry model to human bioassay data. Health Phys 68(3):359-370.

Hunt GJ, et al. 1990. Transfer of environmental plutonium and americium across the human gut: a second study. Sci Total Environ 90: 273-282.

International Commission on Radiological Protection (ICRP). 1991. 1990 Recommendations of the International Commission on Radiation Protection. Publication 60, Pergamon Press, Oxford, United Kingdom, Annals of ICRP 21, No. 1-3.

International Commission on Radiological Protection (ICRP). 1993. Age dependent doses to members of the public from intake of radionuclides: Part 2. Ingestion dose coefficients. Appendix B: Age-specific biokinetic models for plutonium, americium, and neptunium. ICRP Publication 67, Elsevier, New York, Annals of ICRP 23:3/4.

International Commission on Radiological Protection (ICRP). 1994a. Human Respiratory Tract Model for Radiological Protection. Publication 66, Pergamon Press, Oxford, United Kingdom, Annals of ICRP 24(1-3).

International Commission on Radiological Protection (ICRP). 1994b. Dose coefficients for intakes of radionuclides by workers. Publication 68, Pergamon Press, Oxford, United Kingdom, Annals of ICRP 24(4).

International Commission on Radiological Protection (ICRP). 1995. Basic Anatomical \& Physiological Data for use in Radiological Protection. ICRP Publication 70. Annals of ICRP 25 (2).

James AC, et al. 2003. USTUR Case 0259 whole body donation: A comprehensive test of the current ICRP models for the behavior of inhaled ${ }^{238} \mathrm{PuO}_{2}$ ceramic particles. Health Phys 84(1):2-33.

Jech JJ, et al. 1972. Interpretation of human urinary excretion of plutonium for cases treated with DTPA. Health Phys 22:787.

Jolly L, et al. 1972. Treatment and evaluation of a plutonium-238 nitrate contaminated puncture wound. A two-year case history. Health Phys 23:333.

Khokhryakov VF, et al. 2005. Adaptation of the ICRP Publication 66 respiratory tract model to data on plutonium biokinetics for Mayak workers. Health Phys 88(2):125.

Leggett RW, et al. 2005. Mayak worker study: an improved biokinetic model for reconstructing doses from internally deposited plutonium. Radiat. Res. 164(2):111-122. 
Marks LB, et al. 2010. Radiation Dose-Volume Effects in the Lung. International Journal of Radiation Oncology Biology Physics 76(3): S70-S76.

Mettler FA and Upton AC. 2008. Medical Effects of Ionizing Radiation, 3rd ed. Philadelphia, Saunders.

Maydew RC, Bush J. 1997. America’s Lost H-Bomb: Palomares, Spain, 1966. Sunflower University Press.

Meadows M. 2001. Pregnancy and the drug dilemma. FDA Consumer 35(3):16-20.

Mewhinney JA, et al. 1983. Retention of inhaled ${ }^{238} \mathrm{PuO}_{2}$ in beagles: A mechanistic approach to description. Health Physics, 45(1):39-60.

Millage KK, et al. 2010. A review of inhalability fraction models: discussion and recommendations. Inhalation Toxicology, 22(2): 151-159.

Ménétrier FL. et al. 2005. Treatment of accidental intakes of plutonium and americium: Guidance notes. Appl Radiat Isotopes 62(6): 829-846.

National Council on Radiological Protection (NCRP). 2008a. Management of Persons Contaminated with Radionuclides: Scientific Handbook, National Council on Radiation Protection and Measurements. NCRP Report No. 161 Vol. I.

National Council on Radiological Protection (NCRP). 2008b. Management of Persons Contaminated with Radionuclides: Scientific and Technical Bases, NCRP Report No. 161 Vol. II.

National Research Council, Committee on Radiation Source Use and Replacement. 2008. Radiation Source Use and Replacement. Washington, DC: National Academies Press.

Niinimaa V, et al. 1981. Oronasal distribution of respiratory airflow. Respiration Physiology, 43(1):69-75.

Norwood WD. 1960. DTPA - Effectiveness in removing internally deposited plutonium from humans. J Occup Med 2:371-376.

Norwood WD. 1962. Long-term administration of DTPA for plutonium elimination. A follow-up study in one patient. J Occup Med 4:130-132.

Phan G, et al. 2005. Pharmacokinetics of DTPA entrapped in conventional and long-circulating liposomes of different size for plutonium decorporation. Journal of Controlled Release 110(1):177-188.

Phan GB, et al. 2006a. Enhanced decorporation of plutonium by DTPA encapsulated in small PEG-coated liposomes. Biochimie, 88(11):1843-1849.

Phan G, et al. 2006b. Predicting plutonium decorporation efficacy after intravenous administration of DTPA formulations: Study of pharmacokinetic-pharmacodynamic relationships in rats. Pharmaceutical Research 23(9):2030-2035.

Puncher M, et al. 2012. Uncertainty analysis of doses from ingestion of plutonium and americium. Radiat Prot Dosim 148(3):284-96.

Raabe OG, et al. 1976. Tracheobronchial geometry: Human, dog, rat, hamster (Report LF-53). Lovelace Foundation, Albuquerque, NM. 
Radiation Emergency Medical Management (REMM), US Department of Health and Human Services, 2011, "Managing Internal Contamination," http://www.remm.nlm.gov/int_contamination.htm.

Radiation Emergency Medical Management (REMM), US Department of Health and Human Services, 2012, "Strategic National Stockpile," http://www.remm.nlm.gov/sns.htm Accessed September 17, 2012.

Richardson RB. 2010. A physiological skeletal model for radionuclide and stable element biokinetics in children and adults. Health Phys 99(4):471-482.

RIVM (National Institute for Public Health and the Environment: RIVM). 2002. Multiple Path Particle Dosimetry Model (MPPD v 1.0): A Model for Human and Rat Airway Particle Dosimetry. Bilthoven, The Netherlands. RIVA Report 650010030.

Rojas-Palma C, et al. 2009. TMT Handbook: Triage, monitoring, and treatment of people exposed to ionising radiation following a malevolent act. NRPA, ISBN (pdf version): 978-82-90362-28-2.

Schofield GB, et al. 1974. Assessment and management of a plutonium contaminated wound case. Health Phys 26:541.

Sérandour A-L, et al. 2008. Pulmonary retention of actinides after dissolution of PuO2 aerosols: interest in modelling DTPA decorporation. Radioprotection 43(2):239-254.

Shleien B, ed. 1992. The Health Physics and Radiological Health Handbook.

Snyder WS, et al. 1978. Estimates of Specific Absorbed Fractions for Photon Sources Uniformly Distributed in Various Organs of a Heterogeneous Phantom. MIRD Pamphlet No. 5, Revised, Society of Nuclear Medicine, NY, NY.

Srimok B. 2006. Investigation of particle size effects in inhalation dose assessment for short term radiological events. Master's Thesis, Department of Nuclear Engineering, North Carolina State University.

Stather JW, et al. 1983. The retention of ${ }^{14} \mathrm{C}$-DTPA in human volunteers after inhalation or intravenous injection. Health Physics 44(1): 45-52.

TERA (Toxicology Excellence for Risk Assessment). 2012. Dose response boot camp. American Board of Industrial Hygienists certification management course; required software. Accessed at http://www.tera.org/Global/Bootcamp/index.html on September 24, 2012.

US EPA. United States Environmental Protection Agency. 1999. Federal Guidance Report No. 13: Cancer risk coefficients for environmental exposure to radionuclides. EPA 401-R-99001.

Volf V. 1978. Treatment of incorporated transuranium elements. Technical Report Series No. 184. International Atomic Energy Agency, Vienna.

Volf V. 1986. Chelation therapy of incorporated plutonium-238 and americium-241: Comparison of LICAM(C), DTPA and DFOA in rats, hamsters and mice. Int J Radiat Biol, 49(3): 449-462. 
Volf V, et al. 1993. Early chelation therapy for injected Pu-238 and Am-241 in the rat: Comparison of 3, 4, 3-LIHOPO, DFO-HOPO, DTPA-DX, DTPA and DFOA. Int $\mathbf{J}$ Radiat Biol, 63(6):785-793.

Wichers LB, et al. 2006. Particle deposition in spontaneously hypertensive rats exposed via whole body inhalation: measured and estimated dose. Toxicol Sci 93(2): 400-410.

Wood R, et al. 2000. Decorporation treatment—medical overview. Radiat Prot Dosim 87(1):5157. 


\section{Section 10.}

\section{Definitions, Acronyms, and Abbreviations}

\begin{tabular}{|c|c|}
\hline $\mathrm{Al}$ & Alveolar Interstitial \\
\hline AMedP-8 & Allied Medical Publication 8 \\
\hline Am & Americium \\
\hline ARA & Applied Research Associates, Inc. \\
\hline $\mathrm{bb}$ & Bronchioles \\
\hline BB & Bronchi \\
\hline BEIR & Biological Effects of Ionizing Radiation \\
\hline $\mathrm{Bq}$ & Becquerel \\
\hline CBD & Chemical and Biological Defense Program \\
\hline $\mathrm{CBI}$ & Information Systems Capability Development Division \\
\hline $\mathrm{Ca}$ & Calcium \\
\hline CEDE & Committed effective dose equivalent \\
\hline $\mathrm{Ci}$ & Curie \\
\hline $\mathrm{Cm}$ & Curium \\
\hline $\mathrm{Cs}$ & Cesium \\
\hline DFOA & Desferrioxamine \\
\hline DoD & Department of Defense \\
\hline DOE & Department of Energy \\
\hline DTPA & Diethylenetriaminepentaacetate (or diethylenetriaminepentaacetic acid) \\
\hline DTRA & Defense Threat Reduction Agency \\
\hline EDTA & Ethylenediamine tetraaceticacid \\
\hline $\mathrm{EEF}$ & Enhanced excretion factor \\
\hline EPA & Environmental Protection Agency \\
\hline ET & Extrathoracic \\
\hline EVS & Environmental Science Division (Argonne National Laboratory) \\
\hline $\operatorname{Exp}$ & Exposure \\
\hline FDA & Food and Drug Administration \\
\hline FGR & Federal guidance report \\
\hline g & Gram \\
\hline
\end{tabular}




\begin{tabular}{|c|c|}
\hline GI & Gastrointestinal tract \\
\hline Gryphon & Gryphon Scientific, LLC \\
\hline GUI & Graphical user interface \\
\hline Gy & Gray \\
\hline ICRP & International Commission on Radiological Protection \\
\hline IRF & Interstitial removal fraction \\
\hline IUPAC & International Union of Pure and Applied Chemistry \\
\hline HHS & Department of Health and Human Services \\
\hline HPAC & Hazard Prediction \& Assessment Capability \\
\hline JPEO-CBD & Joint Program Executive Office for Chemical/Biological Defense \\
\hline JPM-IS & Joint Program Manager Information Systems \\
\hline JSTO & Joint Science and Technology Office \\
\hline $\mathrm{KeV}$ & Kilo-electron volt \\
\hline $\mathrm{L}$ & Liter \\
\hline $\mathrm{LD}_{50}$ & Lethal dose in $50 \%$ of the population \\
\hline LET & Linear energy transfer \\
\hline $\mathrm{LN}$ & Lymph nodes \\
\hline $\mathrm{MCM}$ & Medical Countermeasure Model \\
\hline MIRD & Medical Internal Radiation Dose \\
\hline $\mathrm{mCi}$ & Millicurie \\
\hline$\mu \mathrm{Ci}$ & Microcurie \\
\hline $\min$ & minute \\
\hline$\mu \mathrm{m}$ & Micrometer, or micron \\
\hline $\mathrm{MeV}$ & Mega-electron volts \\
\hline MPPD & Multiple-Path Particle Dosimetry \\
\hline NCRP & National Council on Radiation Protection and Measurements \\
\hline NNSA & National Nuclear Security Administration \\
\hline NRC & National Research Council \\
\hline $\mathrm{P}$ & Pulmonary \\
\hline $\mathrm{Pu}$ & Plutonium \\
\hline $\mathrm{PuO}_{2}$ & Plutonium Dioxide \\
\hline PBPK/PD & Physiologically Based Pharmacokinetic/Pharmacodynamic \\
\hline
\end{tabular}




$\begin{array}{ll}\text { RBM } & \text { Red bone marrow } \\ \text { RD } & \text { Research and Development Directorate } \\ \text { RDD } & \text { Radiological dispersal device } \\ \text { REMM } & \text { Radiation Emergency Medical Management website (HHS) } \\ \text { RTG } & \text { Radioisotope thermoelectric generators } \\ \text { QF } & \text { Quality factor } \\ \text { SAF } & \text { Specific absorbed fraction } \\ \text { SNS } & \text { Strategic National Stockpile } \\ \text { Sv } & \text { Sievert } \\ \text { TB } & \text { Tracheobronchial } \\ \text { TC } & \text { Transfer coefficient } \\ \text { TERA } & \text { Toxicology Excellence for Risk Assessment } \\ \text { USTUR } & \text { United States Transuranium and Uranium Registries } \\ \text { Zn } & \text { Zinc }\end{array}$


This page is intentionally left blank. 


\section{Appendix A.}

\section{Inhalation Exposure Model}

As described in Figure 3, the inhalation exposure model will determine the amount of plutonium deposited in the three major regions of the respiratory tract, based on plutonium air concentration, duration of exposure, wind speed, breathing rate, and particle size distribution. Example outputs from the model for different particle sizes and breathing rates are provided in Table 13 and Table 14. In Table 13, the fraction of the exposure that actually gets deposited in the respiratory tract and determines the intake is provided for two different particle sizes and breathing rates. In these cases, intake is defined as the amount of material deposited in the respiratory tract. The estimates show that the intake is significantly impacted by the particle size of the exposure and, to a lesser degree, the breathing rate.

Table 13. Fraction of Exposure Deposited in the Three Primary Respiratory Regions

\begin{tabular}{|c|c|c|c|c|}
\hline \multirow[b]{2}{*}{ Region } & \multicolumn{4}{|c|}{ Particle Size and Breathing Rate } \\
\hline & $\begin{array}{c}1 \mu \mathrm{m} \\
15 \mathrm{~L} / \mathrm{min}\end{array}$ & $\begin{array}{c}1 \mu \mathrm{m} \\
20 \mathrm{~L} / \mathrm{min}\end{array}$ & $\begin{array}{c}5 \mu \mathrm{m} \\
15 \mathrm{~L} / \mathrm{min}\end{array}$ & $\begin{array}{c}5 \mu \mathrm{m} \\
20 \mathrm{~L} / \mathrm{min}\end{array}$ \\
\hline Extra-thoracic & 0.006 & 0.007 & 0.208 & 0.240 \\
\hline Tracheobronchial & 0.061 & 0.066 & 0.266 & 0.294 \\
\hline Pulmonary & 0.093 & 0.086 & 0.260 & 0.226 \\
\hline
\end{tabular}

Since the three regions clear at different rates and by different modes (see section 4.2.5), particle size and breathing rate further impact the fate of plutonium in the body and ultimately the dose received. Larger particle sizes and faster breathing rates yield overall greater total intake (see Table 13).

Calculating the intake provides the fraction of the intake for each region, (Table 14) used to estimate the amount of the intake in each of the three respiratory regions.

Table 14. Fraction of Intake Deposited in the Three Primary Respiratory Regions

\begin{tabular}{|c|c|c|c|c|}
\hline \multirow[b]{2}{*}{ Region } & \multicolumn{4}{|c|}{ Particle Size and Breathing Rate } \\
\hline & $\begin{array}{c}1 \mu \mathrm{m} \\
15 \mathrm{~L} / \mathrm{min}\end{array}$ & $\begin{array}{c}1 \mu \mathrm{m} \\
20 \mathrm{~L} / \mathrm{min}\end{array}$ & $\begin{array}{c}5 \mu \mathrm{m} \\
15 \mathrm{~L} / \mathrm{min}\end{array}$ & $\begin{array}{c}5 \mu \mathrm{m} \\
20 \mathrm{~L} / \mathrm{min}\end{array}$ \\
\hline Extra-thoracic & 0.04 & 0.04 & 0.28 & 0.31 \\
\hline Tracheobronchial & 0.38 & 0.42 & 0.36 & 0.39 \\
\hline Pulmonary & 0.58 & 0.54 & 0.36 & 0.30 \\
\hline
\end{tabular}


Since the respiratory tract model further requires additional detail about the distribution of particles in the tracheobronchial region, MPPD was used to determine the fractional distribution of particles in the bronchi and bronchioles in the TB region.

Table 15. Fraction of the Tracheobronchial Deposition in the Bronchi and Bronchioles

\begin{tabular}{|c|c|c|c|c|}
\hline Region & \multicolumn{4}{|c|}{ Particle Size and Breathing Rate } \\
& $\begin{array}{c}\mathbf{1} \boldsymbol{\mu} \mathbf{m} \\
\mathbf{1 5} \mathbf{~ L / m i n}\end{array}$ & $\begin{array}{c}\mathbf{1} \boldsymbol{\mu} \mathbf{~} / \mathbf{m i n} \\
\mathbf{5} \boldsymbol{\mu m}\end{array}$ & $\mathbf{5} \mathbf{~} / \mathbf{m i n}$ & $\mathbf{2 0} \mathbf{~} / \mathbf{m i n}$ \\
\hline Bronchi $\left(\mathrm{TB}_{\mathrm{BB}}\right)$ & 0.37 & 0.44 & 0.22 & 0.27 \\
\hline Bronchioles $\left(\mathrm{TB}_{\mathrm{bb}}\right)$ & 0.63 & 0.56 & 0.78 & 0.73 \\
\hline
\end{tabular}




\section{Appendix B.}

\section{Respiratory Clearance and Uptake Model}

The respiratory clearance model uses the initial amount of plutonium in the ET, TB (BB and $\mathrm{bb}$ ), and $\mathrm{P}$ regions to calculate the amount and rate of transfer from the respiratory tract to either the GI tract via transport processes, such as ciliary action, or directly to the blood stream via absorption. The initial amount of plutonium in each of the respiratory compartments is calculated by adjusting each one's fraction according to the parameters listed in Table 1 and Table 13. The values for the TB region are subdivided into to bronchi (BB) or bronchiole (bb) fractions according to the partition listed in Table 15.

$$
\begin{aligned}
& E T 1_{o}=E T 1_{\text {frac }} * E T \\
& E T 2_{o}=E T 2_{\text {frac }} * E T \\
& E T s e q_{o}=E T s e q_{\text {frac }} * E T \\
& B B 1_{o}=B B 1_{\text {frac }} * T B_{B B} \\
& B B 2_{o}=B B 2_{\text {frac }} * T B_{B B} \\
& B B s e q_{o}=B B s e q_{\text {frac }} * T B_{B B} \\
& b b 1_{o}=b b 1_{\text {frac }} * T B_{b b} \\
& b b 2_{o}=b b 2_{\text {frac }} * T B_{b b} \\
& b b s e q_{o}=b b s e q_{\text {frac }} * T B_{b b} \\
& A I 1_{o}=A I 1_{\text {frac }} * P \\
& A I 2_{o}=A I 2_{\text {frac }} * P \\
& A I 3_{o}=A I 3_{\text {frac }} * P
\end{aligned}
$$

The movement of plutonium particulates within the respiratory tract is depicted in Figure 6 and can be represented by the following mathematical functions:

$$
\begin{aligned}
& \frac{d}{d t}\left(E T_{1}\right)=-E T_{1} * T R_{E T 1 \rightarrow E n v} \\
& \frac{d}{d t}\left(E T_{2}\right)=-E T_{2} * T R_{E T 2 \rightarrow G I C}+B B_{1} * T R_{B B 1 \rightarrow E T 2}+B B_{2} * T R_{B B 2 \rightarrow E T 2}-E T_{2} * f_{S r} * s_{r}-E T_{2} * f_{S S} * s_{S} \\
& \frac{d}{d t}\left(E T_{s e q}\right)=-E T * T R_{E T s e q \rightarrow L N e t} \\
& \frac{d}{d t}\left(B B_{1}\right)=-B B_{1} * T R_{B B 1 \rightarrow E T 2}+b b_{1} * T R_{b b 1 \rightarrow B B 1}+b b_{2} * T R_{b b 2 \rightarrow B B 1}-B B_{1} * f_{s r} * s_{r}-B B_{1} * f_{s s} * s_{S}
\end{aligned}
$$




$$
\begin{aligned}
& \frac{d}{d t}\left(B B_{2}\right)=-B B_{2} * T R_{B B 2 \rightarrow E T 2}-B B_{2} * f_{s r} * s_{r}-B B_{2} * f_{s S} * s_{S} \\
& \frac{d}{d t}\left(B B_{\text {seq }}\right)=-B B_{\text {seq }} * T R_{B B s e q \rightarrow L N t h} \\
& \begin{array}{c}
\frac{d}{d t}\left(b b_{1}\right)=-b b_{1} * T R_{b b 1 \rightarrow B B 1}+A I_{1} * T R_{A I 1 \rightarrow b b 1}+A I_{2} * T R_{A I 2 \rightarrow b b 1}+A I_{3} * T R_{A I 3 \rightarrow b b 1}-b b_{1} * f_{s r} * s_{r}-b b_{1} * f_{s S} \\
* s_{S}
\end{array} \\
& \frac{d}{d t}\left(b b_{2}\right)=-b b_{2} * T R_{b b 2 \rightarrow B B 1}-b b_{2} * f_{s r} * s_{r}-b b_{2} * f_{s s} * s_{s} \\
& \frac{d}{d t}\left(b b_{\text {seq }}\right)=-b b_{\text {seq }} * T R_{b b s e q \rightarrow L N t h} \\
& \frac{d}{d t}\left(A I_{1}\right)=-A I_{1} * T R_{A I 1 \rightarrow b b 1}-A I_{1} * f_{S r} * S_{r}-A I_{1} * f_{s S} * S_{S} \\
& \frac{d}{d t}\left(A I_{2}\right)=-A I_{2} * T R_{A I 2 \rightarrow b b 1}-A I_{2} * f_{s r} * s_{r}-A I_{2} * f_{s S} * s_{S} \\
& \frac{d}{d t}\left(A I_{3}\right)=-A I_{3} * T R_{A I 1 \rightarrow b b 1}-A I_{3} * f_{s r} * s_{r}-A I_{3} * f_{S S} * S_{S}-A I_{3} * T R_{A I 3 \rightarrow L N t h} \\
& \frac{d}{d t}(L N)=b b_{s e q} * T R_{b b s e q \rightarrow L N t h}+A I_{3} * T R_{A I 3 \rightarrow L N t h}+B B_{s e q} * T R_{B B s e q \rightarrow L N t h}+E T * T R_{E T s e q \rightarrow L N e t}
\end{aligned}
$$

The compartments are defined in Table 1 of the main text and respiratory absorption tract values are listed in Table 2 (Bailey 2007 values are implemented). ET is the extrathoracic, TB is the tracheobronchial, BB is the bronchi, bb are the bronchioles, AI is the alveolar interstitial, and LN are lymph nodes. 


\section{Appendix C.}

\section{Plutonium Biokinetic Model}

The plutonium biokinetic model obtains the input from the uptake model to determine the amount of plutonium in the blood, entering the systemic circulation. The computation is accomplished by solving a series of interdependent differential equations, over a specified period of time:

$$
\begin{aligned}
& \frac{d}{d t}\left(P u_{\text {blood } 1}\right)=-P u_{\text {blood } 1} * T C_{\text {blood } 1 \rightarrow \text { liver } 1}-P u_{\text {blood } 1} * T C_{\text {blood } 1 \rightarrow C S}-P u_{\text {blood } 1} * T C_{\text {blood } 1 \rightarrow C V}-P u_{\text {blood } 1} \\
& * T C_{\text {blood } 1 \rightarrow T S}-P u_{\text {blood } 1} * T C_{\text {blood } 1 \rightarrow T V}-P u_{\text {blood } 1} * T C_{\text {blood } 1 \rightarrow U B C}-P u_{\text {blood } 1} * T C_{\text {blood } 1 \rightarrow R T} \\
& -P u_{\text {blood } 1} * T C_{\text {blood } 1 \rightarrow \text { OKT }}-P u_{\text {blood } 1} * T C_{\text {blood } 1 \rightarrow U G I}-P u_{\text {blood } 1} * T C_{\text {blood } 1 \rightarrow \text { gonads }}-P u_{\text {blood } 1} \\
& * T C_{\text {blood } 1 \rightarrow S T 2}-P u_{\text {blood } 1} * T C_{\text {blood } 1 \rightarrow S T 3}+P u_{S T 1} * T C_{S T 1 \rightarrow \text { blood } 1}+P u_{\text {blood } 2} * T C_{\text {blood } 2 \rightarrow \text { blood } 1} \\
& +E T_{2} * f_{s r} * s_{r}+E T_{2} * f_{s s} * s_{s}+B B_{1} * f_{s r} * s_{r}+B B_{1} * f_{s s} * s_{s}+B B_{2} * f_{s r} * s_{r}+B B_{2} * f_{s s} \\
& * s_{s}+b b_{1} * f_{s r} * s_{r}+b b_{1} * f_{s s} * s_{s}+b b_{2} * f_{s r} * s_{r}+b b_{2} * f_{s s} * s_{s}+A I_{1} * f_{s r} * s_{r}+A I_{1} * f_{s s} \\
& * s_{s}+A I_{2} * f_{s r} * s_{r}+A I_{2} * f_{s s} * s_{s}+A I_{3} * f_{s r} * s_{r}+A I_{3} * f_{s s} * s_{s}+G I_{\text {frac }} * E T_{2} * T C_{E T 2 \rightarrow G I C} \\
& \frac{d}{d t}\left(P u_{\text {blood } 2}\right)=-P u_{\text {blood } 2} * T C_{\text {blood } 2 \rightarrow U B C}-P u_{\text {blood } 2} * T C_{\text {blood } 2 \rightarrow \text { blood } 1}-P u_{\text {blood } 2} * T C_{\text {blood } 2 \rightarrow S T 1}+P u_{O K} \\
& * T C_{O K \rightarrow \text { blood } 2}+P u_{S T 2} * T C_{S T 2 \rightarrow \text { blood } 2}+P u_{S T 3} * T C_{S T 3 \rightarrow \text { blood } 2}+P u_{\text {liver } 2} * T C_{\text {liver } 2 \rightarrow \text { blood } 2} \\
& +P u_{\text {liver } 3} * T C_{\text {liver } 3 \rightarrow \text { blood } 2}+P u_{\text {gonads }} * T C_{\text {gonads } \rightarrow \text { blood } 2}+P u_{C M} * T C_{C M \rightarrow \text { blood } 2}+P u_{T M} \\
& * T C_{T M \rightarrow \text { blood } 2} \\
& \frac{d}{d t}\left(P u_{\text {liver } 1}\right)=-P u_{\text {liver } 1} * T C_{\text {liver } 1 \rightarrow \text { SIC }}-P u_{\text {liver } 1} * T C_{\text {liver } 1 \rightarrow \text { liver } 2}+P u_{\text {blood } 1} * T C_{\text {blood } 1 \rightarrow \text { liver } 1} \\
& \frac{d}{d t}\left(P u_{\text {liver } 2}\right)=-P u_{\text {liver } 2} * T C_{\text {liver } 2 \rightarrow \text { blood } 2}-P u_{\text {liver } 2} * T C_{\text {liver } 2 \rightarrow \text { liver } 3}+P u_{\text {liver } 1} * T C_{\text {liver } 1 \rightarrow \text { liver } 2} \\
& \frac{d}{d t}\left(P u_{\text {liver } 3}\right)=-P u_{\text {liver } 3} * T C_{\text {liver } 3 \rightarrow \text { blood } 2}+P u_{\text {liver } 2} * T C_{\text {liver } 2 \rightarrow \text { liver } 3} \\
& \frac{d}{d t}\left(P u_{S T 1}\right)=-P u_{S T 1} * T C_{S T 1 \rightarrow \text { blood } 1}+P u_{\text {blood } 2} * T C_{\text {blood } 2 \rightarrow S T 1} \\
& \frac{d}{d t}\left(P u_{S T 2}\right)=-P u_{S T 2} * T C_{S T 2 \rightarrow \text { blood } 2}+P u_{\text {blood } 1} * T C_{\text {blood } 1 \rightarrow S T 2} \\
& \frac{d}{d t}\left(P u_{S T 3}\right)=-P u_{S T 3} * T C_{S T 3 \rightarrow \text { blood } 2}+P u_{\text {blood } 1} * T C_{\text {blood } 1 \rightarrow S T 3} \\
& \frac{d}{d t}\left(P u_{C M}\right)=P u_{C S} * T C_{C S \rightarrow C M}+P u_{C V} * T C_{C V \rightarrow C M}-P u_{C M} * T C_{C M \rightarrow \text { blood } 2} \\
& \frac{d}{d t}\left(P u_{C S}\right)=-P u_{C S} * T C_{C S \rightarrow C V}-P u_{C S} * T C_{C S \rightarrow C M}+P u_{\text {blood } 1} * T C_{\text {blood } 1 \rightarrow C S} \\
& \frac{d}{d t}\left(P u_{C V}\right)=P u_{C S} * T C_{C S \rightarrow C V}-P u_{C V} * T C_{C V \rightarrow C M}+P u_{\text {blood } 1} * T C_{\text {blood } 1 \rightarrow C V} \\
& \frac{d}{d t}\left(P u_{T M}\right)=P u_{T V} * T C_{T V \rightarrow T M}+P u_{T S} * T C_{T S \rightarrow T M}-P u_{T M} * T C_{T M \rightarrow \text { blood } 2} \\
& \frac{d}{d t}\left(P u_{T S}\right)=P u_{\text {blood } 1} * T C_{\text {blood } 1 \rightarrow T S}-P u_{T S} * T C_{T S \rightarrow T M}-P u_{T S} * T C_{T S \rightarrow T V}
\end{aligned}
$$




$$
\begin{aligned}
& \frac{d}{d t}\left(P u_{T V}\right)=P u_{T S} * T C_{T S \rightarrow T V}-P u_{T V} * T C_{T V \rightarrow T M}+P u_{\text {blood } 1} * T C_{\text {blood } 1 \rightarrow T V} \\
& \frac{d}{d t}\left(P u_{R T}\right)=P u_{\text {blood } 1} * T C_{\text {blood } 1 \rightarrow R T}-P u_{R T} * T C_{R T \rightarrow U B C} \\
& \frac{d}{d t}\left(P u_{O K T}\right)=P u_{\text {blood } 1} * T C_{\text {blood } 1 \rightarrow O K T}-P u_{O K T} * T C_{O K T \rightarrow \text { blood } 2} \\
& \frac{d}{d t}\left(P u_{\text {gonads }}\right)=P u_{\text {blood } 1} * T C_{\text {blood } 1 \rightarrow \text { gonads }}-P u_{\text {gonads }} * T C_{\text {gonads } \rightarrow \text { blood } 2} \\
& \frac{d}{d t}\left(P u_{U B C}\right)=P u_{R T} * T C_{R T \rightarrow U B C}+P u_{\text {blood } 1} * T C_{\text {blood } 1 \rightarrow U B C}+P u_{\text {blood } 2} * T C_{\text {blood } 2 \rightarrow U B C}-P u_{U B C} * T C_{U B C \rightarrow \text { urine }} \\
& \frac{d}{d t}\left(P u_{\text {urine }}\right)=P u_{U B C} * T C_{U B C \rightarrow \text { urine }} \\
& \frac{d}{d t}\left(P u_{G I C}\right)=P u_{\text {liver } 1} * T C_{\text {liver } 1 \rightarrow S I C}+P u_{\text {blood } 1} * T C_{\text {blood } 1 \rightarrow U G I}-P u_{G I C} * T C_{G I C \rightarrow \text { feces }} \\
& \quad+\left(\left(P u_{E T 2} T C_{E T 2 \rightarrow G I C}\right) *\left(1-G I_{\text {frac }}\right)\right. \\
& \frac{d}{d t}\left(P u_{\text {feces }}\right)=P u_{G I C} * T C_{G I C \rightarrow \text { feces }}
\end{aligned}
$$

where:

TC is the transfer coefficient; ST1, 2, and 3 are soft tissues 1, 2, and 3; CS is cortical surface, $\mathrm{CM}$ is cortical marrow, $\mathrm{CV}$ is cortical volume, TS is trabecular surface, TV is trabecular volume, $\mathrm{TM}$ is trabecular bone marrow, and RT is renal tubules and OKT is other kidney tissue. UBC is urinary bladder contents, UGI is upper gastrointestinal tract, GIC is gastrointestinal contents, SIC is small intestines contents, and $\mathrm{GI}_{\text {frac }}$ is the fractional of absorption of $\mathrm{Pu}$ from the GI tract. Respiratory parameters are defined in Appendix A and B. Values for transfer coefficients are listed in Table 3. In addition to the Pu specific parameters listed in Table 3, the generic transfer coefficients for transfer from the urinary bladder and GI tract to excreted urine and feces $\left(T C_{U B C \rightarrow \text { urine }}\right.$ and $T C_{G I C \rightarrow \text { feces }}$ ) are 7 and 0.5 per day, respectively (ICRP 1993). 